\title{
Indium-Catalyzed Aromative Spiro Coupling of Quinones with Oxindoles for Highly Functionalized Xanthenes as Efficient Fluorophores
}

Mohammad Aslam, ${ }^{\mathrm{a}}$ Sonaimuthu Mohandoss, ${ }^{\mathrm{a}}$ Palanisamy Subramanian, ${ }^{\mathrm{b}}$ SangGuan You, ${ }^{\mathrm{b}}$ Won-Guen Yang, ${ }^{c}$ Sung Hong Kim, ${ }^{c}$ and Yong Rok Lee ${ }^{\mathrm{a}, *}$

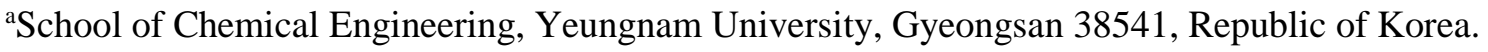

E-mail: yrlee@yu.ac.kr; Fax: +82-53-810-4631; Tel: +82-53-810-2529

${ }^{b}$ Department of Marine Food Science and Technology, Gangneung-Wonju National University, 120

Gangneungdaehangno, Gangneung, Gangwon 25457, Republic of Korea.

${ }^{\mathrm{c} A n a l y s i s ~ R e s e a r c h ~ D i v i s i o n, ~ D a e g u ~ C e n t e r, ~ K o r e a ~ B a s i c ~ S c i e n c e ~ I n s t i t u t e, ~ D a e g u ~ 41566, ~ R e p u b l i c ~ o f ~}$ Korea 


\section{Table of Contents}

$1 \quad$ General remarks

2. General procedure for the synthesis of compounds 3-5

3. Representative $\mathbf{1} \mathbf{m m o l}$ scale synthesis of $\mathbf{3 a}$

4. General procedure for the synthesis of 7

5. Characterization data for synthesized compounds

6. Copies of ${ }^{1} \mathrm{H}$ NMR and ${ }^{13} \mathrm{C}$ NMR spectra of the synthesized compounds S18

7. Details of fluorophore analysis for metal sensing

8. Details of cell imaging experiments

9. References

10. Crystal refinement data for compound $4 \mathrm{~m}$

11. Crystal refinement data for compound $5 e$ 


\section{General remarks}

All experiments were carried out under air atmosphere unless stated otherwise. Solvents were purchased from Sigma Aldrich and used without further purification. Oxindoles derivatives $\mathbf{2 b}$, 2c, 2d, 2e, 2f, $2 \mathbf{l}$ and $\mathbf{2 m}$ and benzoquinone derivatives 1a, 1c, 1d, 1e, $1 \mathbf{f}$ and $1 \mathrm{~g}$ were purchased from the Sigma Aldrich, Thermo fisher and TCI chemicals. Other derivatives of oxindoles $\mathbf{2 g}$, $\mathbf{2} \mathbf{j}$ and $\mathbf{2} \mathbf{k}$ were prepared by the reported methods. ${ }^{1-3}$ Benzoquinone derivative $\mathbf{1 b}$ was prepared by reported method. ${ }^{4}$ Merck precoated silica gel plates (Art. 5554) treated with a fluorescent indicator were used for analytical thin-layer chromatography (TLC). Column chromatography was performed using silica gel 9385 (Merck) and ethyl acetate/hexane were used as eluents. Melting points are uncorrected and were determined using Fisher-Johns Melting Point Apparatus. ${ }^{1} \mathrm{H}$ NMR and ${ }^{13} \mathrm{C}$ NMR spectra were recorded on VNS (600 and $150 \mathrm{MHz}$ ) spectrometer at the core research support center for natural products and medical materials of Yeungnam University. The NMR spectra recorded in DMSO using $\delta=2.5$ and $39.5 \mathrm{ppm}$ as the solvent chemical shifts. All chemical shifts $(\delta)$ are expressed in units of ppm and $J$ values are given in Hz. Multiplicities are abbreviated as follows: $\mathrm{s}=$ singlet, $\mathrm{d}=$ doublet, $\mathrm{t}=$ triplet, $\mathrm{q}$ $=$ quartet, $\mathrm{m}=$ multiplet or overlap of nonequivalent resonances, and $\mathrm{dd}=$ doublet of doublets. Infrared (IR) spectra were recorded on a PerkinElmer Spectrum Two ${ }^{\mathrm{TM}}$ IR spectrometer with frequencies expressed in $\mathrm{cm}^{-1}$, and high-resolution mass spectrometry (HRMS) was carried out using a JEOL JMS-700 spectrometer (Magnetic sector-Electric sector double focusing mass analyzer) at the Korea Basic Science Institute. The compound $\mathbf{4 l}$ was analysed for HRMS using Thermo Fisher Q exactive orbitrap mass spectrometer. The crystal structure of the compound was determined by single-crystal diffraction methods at the Korea Basic Science Institute (KBSI, Western Seoul Center, Korea).

\section{General procedure for the synthesis of compounds 3-5}

An oven dried round bottom flask $(25 \mathrm{~mL})$ equipped with a magnetic stirrer was charged with oxindole $2(0.5 \mathrm{mmol})$, acetonitrile $(3 \mathrm{~mL}), \operatorname{In}(\mathrm{OTf})_{3}(10 \mathrm{~mol} \%)$ and $p$-benzoquinone 1 (2 equiv). The reaction mixture was stirred on an oil bath for $8 \mathrm{~h}$ at $70{ }^{\circ} \mathrm{C}$. The progress of the reaction was monitored by TLC. After completion of the reaction, the volatiles were evaporated under reduced pressure. The crude product was purified over a column of silica gel and eluted with 7:3 hexane/ethyl acetate to afford the compounds 3-5. 


\section{Representative $1 \mathrm{mmol}$ scale synthesis of 3a}

An oven dried round bottom flask $(25 \mathrm{~mL})$ equipped with a magnetic stirrer was charged with oxindole 2a (209.0 mg, $1.0 \mathrm{mmol})$, acetonitrile $(5 \mathrm{~mL}), \operatorname{In}(\mathrm{OTf})_{3}(10 \mathrm{~mol} \%)$ and $p$ benzoquinone 1a (216 mg, 2 equiv). The reaction mixture was stirred on an oil bath for $8 \mathrm{~h}$ at $70{ }^{\circ} \mathrm{C}$. The progress of the reaction was monitored by TLC. After completion of the reaction, the volatiles were evaporated under reduced pressure. The crude product was purified over a column of silica gel and eluted with 7:3 hexane/ethyl acetate to afford pure 3a (360 mg, Yield: $88 \%)$.

\section{General procedure for the synthesis of 7}

A round bottom flask $(25 \mathrm{~mL})$ was charged with 3 -methyl 2-oxindole $(0.5 \mathrm{mmol})$, acetonitrile $(3 \mathrm{~mL}), \operatorname{In}(\mathrm{OTf})_{3}(10 \mathrm{~mol} \%)$ and $\mathrm{p}$-benzoquinone (1 equiv). The resulting reaction mixture was heated on an oil bath for $6 \mathrm{~h}$ at $70{ }^{\circ} \mathrm{C}$. The progress of the reaction was monitored by TLC. The solvent was evaporated under reduced pressure. The crude product was purified over a column of silica gel and eluted with 6:4 hexane/ethyl acetate to afford 7.

\section{Characterization data for synthesized compounds}

\section{2',7'-Dihydroxy-1-phenylspiro[indoline-3,9'-xanthen]-2-one (3a):}

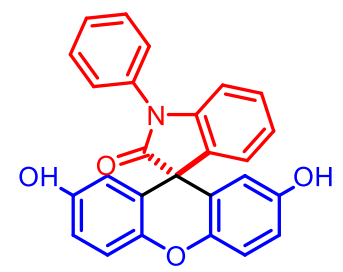

The compound was prepared according to the general procedure and purified by column chromatography $($ EtOAc/hexane $=30: 70)$. Yield: 90\% (184 mg); State: white solid; mp: $295-297{ }^{\circ} \mathrm{C} ;{ }^{1} \mathrm{H}$ NMR (600 MHz, DMSO- $\left.d_{6}\right) \delta 9.23(2 \mathrm{H}, \mathrm{s}), 7.64(2 \mathrm{H}, \mathrm{t}, J=7.8 \mathrm{~Hz}), 7.54-7.48(3 \mathrm{H}, \mathrm{m})$, $7.37(1 \mathrm{H}, \mathrm{t}, J=7.8 \mathrm{~Hz}), 7.15(1 \mathrm{H}, \mathrm{t}, J=7.8 \mathrm{~Hz}), 7.07(3 \mathrm{H}, \mathrm{d}, J=8.4$ $\mathrm{Hz}), 6.93(1 \mathrm{H}, \mathrm{d}, J=7.8 \mathrm{~Hz}), 6.74(2 \mathrm{H}, \mathrm{dd}, J=8.4,1.8 \mathrm{~Hz}), 6.15(2 \mathrm{H}, \mathrm{s}) ;{ }^{13} \mathrm{C}$ NMR $(150 \mathrm{MHz}$, DMSO- $\left.d_{6}\right) \delta 176.5,152.9,143.7,143.1,135.2,133.9,129.9,129.1,128.5,126.7,125.3,124.3$, 120.3, 117.6, 116.7 112.2, 109.5, 52.7; IR (ATR): 3317, 1673, 1493, 1204, $750 \mathrm{~cm}^{-1}$; HRMS (FAB) $m / z[\mathrm{M}+\mathrm{H}]^{+}$calcd for $\mathrm{C}_{26} \mathrm{H}_{18} \mathrm{NO}_{4}$ : 408.1236, Found: 408.1238 . 


\section{2',7'-Dihydroxy-1-methylspiro[indoline-3,9'-xanthen]-2-one (3b):}

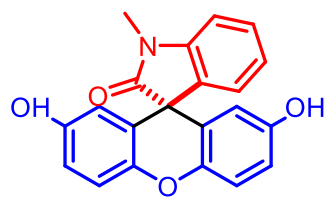

The compound was prepared according to the general procedure and purified by column chromatography (EtOAc/hexane $=30: 70)$. Yield: $80 \%$ (138 mg); State: white solid; mp: >300 ${ }^{\circ} \mathrm{C} ;{ }^{1} \mathrm{H}$ NMR (600 MHz, DMSO$\left.d_{6}\right) \delta 9.12(2 \mathrm{H}, \mathrm{s}), 7.43(1 \mathrm{H}, \mathrm{td}, J=7.8,1.2 \mathrm{~Hz}), 7.24(1 \mathrm{H}, \mathrm{d}, J=7.8 \mathrm{~Hz})$, $7.10(1 \mathrm{H}, \mathrm{td}, J=7.8,1.2 \mathrm{~Hz}), 7.03(2 \mathrm{H}, \mathrm{d}, J=8.4 \mathrm{~Hz}), 7.00(1 \mathrm{H}, \mathrm{d}, J=6.3 \mathrm{~Hz}), 6.71(1 \mathrm{H}, \mathrm{d}, J$ $=3.0 \mathrm{~Hz}), 6.69(1 \mathrm{H}, \mathrm{d}, J=3.0 \mathrm{~Hz}), 5.90(1 \mathrm{H}, \mathrm{s}), 5.90(1 \mathrm{H}, \mathrm{s}), 3.23(3 \mathrm{H}, \mathrm{s}) ;{ }^{13} \mathrm{C} \mathrm{NMR}(150$ MHz, DMSO- $\left.d_{6}\right) \delta 176.9,152.7,143.8,143.7,135.0,129.1,124.7,123.5,120.5,117.4,116.4$, 112.2, 109.0, 52.6, 26.4; IR (ATR): 3301, 1686, 1444, 1197, $816 \mathrm{~cm}^{-1}$; HRMS (FAB) $\mathrm{m} / \mathrm{z}$ $[\mathrm{M}+\mathrm{H}]^{+}$calcd for $\mathrm{C}_{21} \mathrm{H}_{16} \mathrm{NO}_{4}: 346.1079$, Found: 346.1076 .

\section{1-Acetyl-2',7'-dihydroxyspiro[indoline-3,9'-xanthen]-2-one (3c):}

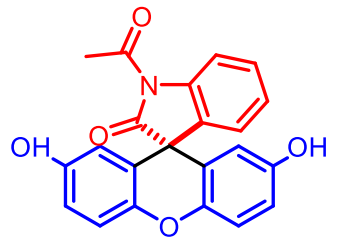

The compound was prepared according to the general procedure and purified by column chromatography (EtOAc/hexane $=30: 70)$. Yield: 82\% (154 mg); State: white solid; mp: >300 ${ }^{\circ} \mathrm{C} ;{ }^{1} \mathrm{H}$ NMR $(600 \mathrm{MHz}$, DMSO- $\left.d_{6}\right) \delta 9.22(2 \mathrm{H}, \mathrm{s}), 8.31(1 \mathrm{H}, \mathrm{d}, J=8.2 \mathrm{~Hz}), 7.52-7.49(1 \mathrm{H}, \mathrm{m})$, 7.33-7.30 (1H, m), $7.13-7.07(3 \mathrm{H}, \mathrm{m}), 6.75(2 \mathrm{H}, \mathrm{dd}, J=8.8,2.8 \mathrm{~Hz}),, 5.97(2 \mathrm{H}, \mathrm{d}, J=2.8$ $\mathrm{Hz}), 2.54(3 \mathrm{H}, \mathrm{s}) ;{ }^{13} \mathrm{C}$ NMR (150 MHz, DMSO- $\left.d_{6}\right) \delta 177.3,170.8,152.9,143.7,140.3,133.2$, 129.3, 126.4, 125.3 120.1, 117.7, 117.0, 115.6, 112.5, 53.3, 26.3; IR (ATR): 3447, 3023, 1739, 1214, $813 \mathrm{~cm}^{-1}$; HRMS (FAB) $\mathrm{m} / z$ [M] $]^{+}$calcd for $\mathrm{C}_{22} \mathrm{H}_{15} \mathrm{NO}_{5}: 373.0950$, Found: 373.0951.

\section{2',7'-Dihydroxyspiro[indoline-3,9'-xanthen]-2-one (3d):}

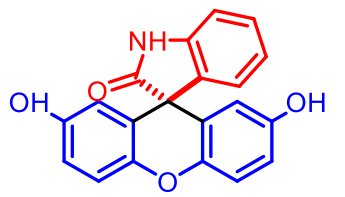

The compound was prepared according to the general procedure and purified by column chromatography $($ EtOAc/hexane $=30: 70)$. Yield: 86\% (143 mg); State: white solid; mp: >300 ${ }^{\circ} \mathrm{C} ;{ }^{1} \mathrm{H}$ NMR $(600 \mathrm{MHz}$, DMSO- $\left.d_{6}\right) \delta 10.63(1 \mathrm{H}, \mathrm{s}), 9.12(2 \mathrm{H}, \mathrm{s}), 7.32(1 \mathrm{H}, \mathrm{t}, J=7.8 \mathrm{~Hz}), 7.07-7.00(4 \mathrm{H}, \mathrm{m}), 6.94$ $(1 \mathrm{H}, \mathrm{d}, J=7.2 \mathrm{~Hz}), 6.69(2 \mathrm{H}, \mathrm{dd}, J=9.0,2.4 \mathrm{~Hz}), 5.98(2 \mathrm{H}, \mathrm{s}) ;{ }^{13} \mathrm{C}$ NMR $(150 \mathrm{MHz}, \mathrm{DMSO}-$ $\left.d_{6}\right) \delta 178.7,152.7,143.8,142.2,135.9,128.9,125.0,122.9,120.7,117.4,116.3,112.2,109.9$, 53.1; IR (ATR): 3183, 2921, 1703, 1455, 1207, $740 \mathrm{~cm}^{-1}$; HRMS (FAB) $\mathrm{m} / z$ [M+H] $]^{+}$calcd for $\mathrm{C}_{20} \mathrm{H}_{14} \mathrm{NO}_{4}: 332.0923$, Found:332.0922. 


\section{5-Bromo-2',7'-dihydroxyspiro[indoline-3,9'-xanthen]-2-one (3e):}

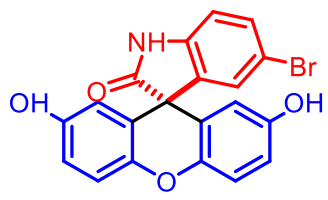

The compound was prepared according to the general procedure and purified by column chromatography $($ EtOAc/hexane $=30: 70)$. Yield: $70 \%$ (144 mg); State: brown solid; mp: 190-192 ${ }^{\circ} \mathrm{C} ;{ }^{1} \mathrm{H}$ NMR $(600 \mathrm{MHz}$, DMSO- $\left.d_{6}\right) \delta 10.80(1 \mathrm{H}, \mathrm{s}), 9.17(2 \mathrm{H}, \mathrm{s}), 7.52(1 \mathrm{H}, \mathrm{dd}, J=8.4,2.4 \mathrm{~Hz}), 7.12(1 \mathrm{H}, \mathrm{d}, J=3.0$ $\mathrm{Hz}), 7.04(1 \mathrm{H}, \mathrm{s}), 7.04-7.02(2 \mathrm{H}, \mathrm{m}), 6.72(2 \mathrm{H}, \mathrm{dd}, J=9.0,3.0 \mathrm{~Hz}), 5.98(2 \mathrm{H}, \mathrm{s}) ;{ }^{13} \mathrm{C} \mathrm{NMR}$ (150 MHz, DMSO-d6) $\delta 178.2,152.8,143.6,141.7,138.1,131.9,127.7,119.9,117.6,116.6$, 114.4, 112.0, 111.9, 53.2; IR (ATR): 3102, 1712, 1449, 1202, $812 \mathrm{~cm}^{-1}$; HRMS (FAB) $\mathrm{m} / \mathrm{z}$ $[\mathrm{M}]^{+}$calcd for $\mathrm{C}_{20} \mathrm{H}_{12} \mathrm{BrNO}_{4}$ : 408.9950, Found: 408.9948 .

\section{2',7'-Dihydroxy-5-nitrospiro[indoline-3,9'-xanthen]-2-one (3f):}

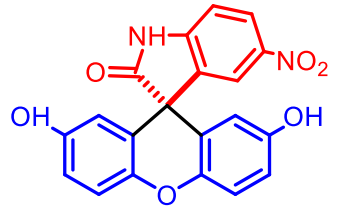

The compound was prepared according to the general procedure and purified by column chromatography $($ EtOAc/hexane $=30: 70)$. Yield: $86 \%$

(162 mg); State: brown solid; mp: 280-282 ${ }^{\circ} \mathrm{C} ;{ }^{1} \mathrm{H}$ NMR $(600 \mathrm{MHz}$, DMSO- $\left.d_{6}\right) \delta 11.43(1 \mathrm{H}, \mathrm{s}), 9.21(2 \mathrm{H}, \mathrm{s}), 8.31(1 \mathrm{H}, \mathrm{dd}, J=8.4,2.4 \mathrm{~Hz}), 7.77(1 \mathrm{H}, \mathrm{s}), 7.29(1 \mathrm{H}$, d, $J=9 \mathrm{~Hz}), 7.08(2 \mathrm{H}, \mathrm{d}, J=9.0 \mathrm{~Hz}), 6.76(2 \mathrm{H}, \mathrm{dd}, J=9.0,3.0 \mathrm{~Hz}), 6.01(2 \mathrm{H}, \mathrm{s}) ;{ }^{13} \mathrm{C} \mathrm{NMR}$ (150 MHz, DMSO- $\left.d_{6}\right) \delta 178.9,152.9,148.6,143.6,143.1,136.7,126.3,120.4,119.2,117.8$, 116.9, 111.8, 110.5, 53.0; IR (ATR): 3465, 3013, 1740, 1220, $524 \mathrm{~cm}^{-1}$;HRMS (FAB) $\mathrm{m} / \mathrm{z}$ $[\mathrm{M}]^{+}$calcd for $\mathrm{C}_{20} \mathrm{H}_{12} \mathrm{~N}_{2} \mathrm{O}_{6}: 376.0695$, Found: 376.0692 .

\section{2',7'-Dihydroxy-5-phenylspiro[indoline-3,9'-xanthen]-2-one (3g):}

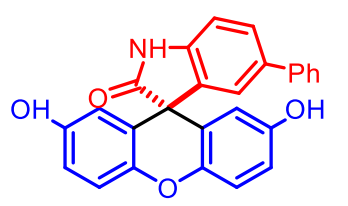

The compound was prepared according to the general procedure and purified by column chromatography (EtOAc/hexane $=30: 70)$. Yield: $80 \%$ (163 mg); State: brown solid; mp: 295-297 ${ }^{\circ} \mathrm{C}$; ${ }^{1} \mathrm{H}$ NMR $(600 \mathrm{MHz}$, DMSO-d6) $\delta 10.75(1 \mathrm{H}, \mathrm{s}), 9.14(2 \mathrm{H}, \mathrm{s}), 7.68(1 \mathrm{H}, \mathrm{d}, J=8.4 \mathrm{~Hz}), 7.52$ $(2 \mathrm{H}, \mathrm{d}, J=7.2 \mathrm{~Hz}), 7.35(2 \mathrm{H}, \mathrm{t}, J=7.8 \mathrm{~Hz}), 7.26(1 \mathrm{H}, \mathrm{t}, J=7.2 \mathrm{~Hz}), 7.23(1 \mathrm{H}, \mathrm{s}), 7.16(1 \mathrm{H}, \mathrm{d}$, $J=8.4 \mathrm{~Hz}), 7.04(2 \mathrm{H}, \mathrm{d}, J=9.0 \mathrm{~Hz}), 6.71(2 \mathrm{H}, \mathrm{dd}, J=9.0,3.0 \mathrm{~Hz}), 6.06(1 \mathrm{H}, \mathrm{s}), 6.05(1 \mathrm{H}, \mathrm{s})$; ${ }^{13} \mathrm{C}$ NMR (150 MHz, DMSO- $\left.d_{6}\right) \delta 178.7,152.7,143.8,141.9,139.4,136.7,134.9,128.8,127.4$, 126.9, 126.1, 123.0, 120.6, 117.4, 116.3, 112.1, 110.4, 53.3; IR (ATR): 3448, 3017, 1733, 1218, $820 \mathrm{~cm}^{-1}$; HRMS (FAB) $\mathrm{m} / z[\mathrm{M}+\mathrm{H}]^{+}$calcd for $\mathrm{C}_{26} \mathrm{H}_{18} \mathrm{NO}_{4}: 408.1236$, Found: 408.1233.

\section{5-(2,5-Dimethylphenyl)-2',7'-dihydroxyspiro[indoline-3,9'-xanthen]-2-one (3h):}




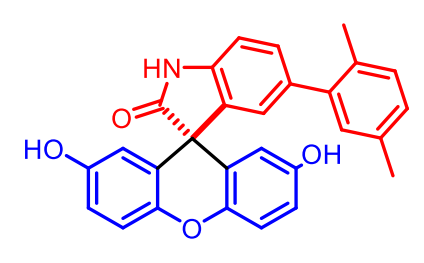

The compound was prepared according to the general procedure and purified by column chromatography (EtOAc/hexane $=30: 70)$. Yield: $76 \%$ (166 mg); State: brown solid; mp: $215-217{ }^{\circ} \mathrm{C} ;{ }^{1} \mathrm{H}$ NMR (600 MHz, DMSO- $\left.d_{6}\right) \delta 10.69(1 \mathrm{H}, \mathrm{s}), 9.15(2 \mathrm{H}, \mathrm{s}), 7.30(1 \mathrm{H}, \mathrm{dd}, J=8.4$, $1.8 \mathrm{~Hz}), 7.12(1 \mathrm{H}, \mathrm{d}, J=7.8 \mathrm{~Hz}), 7.09(1 \mathrm{H}, \mathrm{d}, J=7.8 \mathrm{~Hz}), 7.02(1 \mathrm{H}, \mathrm{s}), 6.99$ (2H, dd, $J=8.4$, $2.4 \mathrm{~Hz}), 6.92(1 \mathrm{H}, \mathrm{s}), 6.84(1 \mathrm{H}, \mathrm{d}, J=1.8 \mathrm{~Hz}), 6.70(1 \mathrm{H}, \mathrm{d}, J=3.0 \mathrm{~Hz}), 6.69(1 \mathrm{H}, \mathrm{d}, J=2.8$ $\mathrm{Hz}), 6.06(1 \mathrm{H}, \mathrm{s}), 6.06(1 \mathrm{H}, \mathrm{s}), 2.23(3 \mathrm{H}, \mathrm{s}), 2.07(3 \mathrm{H}, \mathrm{s}) ;{ }^{13} \mathrm{C}$ NMR $\left(150 \mathrm{MHz}, \mathrm{DMSO}-d_{6}\right) \delta$ 178.7, 152.7, 143.9, 141.2, 140.4, 135.9, 135.4, 134.8, 131.4, 130.3, 129.9, 129.6, 127.7, 125.5, 120.8, 117.4, 116.3, 112.0, 109.7, 53.3, 20.4, 19.6; IR (ATR): 3354, 1728, 1446, 1213, $811 \mathrm{~cm}^{-}$ 1; HRMS (FAB) $m / z[\mathrm{M}]^{+}$calcd for $\mathrm{C}_{28} \mathrm{H}_{21} \mathrm{NO}_{4}$ : 435.1471, Found: 435.1475 .

\section{2',7'-Dihydroxy-5-(naphthalen-2-yl)spiro[indoline-3,9'-xanthen]-2-one (3i):}

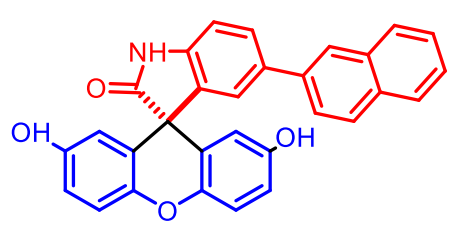

The compound was prepared according to the general procedure and purified by column chromatography (EtOAc/hexane $=30: 70)$. Yield: $78 \%$ (178 mg); State: brown solid; mp: 290-292 ${ }^{\circ} \mathrm{C} ;{ }^{1} \mathrm{H}$ NMR (600 MHz, DMSO-d6) $\delta 10.78(1 \mathrm{H}, \mathrm{s}), 9.15$ (2H, s), 8.10 $(1 \mathrm{H}, \mathrm{s}), 7.94(1 \mathrm{H}, \mathrm{d}, J=7.8 \mathrm{~Hz}), 7.90(1 \mathrm{H}, \mathrm{d}, J=8.4 \mathrm{~Hz}), 7.86(2 \mathrm{H}, \mathrm{t}, J=7.8 \mathrm{~Hz}), 7.75(1 \mathrm{H}$, d, $J=9.0 \mathrm{~Hz}), 7.48-7.44(3 \mathrm{H}, \mathrm{m}), 7.21(1 \mathrm{H}, \mathrm{d}, J=8.4 \mathrm{~Hz}),, 7.06(2 \mathrm{H}, \mathrm{dd}, J=9.0,1.8 \mathrm{~Hz})$, $6.72(2 \mathrm{H}, \mathrm{dd}, J=8.4,2.4 \mathrm{~Hz}), 6.09(2 \mathrm{H}, \mathrm{s}) ;{ }^{13} \mathrm{C}$ NMR (150 MHz, DMSO- $\left.d_{6}\right) \delta 178.7,152.7$, 143.8, 142.2 , 136.7, 136.6, 134.6, 133.3, 131.9, 128.3, 128.0, 127.7, 127.3, 126.2 , 125.8, 124.6, 124.2, 123.2, 120.5, 117.5, 116.4, 112.1, 110.4, 53.3; IR (ATR): 3466, 3002, 1736, 1365, 1215, $817 \mathrm{~cm}^{-1}$; HRMS(FAB) $m / z,[\mathrm{M}+\mathrm{H}]^{+}$calcd for $\mathrm{C}_{30} \mathrm{H}_{20} \mathrm{NO}_{4}: 458.1392$, Found: 458.1390 .

\section{1-Benzyl-5-chloro-2',7'-dihydroxyspiro[indoline-3,9'-xanthen]-2-one (3j):}

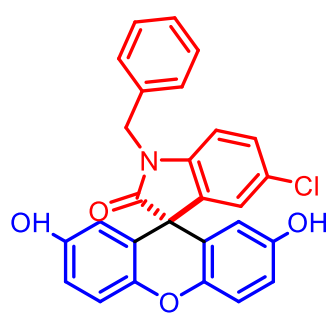

The compound was prepared according to the general procedure and purified by column chromatography $($ EtOAc/hexane $=30: 70)$. Yield: $80 \%$ (182 mg); State: white solid; mp: 295-297 ${ }^{\circ} \mathrm{C}$; ${ }^{1} \mathrm{H}$ NMR $(600 \mathrm{MHz}$, DMSO- $\left.d_{6}\right) \delta 9.24(2 \mathrm{H}, \mathrm{s}), 7.44(1 \mathrm{H}, \mathrm{d}, J=8.4 \mathrm{~Hz}), 7.38-7.30(5 \mathrm{H}, \mathrm{m})$, $7.18(1 \mathrm{H}, \mathrm{dd}, J=8.4,1.8 \mathrm{~Hz}), 7.16(1 \mathrm{H}, \mathrm{d}, J=2.1 \mathrm{~Hz}), 7.10(1 \mathrm{H}, \mathrm{d}, J=$ $1.8 \mathrm{~Hz}), 7.08(1 \mathrm{H}, \mathrm{d}, J=1.8 \mathrm{~Hz}), 6.77(2 \mathrm{H}, \mathrm{d}, J=9 \mathrm{~Hz}), 5.97(2 \mathrm{H}, \mathrm{s}), 4.98(2 \mathrm{H}, \mathrm{s}) ;{ }^{13} \mathrm{C} \mathrm{NMR}$ (150 MHz, DMSO- $\left.d_{6}\right) \delta 152.9,143.8,141.9,136.5,135.9,129.1,128.8,127.8,127.6,127.1$, 125.1, 119.7, 117.7, 116.8, 115.6, 111.9, 111.2, 52.8, 43.1; IR (ATR): 3305, 2967, 1731, 1481, 
1481,1358, $1209 \mathrm{~cm}^{-1}$; HRMS (FAB) $\mathrm{m} / z$ [M] $]^{+}$calcd for $\mathrm{C}_{27} \mathrm{H}_{18} \mathrm{ClNO}_{4}$ : 455.0924, Found: 455.0926 .

2',7'-Dihydroxy-3',4',5',6'-tetramethyl-1-phenylspiro[indoline-3,9'-xanthen]-2-one (4a):

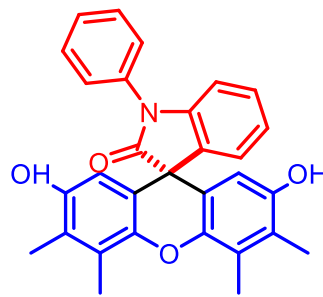

The compound was prepared according to the general procedure and purified by column chromatography $($ EtOAc/hexane $=30: 70)$. Yield: $72 \%$ (167 mg); State: white solid; mp: >300 ${ }^{\circ} \mathrm{C}$; ${ }^{1} \mathrm{H}$ NMR (600 MHz, DMSO$\left.d_{6}\right) \delta 8.91(2 \mathrm{H}, \mathrm{s}), 7.65(2 \mathrm{H}, \mathrm{t}, J=6.6 \mathrm{~Hz}), 7.52(1 \mathrm{H}, \mathrm{t}, J=7.2 \mathrm{~Hz}), 7.47$ $(2 \mathrm{H}, \mathrm{d}, J=7.8 \mathrm{~Hz}), 7.33(1 \mathrm{H}, \mathrm{t}, J=7.8 \mathrm{~Hz}), 7.12(1 \mathrm{H}, \mathrm{t}, J=7.2 \mathrm{~Hz}), 7.04$ $(1 \mathrm{H}, \mathrm{d}, J=7.2 \mathrm{~Hz}), 6.91(1 \mathrm{H}, \mathrm{d}, J=7.8 \mathrm{~Hz}), 6.09(2 \mathrm{H}, \mathrm{s}), 2.34(6 \mathrm{H}, \mathrm{s}), 2.08(6 \mathrm{H}, \mathrm{s}) ;{ }^{13} \mathrm{C} \mathrm{NMR}$ (150 MHz, DMSO- $\left.d_{6}\right) \delta 177.0,150.3,143.0,142.0,135.8,134.1,129.8,128.7,128.4,126.6$, 125.2, 125.0, 124.1, 124.0, 116.9, 109.1, 108.7, 52.7, 12.1, 11.9; IR (ATR): 3375, 1723, 1625, 1012, 611; HRMS (EI) $m / z$ [M] $]^{+}$calcd for $\mathrm{C}_{30} \mathrm{H}_{25} \mathrm{NO}_{4}$ : 463.1784, Found: 463.1782.

\section{2',7'-Dihydroxy-1,3',4',5',6'-pentamethylspiro[indoline-3,9'-xanthen]-2-one (4b):}

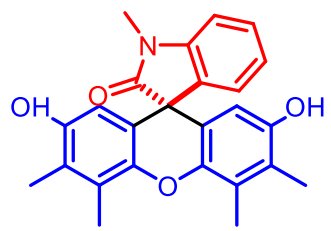

The compound was prepared according to the general procedure and purified by column chromatography (EtOAc/hexane $=30: 70)$. Yield: $77 \%$ (155mg); State: white solid; mp: >300 ${ }^{\circ} \mathrm{C}$; ${ }^{1} \mathrm{H}$ NMR (600 MHz, DMSO$\left.d_{6}\right) \delta 8.80(2 \mathrm{H}, \mathrm{s}), 7.39(1 \mathrm{H}, \mathrm{t}, J=7.8 \mathrm{~Hz}), 7.21(1 \mathrm{H}, \mathrm{d}, J=7.8 \mathrm{~Hz}), 7.07$ $(1 \mathrm{H}, \mathrm{t}, J=7.8 \mathrm{~Hz}), 6.95(1 \mathrm{H}, \mathrm{d}, J=6.0 \mathrm{~Hz}), 5.81(2 \mathrm{H}, \mathrm{s}), 3.20(3 \mathrm{H}, \mathrm{s}), 2.31(6 \mathrm{H}, \mathrm{s}), 2.05(6 \mathrm{H}$, s); ${ }^{13} \mathrm{C}$ NMR (150 MHz, DMSO- $\left.d_{6}\right) \delta 177.4,150.1,143.7,142.1,135.4,128.8,126.0,124.8$, 124.8, 123.9, 123.4, 117.1, 108.7, 52.6, 26.4, 12.1, 11.8; IR (ATR): 3370, 1683, 1417, 1083, $745 \mathrm{~cm}^{-1}$; HRMS (EI) $\mathrm{m} / z$ [M] $]^{+}$calcd for $\mathrm{C}_{25} \mathrm{H}_{23} \mathrm{NO}_{4}$ : 401.1627, Found: 401.1624 .

\section{2',7'-Dihydroxy-3',4',5',6'-tetramethylspiro[indoline-3,9'-xanthen]-2-one (4c):}

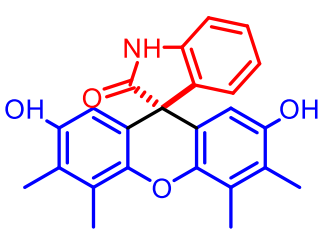

The compound was prepared according to the general procedure and purified by column chromatography (EtOAc/hexane $=30: 70)$. Yield: $70 \%$ (135 mg); State: white solid; mp: >300 ${ }^{\circ} \mathrm{C}$; ${ }^{1} \mathrm{H}$ NMR (600 MHz, DMSO$\left.d_{6}\right) \delta 10.51(1 \mathrm{H}, \mathrm{s}), 8.82(2 \mathrm{H}, \mathrm{s}), 7.28(1 \mathrm{H}, \mathrm{t}, J=7.8 \mathrm{~Hz}), 7.03-6.96$ $(2 \mathrm{H}, \mathrm{m}), 6.90(1 \mathrm{H}, \mathrm{d}, J=7.2 \mathrm{~Hz}), 5.89(2 \mathrm{H}, \mathrm{s}), 2.31(6 \mathrm{H}, \mathrm{s}), 2.05(6 \mathrm{H}, \mathrm{s}) ;{ }^{13} \mathrm{C}$ NMR $(150 \mathrm{MHz}$, DMSO- $\left.d_{6}\right) \delta 179.2,150.1,142.3,142.1,136.5,128.6,125.1,124.7,123.7,122.7,117.3,109.6$, 
108.7, 53.1, 12.1, 11.8; IR (ATR): 3213, 2926, 1692, 1407, 1210, $739 \mathrm{~cm}^{-1}$; HRMS (EI) $\mathrm{m} / \mathrm{z}$ $[\mathrm{M}]^{+}$calcd for $\mathrm{C}_{24} \mathrm{H}_{21} \mathrm{NO}_{4}$ : 387.1471, Found: 387.1468 .

\section{2',7'-Dihydroxy-3',6'-dimethyl-1-phenylspiro[indoline-3,9'-xanthen]-2-one (4d):}

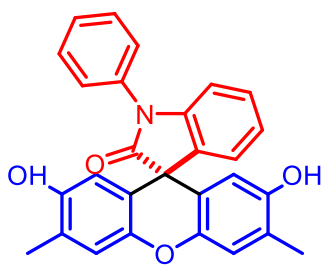

The compound was prepared according to the general procedure and purified by column chromatography $($ EtOAc/hexane $=30: 70)$. Yield: $78 \%$ (148 mg); State: white solid; mp :>300 ${ }^{\circ} \mathrm{C},{ }^{1} \mathrm{H}$ NMR $(600 \mathrm{MHz}$, DMSO- $\left.d_{6}\right) \delta \delta 9.03(2 \mathrm{H}, \mathrm{s}), 7.65(2 \mathrm{H}, \mathrm{t}, J=7.8 \mathrm{~Hz}), 7.53(1 \mathrm{H}, \mathrm{t}, J=$ $7.2 \mathrm{~Hz}), 7.48(2 \mathrm{H}, \mathrm{d}, J=7.8 \mathrm{~Hz}), 7.34(1 \mathrm{H}, \mathrm{t}, J=7.8 \mathrm{~Hz}),, 7.13(1 \mathrm{H}, \mathrm{t}$, $J=7.2 \mathrm{~Hz}), 7.04(1 \mathrm{H}, \mathrm{d}, J=7.2 \mathrm{~Hz}), 6.96(2 \mathrm{H}, \mathrm{s}), 6.92(1 \mathrm{H}, \mathrm{d}, J=7.8 \mathrm{~Hz}), 6.19(2 \mathrm{H}, \mathrm{s}), 2.11$ $(6 \mathrm{H}, \mathrm{s}) ;{ }^{13} \mathrm{C}$ NMR $\left(150 \mathrm{MHz}, \mathrm{DMSO}-d_{6}\right) \delta$ 176.9, 151.1, 143.4, 143.1, 135.7, 134.0, 129.9, $128.9,128.5,126.7,125.9,125.3,124.2,118.2,117.3,111.4,109.30,52.2,15.8$; IR (ATR): 3268, 1693, 1409, 1192, $695 \mathrm{~cm}^{-1}$; HRMS (EI) $\mathrm{m} / z[\mathrm{M}+\mathrm{H}]^{+}$calcd for $\mathrm{C}_{28} \mathrm{H}_{22} \mathrm{NO}_{4}: 436.1549$, Found: 436.1547.

\section{3',6'-Di-tert-butyl-2',7'-dihydroxy-1-phenylspiro[indoline-3,9'-xanthen]-2-one (4e)}

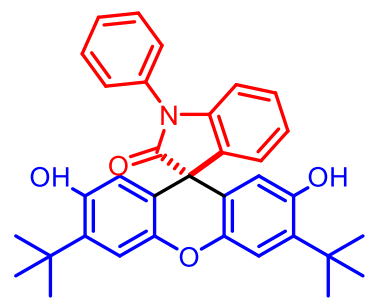

The compound was prepared according to the general procedure and purified by column chromatography (EtOAc/hexane $=30: 70)$. Yield: 73\% (190 mg); Appearance: white solid; mp: >300 ${ }^{\circ} \mathrm{C} ;{ }^{1} \mathrm{H}$ NMR (600 MHz, DMSO-d6) $\delta 9.09(2 \mathrm{H}, \mathrm{s}), 7.65(2 \mathrm{H}, \mathrm{t}, J=7.8 \mathrm{~Hz}), 7.54(1 \mathrm{H}, \mathrm{t}$, $J=7.8 \mathrm{~Hz}), 7.48(2 \mathrm{H}, \mathrm{d}, J=7.8 \mathrm{~Hz}), 7.35(1 \mathrm{H}, \mathrm{t}, J=7.8 \mathrm{~Hz}), 7.13$ $(1 \mathrm{H}, \mathrm{t}, J=7.8 \mathrm{~Hz}), 7.09(1 \mathrm{H}, \mathrm{d}, J=7.8 \mathrm{~Hz}), 6.97(2 \mathrm{H}, \mathrm{s}), 6.91(1 \mathrm{H}, \mathrm{d}, J=7.9 \mathrm{~Hz}), 6.20(2 \mathrm{H}$, s), $1.34(18 \mathrm{H}, \mathrm{s}) ;{ }^{13} \mathrm{C}$ NMR (150 MHz, DMSO- $\left.d_{6}\right) \delta 176.7,151.4,143.3,143.2,137.2,135.3$, 134.0, 129.9, 129.0, 128.5, 126.7, 125.5, 124.2, 117.2, 114.6, 112.9, 109.2, 51.8, 34.3, 29.0; IR (ATR): 3312, 2961, 1707, 1385, 1200, $556 \mathrm{~cm}^{-1}$; HRMS (EI) $\mathrm{m} / z$ [M] ${ }^{+}$calcd for $\mathrm{C}_{34} \mathrm{H}_{33} \mathrm{NO}_{4}$ : 519.2410, Found: 519.2410.

\section{2',7'-Dihydroxy-1,3',6' -triphenylspiro[indoline-3,9'-xanthen]-2-one (4f):}

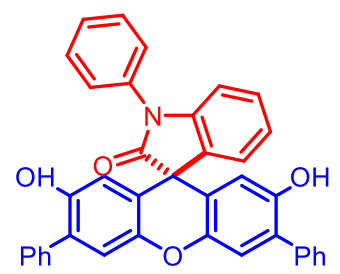

The compound was prepared according to the general procedure and purified by column chromatography (EtOAc/hexane $=30: 70)$. Yield: $76 \%$ (213 mg); State: white solid; mp: $>300{ }^{\circ} \mathrm{C} ;{ }^{1} \mathrm{H}$ NMR (600 MHz,) $\delta 9.35$ $(2 \mathrm{H}, \mathrm{s}), 7.68(2 \mathrm{H}, \mathrm{t}, J=7.2 \mathrm{~Hz}), 7.60(4 \mathrm{H}, \mathrm{d}, J=7.8 \mathrm{~Hz}), 7.56(1 \mathrm{H}, \mathrm{d}, J$ 
$=7.8 \mathrm{~Hz}), 7.53(2 \mathrm{H}, \mathrm{d}, J=7.8 \mathrm{~Hz}) 7.41(5 \mathrm{H}, \mathrm{t}, J=7.2 \mathrm{~Hz}), 7.33(2 \mathrm{H}, \mathrm{t}, J=7.2 \mathrm{~Hz}), 7.22$ $(1 \mathrm{H}, \mathrm{t}, 7.8 \mathrm{~Hz}), 7.19(1 \mathrm{H}, \mathrm{t}, 7.2 \mathrm{~Hz}), 7.16(2 \mathrm{H}, \mathrm{s}), 6.97(1 \mathrm{H}, \mathrm{d}, J=7.8 \mathrm{~Hz}), 6.42(2 \mathrm{H}, \mathrm{s}) ;{ }^{13} \mathrm{C}$ NMR (150 MHz, DMSO-d $d_{6} \delta$ 176.5, 150.0, 143.8, 143.2, 137.3, 135.0, 133.9, 129.9, 129.2, 129.2, 129.0, 128.6, 128.0, 127.0, 126.7, 125.5, 124.4, 119.3, 117.8, 113.2, 109.4, 52.3; IR (ATR): 3355, 1698, 1387, 1184, $693 \mathrm{~cm}^{-1}$; HRMS (EI) $\mathrm{m} / z$ [M] $]^{+}$calcd for $\mathrm{C}_{38} \mathrm{H}_{25} \mathrm{NO}_{4}: 559.1784$, Found: 559.1781.

\section{2',7'-Dihydroxy-1-methyl-3',6'-diphenylspiro[indoline-3,9'-xanthen]-2-one (4g):}

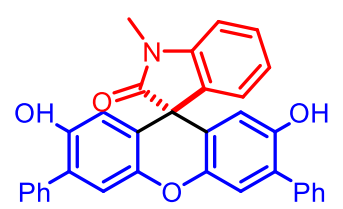

The compound was prepared according to the general procedure and purified by column chromatography (EtOAc/hexane $=30: 70)$. Yield: $70 \%$ (174 mg); State: white solid; mp: 293-295 ${ }^{\circ} \mathrm{C} ;{ }^{1} \mathrm{H}$ NMR $(600 \mathrm{MHz}$, DMSO- $\left.d_{6}\right) \delta 9.25(2 \mathrm{H}, \mathrm{s}), 7.58(4 \mathrm{H}, \mathrm{d}, J=6.6 \mathrm{~Hz}), 7.48(1 \mathrm{H}, \mathrm{dt}, J=7.8$, $4.2 \mathrm{~Hz}), 7.40(4 \mathrm{H}, \mathrm{t}, J=8.4 \mathrm{~Hz}), 7.32(3 \mathrm{H}, \mathrm{t}, J=7.2 \mathrm{~Hz}), 7.17(2 \mathrm{H}, \mathrm{d}, J=4.2 \mathrm{~Hz}), 7.13(2 \mathrm{H}$, s), $6.16(2 \mathrm{H}, \mathrm{s}), 3.27(3 \mathrm{H}, \mathrm{s}) ;{ }^{13} \mathrm{C}$ NMR $\left(150 \mathrm{MHz}, \mathrm{DMSO}-d_{6}\right) \delta 176.9,149.8,144.0,143.9$, 137.3, 134.7, 129.3, 129.0, 128.0, 127.0, 125.1, 123.7, 119.63, 117.7, 113.1, 109.0, 52.3, 26.5; IR (ATR): 3317, 1692, 1405, 1175, $692 \mathrm{~cm}^{-1}$; HRMS (EI) $\mathrm{m} / z$ [M] calcd for $\mathrm{C}_{33} \mathrm{H}_{23} \mathrm{NO}_{4}$ : 497.1627, Found: 497.1630.

\section{2',7'-Dihydroxy-3',6'-dimethylspiro[indoline-3,9'-xanthen]-2-one (4h):}

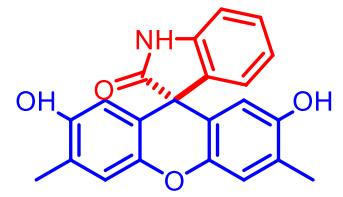

The compound was prepared according to the general procedure and purified by column chromatography $($ EtOAc/ hexane $=30: 70)$. Yield: $71 \%$ (126 mg); State: white solid; mp: $>300{ }^{\circ} \mathrm{C} ;{ }^{1} \mathrm{H}$ NMR $(600 \mathrm{MHz}$, DMSO-d $) \delta 10.58(1 \mathrm{H}, \mathrm{s}), 8.95(2 \mathrm{H}, \mathrm{s}), 7.30-7.27(1 \mathrm{H}, \mathrm{m}), 7.03(1 \mathrm{H}, \mathrm{d}$, $J=7.8 \mathrm{~Hz}), 7.00-6.97(1 \mathrm{H}, \mathrm{m}), 6.92-6.90(3 \mathrm{H}, \mathrm{m}), 6.00(2 \mathrm{H}, \mathrm{s}), 2.08(6 \mathrm{H}, \mathrm{s}) ;{ }^{13} \mathrm{C} \mathrm{NMR}(150$ MHz, DMSO- $\left.d_{6}\right) \delta 179.1,150.9,143.4,142.2,136.5,128.7,125.5,125.0,122.8,118.1,117.7$, 111.4, 109.7, 52.6, 15.7; IR (ATR): 3224, 2925, 1727, 1406, 1212, $740 \mathrm{~cm}^{-1}$; HRMS (EI) $\mathrm{m} / \mathrm{z}$ $[\mathrm{M}]^{+}$calcd for $\mathrm{C}_{22} \mathrm{H}_{17} \mathrm{NO}_{4}$ : 359.1158, Found: 359.1157 .

3',6'-Di-tert-butyl-2',7'-dihydroxyspiro[indoline-3,9'-xanthen]-2-one (4i): 


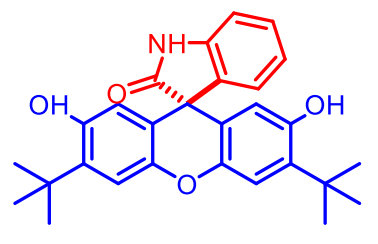

The compound was prepared according to the general procedure and purified by column chromatography $($ EtOAc/hexane $=30: 70)$. Yield: 79\% (176 mg); State: white solid; mp: $290-292{ }^{\circ} \mathrm{C} ;{ }^{1} \mathrm{H}$ NMR $(600 \mathrm{MHz}$, DMSO- $\left.d_{6}\right) \delta 10.61(1 \mathrm{H}, \mathrm{s}), 9.00(2 \mathrm{H}, \mathrm{s}), 7.30(1 \mathrm{H}, \mathrm{t}, J=7.8 \mathrm{~Hz}), 7.03$ $(1 \mathrm{H}, \mathrm{d}, J=7.8 \mathrm{~Hz}), 7.00(1 \mathrm{H}, \mathrm{t}, J=7.8 \mathrm{~Hz}), 6.95(1 \mathrm{H}, \mathrm{d}, J=7.2 \mathrm{~Hz}), 6.92(2 \mathrm{H}, \mathrm{s}), 6.03(2 \mathrm{H}$, s), $1.32(18 \mathrm{H}, \mathrm{s}) ;{ }^{13} \mathrm{C}$ NMR (150 MHz, DMSO- $\left.d_{6}\right) \delta 179.02,151.22,143.50,142.27,136.83$, 136.22, 128.78, 125.26, 122.81, 117.75, 114.47, 112.98, 109.78, 52.29, 34.26, 29.10; IR (ATR): 3213, 2926, 1722, 1204, 1009, $598 \mathrm{~cm}^{-1}$; HRMS (FAB) $\mathrm{m} / z[\mathrm{M}]^{+}$calcd for $\mathrm{C}_{28} \mathrm{H}_{29} \mathrm{NO}_{4}$ : 443.2097, Found: 443.2098.

\section{2',7'-Dihydroxy-3',6'-diphenylspiro[indoline-3,9'-xanthen]-2-one (4j):}

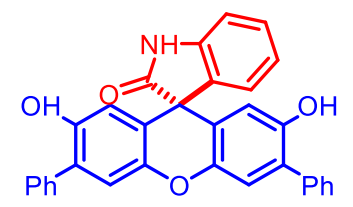

The compound was prepared according to the general procedure and purified by column chromatography $($ EtOAc/hexane $=30: 70)$. Yield:

$76 \%$ (184 mg); State: white solid; mp: >300 ${ }^{\circ} \mathrm{C} ;{ }^{1} \mathrm{H}$ NMR $(600 \mathrm{MHz}$, DMSO- $\left.d_{6}\right) \delta 10.74(1 \mathrm{H}, \mathrm{s}), 9.28(2 \mathrm{H}, \mathrm{s}), 7.58(3 \mathrm{H}, \mathrm{d}, J=7.8 \mathrm{~Hz}), 7.40(4 \mathrm{H}, \mathrm{t}, J=7.8 \mathrm{~Hz}), 7.40$ $(2 \mathrm{H}, \mathrm{t}, J=7.8 \mathrm{~Hz}), 7.31(2 \mathrm{H}, \mathrm{t}, J=7.2 \mathrm{~Hz}), 7.13-7.05(5 \mathrm{H}, \mathrm{m}), 6.25(2 \mathrm{H}, \mathrm{s}) ;{ }^{13} \mathrm{C} \operatorname{NMR}(150$ MHz, DMSO- $\left.d_{6}\right) \delta 178.8,149.9,144.0,142.4,137.4,135.8,129.0,128.9,128.3,128.0,127.0$, 125.3, 123.0, 119.8, 117.6, 113.2, 110.0, 52.8; IR: 3371, 2929, 1700, 1404, 1188, $695 \mathrm{~cm}^{-1}$; HRMS (FAB) $m / z[\mathrm{M}+\mathrm{H}]^{+}$calcd for $\mathrm{C}_{32} \mathrm{H}_{22} \mathrm{NO}_{4}$ : 484.1549, Found: 484.1546.

\section{3',6'-Dichloro-2',7'-dihydroxy-1-phenylspiro[indoline-3,9'-xanthen]-2-one (4k):}

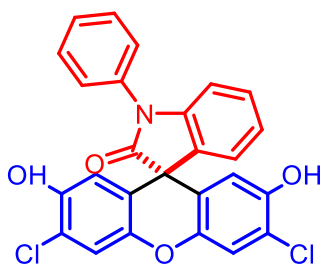

The compound was prepared according to the general procedure and purified by column chromatography (EtOAc/ hexane $=15: 85)$. Yield: $62 \%$ (148 mg); state: brown solid; mp: 200-202 ${ }^{\circ} \mathrm{C}$; ${ }^{1} \mathrm{H}$ NMR $(600 \mathrm{MHz}$, DMSO- $\left.d_{6}\right) \delta 9.96(2 \mathrm{H}, \mathrm{s}), 7.65(2 \mathrm{H}, \mathrm{t}, J=7.8 \mathrm{~Hz}), 7.54(1 \mathrm{H}, \mathrm{t}, J=7.2$ Hz), $7.48(2 \mathrm{H}, \mathrm{d}, J=7.2 \mathrm{~Hz}), 7.40(1 \mathrm{H}, \mathrm{t}, J=7.0 \mathrm{~Hz}), 7.31(2 \mathrm{H}, \mathrm{s}), 7.20-7.15(2 \mathrm{H}, \mathrm{m}), 6.95$ $(1 \mathrm{H}, \mathrm{d}, J=8.0 \mathrm{~Hz}), 6.39(2 \mathrm{H}, \mathrm{s}) ;{ }^{13} \mathrm{C}$ NMR $\left(150 \mathrm{MHz}, \mathrm{DMSO}-d_{6}\right) \delta 175.9,149.2,143.4,143.2$, 134.1, 133.7, 129.9, 129.6, 128.7, 126.7, 125.5, 124.5, 120.5, 119.2, 117.8, 113.4, 109.6, 52.1; IR (ATR): 3200, 1719, 1610, 1408, 1194, 947, $751 \mathrm{~cm}^{-1}$; HRMS (EI) $\mathrm{m} / z[\mathrm{M}+\mathrm{H}]^{+}$calcd for $\mathrm{C}_{26} \mathrm{H}_{15} \mathrm{Cl}_{2} \mathrm{NO}_{4}$ : 475.0378, Found: 475.0381

3',6'-Dibromo-2',7'-dihydroxy-1-phenylspiro[indoline-3,9'-xanthen]-2-one (4l): 


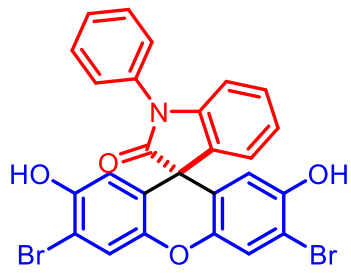

The compound was prepared according to the general procedure and purified by column chromatography $($ EtOAc/ hexane $=20: 80)$. Yield: $52 \%$ (147 mg); state: white solid; mp: $218-220{ }^{\circ} \mathrm{C} ;{ }^{1} \mathrm{H}$ NMR $(600 \mathrm{MHz}$, DMSO- $\left.d_{6}\right) \delta 10.01(2 \mathrm{H}, \mathrm{s}), 7.65(2 \mathrm{H}, \mathrm{t}, J=7.8 \mathrm{~Hz}), 7.54(1 \mathrm{H}, \mathrm{t}, J=7.2$ Hz), $7.47(2 \mathrm{H}, \mathrm{d}, J=7.8 \mathrm{~Hz}), 7.44(2 \mathrm{H}, \mathrm{s}), 7.41(1 \mathrm{H}, \mathrm{t}, J=8.4 \mathrm{~Hz}), 7.18$ $(2 \mathrm{H}, \mathrm{q}, J=7.8 \mathrm{~Hz}), 6.95(1 \mathrm{H}, \mathrm{d}, J=8.4 \mathrm{~Hz}), 6.38(2 \mathrm{H}, \mathrm{s}) ;{ }^{13} \mathrm{C}$ NMR $\left(150 \mathrm{MHz}, \mathrm{DMSO}-d_{6}\right) \delta$ 175.8, 150.2, 143.6, 143.3, 134.0, 133.7, 129.9, 129.6, 128.7, 126.7, 125.5, 124.5, 120.6, 119.9, 113.0, 109.8, 109.6, 52.3; IR (ATR) 3249, 1690, 1457, 1402,1185, $750 \mathrm{~cm}^{-1}$; HRMS (EI) $\mathrm{m} / \mathrm{z}$ $[\mathrm{M}+\mathrm{H}]^{+} \mathrm{C}_{26} \mathrm{H}_{16} \mathrm{NO}_{4} \mathrm{Br}^{79} \mathrm{Br}^{81}$ : 565.9417, Found: 565.9420 .

\section{1-Benzyl-2',7' -dihydroxy-5-methoxy-3',6' -dimethylspiro[indoline-3,9' -xanthen]-2-} oneone $(4 \mathrm{~m})$ :

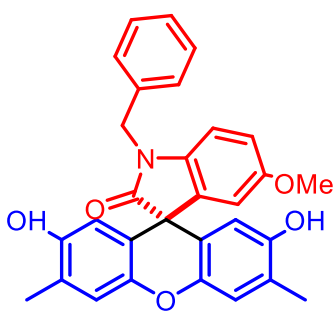

The compound was prepared according to the general procedure and purified by column chromatography $($ EtOAc/hexane $=30: 70)$. Yield: 86\% (206 mg); state: white solid; mp: $194-196{ }^{\circ} \mathrm{C} ;{ }^{1} \mathrm{H}$ NMR $(600 \mathrm{MHz}$, DMSO- $\left.d_{6}\right) \delta 9.01(2 \mathrm{H}, \mathrm{s}), 7.35(2 \mathrm{H}, \mathrm{t}, J=7.2 \mathrm{~Hz}), 7.32-7.28(3 \mathrm{H}, \mathrm{m})$, $7.00(1 \mathrm{H}, \mathrm{d}, J=9.0 \mathrm{~Hz}), 6.94(2 \mathrm{H}, \mathrm{s}), 6.91(1 \mathrm{H}, \mathrm{d}, J=9.0 \mathrm{~Hz}), 6.62$ $(1 \mathrm{H}, \mathrm{s}), 5.99(2 \mathrm{H}, \mathrm{s}), 4.90(2 \mathrm{H}, \mathrm{s}), 3.63(3 \mathrm{H}, \mathrm{s}), 2.10(6 \mathrm{H}, \mathrm{s}) ;{ }^{13} \mathrm{C}$ NMR (150 MHz, DMSO-d $)$ $\delta 177.2,156.3,150.9,143.6,136.5,136.3,135.9,128.8,127.4,126.9,125.8,118.2,117.5$, 113.8, 111.4, 111.4, 110.1, 55.5, 52.6, 42.9, 15.7; IR: 3355, 1705, 1188, 992, $699 \mathrm{~cm}^{-1}$; HRMS (EI) $m / z[\mathrm{M}+\mathrm{H}]^{+}$calcd for $\mathrm{C}_{30} \mathrm{H}_{25} \mathrm{NO}_{5}: 479.1733$, Found: 479.1731 .

\section{5,9-Dihydroxy-1'-phenylspiro[dibenzo[c,h] xanthene-7,3'-indolin]-2'-one (5a):}

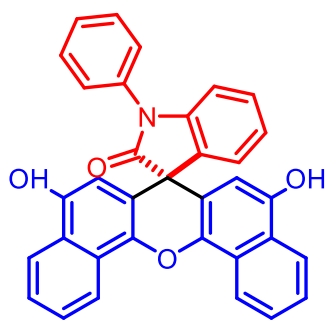

The compound was prepared according to the general procedure and purified by column chromatography $($ EtOAc/hexane $=30: 70)$. Yield: $90 \%$ (229 mg); State: brown solid; mp: $290-292{ }^{\circ} \mathrm{C}{ }^{1} \mathrm{H}$ NMR (600 MHz, DMSO- $\left.d_{6}\right) \delta 9.93(\mathrm{~s}, 2 \mathrm{H}), 8.66(2 \mathrm{H}, \mathrm{d}, J=8.4 \mathrm{~Hz}), 8.15(2 \mathrm{H}, \mathrm{d}, J=8.4$ $\mathrm{Hz}), 7.77(2 \mathrm{H}, \mathrm{t}, J=7.2 \mathrm{~Hz}), 7.70(2 \mathrm{H}, \mathrm{t}, J=7.8 \mathrm{~Hz}), 7.63(2 \mathrm{H}, \mathrm{t}, J=7.2$ $\mathrm{Hz}), 7.60-7.56(3 \mathrm{H}, \mathrm{m}), 7.41-7.36(1 \mathrm{H}, \mathrm{m}), 7.13(2 \mathrm{H}, \mathrm{d}, J=3.0 \mathrm{~Hz}), 7.00(1 \mathrm{H}, \mathrm{d}, J=7.8$ $\mathrm{Hz}), 6.28$ (s, 2H); ${ }^{13} \mathrm{C}$ NMR (150 MHz, DMSO- $\left.d_{6}\right) \delta 177.0,149.0,142.9,138.3,136.0,134.0$, $129.9,129.2$, 128.6, 127.1, 126.7, 126.1, 125.6, 125.0, 124.6, 124.3, 122.1, 121.3, 113.5, 109.4, 
104.3, 53.1; IR (ATR): 3296, 1692, 1660, 1371, $747 \mathrm{~cm}^{-1}$; HRMS (FAB) $\mathrm{m} / z$ [M] $]^{+}$calcd for $\mathrm{C}_{34} \mathrm{H}_{21} \mathrm{NO}_{4}$ : 507.1471, Found: 507.1468.

\section{1'-(2,6-Dichlorophenyl)-5,9-dihydroxyspiro[dibenzo[c,h] xanthene-7,3'-indolin]-2'-one} (5b):

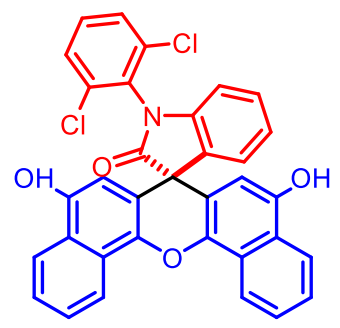

The compound was prepared according to the general procedure and purified by column chromatography $($ EtOAc/hexane $=30: 70)$. Yield: $81 \%$ (230 mg); State: brown solid; mp: $295-297{ }^{\circ} \mathrm{C}$; ${ }^{1} \mathrm{H}$ NMR $(600 \mathrm{MHz}$, DMSO-d $d_{6} \delta 10.01(2 \mathrm{H}, \mathrm{s}), 8.66(2 \mathrm{H}, \mathrm{d}, J=8.4 \mathrm{~Hz}), 8.15(2 \mathrm{H}, \mathrm{d}, J=8.4$ $\mathrm{Hz}), 7.81(2 \mathrm{H}, \mathrm{d}, J=8.4 \mathrm{~Hz}), 7.77(2 \mathrm{H}, \mathrm{t}, J=7.8 \mathrm{~Hz}), 7.68-7.61(3 \mathrm{H}$, m), $7.39(1 \mathrm{H}, \mathrm{t}, J=8.4 \mathrm{~Hz}), 7.23-7.14(2 \mathrm{H}, \mathrm{m}), 6.72(1 \mathrm{H}, \mathrm{d}, J=8.4 \mathrm{~Hz}), 6.39(2 \mathrm{H}, \mathrm{s}) ;{ }^{13} \mathrm{C}$ NMR (150 MHz, DMSO- $\left.d_{6}\right) \delta 175.9,148.8,141.7,138.3,135.6,134.8,132.2,129.4,129.4$, 129.2, 127.2, 126.2, 126.0, 125.2, 124.6, 124.6, 122.2, 121.3, 113.2, 109.1, 104.9, 53.4; IR (ATR): 3472, 2927, 1735, 1368, 1219, $770 \mathrm{~cm}^{-1}$; HRMS (EI) $\mathrm{m} / z$ [M] $]^{+}$calcd for $\mathrm{C}_{34} \mathrm{H}_{19} \mathrm{Cl}_{2} \mathrm{NO}_{4}$ : 575.0691, Found: 575.0687.

\section{5,9-Dihydroxy-1'-methylspiro[dibenzo[c,h]xanthene-7,3'-indolin]-2'-one (5c):}

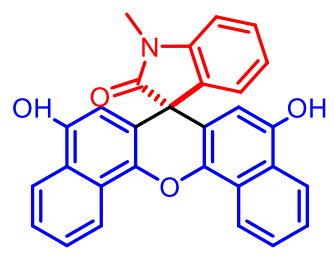

The compound was prepared according to the general procedure and purified by column chromatography (EtOAc/hexane $=30: 70)$. Yield: $83 \%$ (185 mg); State: brown solid; mp: >300 ${ }^{\circ} \mathrm{C} ;{ }^{1} \mathrm{H}$ NMR (600 MHz, DMSO$\left.d_{6}\right) \delta 9.84(2 \mathrm{H}, \mathrm{s}), 8.65(2 \mathrm{H}, \mathrm{d}, J=8.4 \mathrm{~Hz}), 8.13(2 \mathrm{H}, \mathrm{d}, J=8.4 \mathrm{~Hz}), 7.76$ $(2 \mathrm{H}, \mathrm{t}, J=7.8 \mathrm{~Hz}), 7.62(2 \mathrm{H}, \mathrm{t}, J=7.8 \mathrm{~Hz}), 7.45(1 \mathrm{H}, \mathrm{d}, J=7.2 \mathrm{~Hz}), 7.33(1 \mathrm{H}, \mathrm{d}, J=8.4 \mathrm{~Hz})$, $7.07(2 \mathrm{H}, \mathrm{dd}, J=15.6,7.2 \mathrm{~Hz}), 6.01(2 \mathrm{H}, \mathrm{s}), 3.34(3 \mathrm{H}, \mathrm{s}) ;{ }^{13} \mathrm{C}$ NMR (150 MHz, DMSO- $\left.d_{6}\right) \delta$ $177.5,148.8,143.5,138.4,135.9,129.1,127.1,126.0,125.0,125.0,124.64,123.6,122.1$, 121.2, 113.6, 108.9, 104.4, 53.0, 26.6; IR (ATR): 3316, 1686, 1367, 1234, $752 \mathrm{~cm}^{-1}$; HRMS (FAB) $m / z[\mathrm{M}+\mathrm{H}]^{+}$calcd for $\mathrm{C}_{29} \mathrm{H}_{20} \mathrm{NO}_{4}: 446.1392$, Found: 446.1389.

1'-Benzyl-5'-chloro-5,9-dihydroxyspiro[dibenzo[c,h] xanthene-7,3'-indolin]-2'-one (5d): 


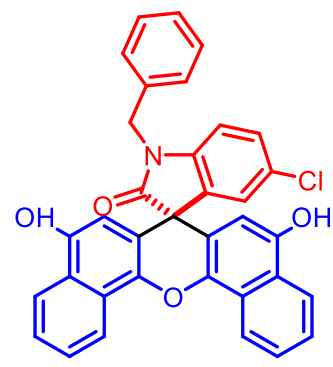

The compound was prepared according to the general procedure and purified by column chromatography $($ EtOAc/hexane $=30: 70)$. Yield: $80 \%$ (222 mg); State: brown solid; mp: 295-297 ${ }^{\circ} \mathrm{C}$; ${ }^{1} \mathrm{H}$ NMR $(600 \mathrm{MHz}$, DMSO- $\left.d_{6}\right) \delta 9.95(2 \mathrm{H}, \mathrm{s}), 8.66(2 \mathrm{H}, \mathrm{d}, J=8.4 \mathrm{~Hz}), 8.15(2 \mathrm{H}, \mathrm{d}, J=8.4$ $\mathrm{Hz}), 7.77(2 \mathrm{H}, \mathrm{t}, J=7.2 \mathrm{~Hz}), 7.63(2 \mathrm{H}, \mathrm{t}, J=7.2 \mathrm{~Hz}), 7.48(1 \mathrm{H}, \mathrm{d}, J=$ $9.0 \mathrm{~Hz}), 7.42(4 \mathrm{H}, \mathrm{dd}, J=4.2,1.2 \mathrm{~Hz}), 7.35-7.33(1 \mathrm{H}, \mathrm{m}), 7.25-7.23$ $(\mathrm{m}, 2 \mathrm{H}), 6.05(2 \mathrm{H}, \mathrm{s}), 5.06(2 \mathrm{H}, \mathrm{s}) ;{ }^{13} \mathrm{C}$ NMR (150 MHz, DMSO- $\left.d_{6}\right) \delta$ 177.3, 149.0, 142.0, 138.6, 137.2, 135.8, 129.2, 128.9, 128.0, 127.6, 127.2, 127.0, 126.2, 125.5, 125.1, 124.7, 122.2, 121.3, 112.9, 111.2, 104.1, 53.2, 43.3; IR (ATR): 3392, 1721, 1015, $533 \mathrm{~cm}^{-1}$; HRMS (FAB) $m / z,[\mathrm{M}+\mathrm{H}]^{+}$calcd for $\mathrm{C}_{35} \mathrm{H}_{23} \mathrm{ClNO}_{4}$ : 556.1316, Found: 556.1313 .

\section{1'-Benzyl-5,9-dihydroxy-5'-methoxyspiro[dibenzo[c,h]xanthene-7,3'-indolin]-2'-one} (5e):

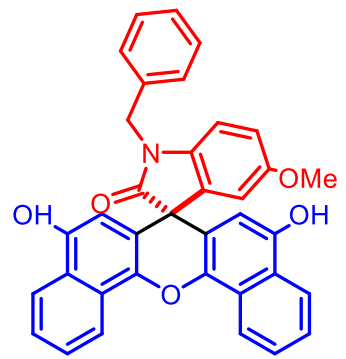

The compound was prepared according to the general procedure and purified by column chromatography (EtOAc/hexane $=30: 70)$. Yield: $75 \%$ (207 mg); State: brown solid; mp: 292-294 ${ }^{\circ} \mathrm{C} ;{ }^{1} \mathrm{H}$ NMR $(600 \mathrm{MHz}$, DMSO-d $d_{6} \delta 9.93(2 \mathrm{H}, \mathrm{s}), 8.66(2 \mathrm{H}, \mathrm{d}, J=8.4 \mathrm{~Hz}), 8.15(2 \mathrm{H}, \mathrm{d}, J=8.4$ $\mathrm{Hz}), 7.79-7.75(2 \mathrm{H}, \mathrm{m}), 7.63(2 \mathrm{H}, \mathrm{t}, J=7.6 \mathrm{~Hz}), 7.43-7.40(4 \mathrm{H}, \mathrm{m})$, $7.34(1 \mathrm{H}, \mathrm{d}, J=5.8 \mathrm{~Hz}), 7.10(1 \mathrm{H}, \mathrm{d}, J=8.7 \mathrm{~Hz}), 6.95(1 \mathrm{H}, \mathrm{d}, J=8.8$

$\mathrm{Hz}), 6.73(1 \mathrm{H}, \mathrm{t}, J=2.1 \mathrm{~Hz}), 6.08(2 \mathrm{H}, \mathrm{s}), 5.02(2 \mathrm{H}, \mathrm{s}), 3.60(3 \mathrm{H}, \mathrm{s}) ;{ }^{13} \mathrm{C}$ NMR $(150 \mathrm{MHz}$, DMSO- $\left.d_{6}\right) \delta 177.4,156.5,148.9,138.5,136.6,136.4,136.2,128.8,127.4,127.1,127.0,126.0$, 125.1, 124.7, 122.2 121.3, 114.1, 113.7, 111.8, 110.3, 104.5, 55.5, 53.5, 43.3; IR (ATR): 3465, 1704, 1447, 1364, 1220, $900 \mathrm{~cm}^{-1}$; HRMS (FAB) $\mathrm{m} / z$ [M+H] $]^{+}$calcd for $\mathrm{C}_{36} \mathrm{H}_{26} \mathrm{NO}_{5}: 552.1811$, Found: 552.1808.

\section{5,9-Dihydroxyspiro[dibenzo[c,h]xanthene-7,3'-indolin]-2'-one (5f):}

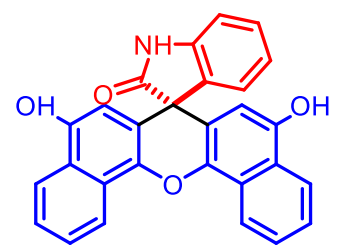

The compound was prepared according to the general procedure and purified by column chromatography $($ EtOAc/hexane $=30: 70)$. Yield: $87 \%$ (188 mg); State: brown solid; mp: >300 ${ }^{\circ} \mathrm{C}$; ${ }^{1} \mathrm{H}$ NMR (600 MHz, DMSO$\left.d_{6}\right) \delta 10.85(1 \mathrm{H}, \mathrm{s}), 9.89(2 \mathrm{H}, \mathrm{s}), 8.64(2 \mathrm{H}, \mathrm{d}, J=8.4 \mathrm{~Hz}), 8.14(2 \mathrm{H}, \mathrm{d}, J$ $=8.4 \mathrm{~Hz}), 7.75(2 \mathrm{H}, \mathrm{t}, J=7.2 \mathrm{~Hz}), 7.61(2 \mathrm{H}, \mathrm{t}, J=7.2 \mathrm{~Hz}), 7.36-7.33(\mathrm{~m}, 1 \mathrm{H}), 7.14(1 \mathrm{H}, \mathrm{d}$, $J=7.8 \mathrm{~Hz}), 7.03-6.98(2 \mathrm{H}, \mathrm{m}), 6.13(2 \mathrm{H}, \mathrm{s}) ;{ }^{13} \mathrm{C} \mathrm{NMR}\left(150 \mathrm{MHz}, \mathrm{DMSO}-d_{6}\right) \delta 179.3,148.9$, 
142.1, 138.4, 137.0, 129.1, 127.1, 126.0, 125.4, 125.0, 124.7, 123.0, 122.2, 121.3, 114.0, 110.0, 104.6, 53.5; IR (ATR): 3195, 1696, 1374, 1071, $750 \mathrm{~cm}^{-1}$; HRMS (FAB) $\mathrm{m} / z$ [M] $]^{+}$calcd for $\mathrm{C}_{28} \mathrm{H}_{17} \mathrm{NO}_{4}$ : 431.1158, Found: 431.1155.

\section{5'-Bromo-5,9-dihydroxyspiro[dibenzo[ $[c, h]$ xanthene-7,3'-indolin]-2'-one (5g):}

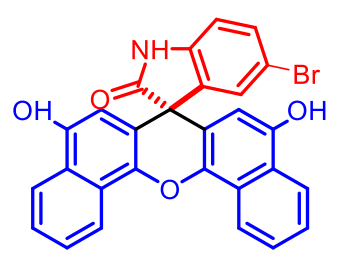

The compound was prepared according to the general procedure and purified by column chromatography $($ EtOAc/hexane $=30: 70)$. Yield: $80 \%$ (205 mg); State: brown solid; mp: >300 ${ }^{\circ} \mathrm{C}$; ${ }^{1} \mathrm{H}$ NMR $(600 \mathrm{MHz}$,

DMSO- $\left.d_{6}\right) \delta 10.98(1 \mathrm{H}, \mathrm{s}), 9.89(2 \mathrm{H}, \mathrm{s}), 8.62(2 \mathrm{H}, \mathrm{d}, J=8.4 \mathrm{~Hz}), 8.12$ $(2 \mathrm{H}, \mathrm{d}, J=8.4 \mathrm{~Hz}), 7.76-7.73(2 \mathrm{H}, \mathrm{m}), 7.63-7.60(2 \mathrm{H}, \mathrm{m}), 7.55(1 \mathrm{H}, \mathrm{dd}, J=8.4,1.8 \mathrm{~Hz})$, $7.19(1 \mathrm{H}, \mathrm{s}), 7.11(1 \mathrm{H}, \mathrm{d}, J=8.4 \mathrm{~Hz}), 6.08(2 \mathrm{H}, \mathrm{s}) ;{ }^{13} \mathrm{C}$ NMR $\left(150 \mathrm{MHz}, \mathrm{DMSO}-d_{6}\right) \delta 178.7$, 148.9, 141.4, 139.0, 138.3 132.0, 128.0, 127.1, 126.0, 125.0, 124.6, 122.1, 121.3, 114.6, 113.0, 112.0, 104.1, 53.6; IR (ATR): 3326, 2922, 1706, 1218, 1081, $709 \mathrm{~cm}^{-1}$; HRMS (FAB) $\mathrm{m} / z$ [M] ${ }^{+}$ calcd for $\mathrm{C}_{28} \mathrm{H}_{16} \mathrm{BrNO}_{4}$ : 509.0263, Found: 509.0260.

\section{5,9-Dihydroxy-5' -nitrospiro[dibenzo[c,h]xanthene-7,3'-indolin]-2' -one (5h):}

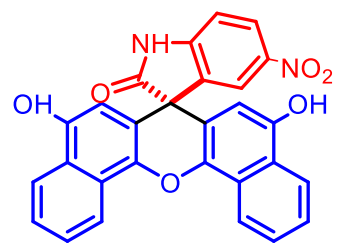

The compound was prepared according to the general procedure and purified by column chromatography $($ EtOAc/hexane $=30: 70)$. Yield: 96\% (229 mg); State: brown solid; mp: 295-297 ${ }^{\circ} \mathrm{C}$; ${ }^{1} \mathrm{H}$ NMR (600 MHz, DMSO- $\left.d_{6}\right) \delta 11.61(1 \mathrm{H}, \mathrm{s}), 9.92(2 \mathrm{H}, \mathrm{s}), 8.65(2 \mathrm{H}, \mathrm{d}, J=8.4 \mathrm{~Hz})$, $8.34(1 \mathrm{H}, \mathrm{dd}, J=9.0,2.4 \mathrm{~Hz}), 8.13(2 \mathrm{H}, \mathrm{d}, J=7.8 \mathrm{~Hz}), 7.84(1 \mathrm{H}, \mathrm{d}, J=2.4 \mathrm{~Hz}), 7.78-7.74(2 \mathrm{H}$, m), 7.64-7.62(2H, m), $7.38(1 \mathrm{H}, \mathrm{d}, J=9.0 \mathrm{~Hz}), 6.08(2 \mathrm{H}, \mathrm{s}) ;{ }^{13} \mathrm{C}$ NMR (150 MHz, DMSO- $\left.d_{6}\right)$ $\delta 179.5,149.1,148.3,143.3,138.5,137.6,127.3,126.4,126.3,125.2$, 124.7, 122.2, 121.4, 120.8, 112.3, 110.5, 10.9, 53.5; IR (ATR): 3387, 2926, 1734, 1338, 1016, $525 \mathrm{~cm}^{-1}$; HRMS (FAB) $m / z$ [M] $]^{+}$calcd for $\mathrm{C}_{28} \mathrm{H}_{16} \mathrm{~N}_{2} \mathrm{O}_{6}: 476.1008$, Found: 476.1006.

Methyl 5,9-dihydroxy-2'-oxospiro[dibenzo[c,h] xanthene-7,3'-indoline]-6'-carboxylate (5i) : 


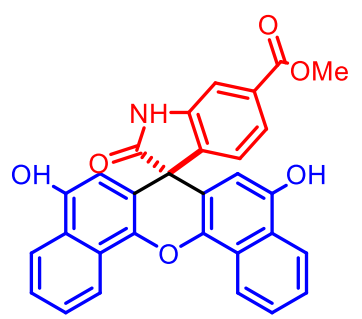

The compound was prepared according to the general procedure and purified by column chromatography (EtOAc/hexane $=30: 70)$. Yield: 80\% (196 mg); State: brown solid; mp: 280-282 ${ }^{\circ} \mathrm{C} ;{ }^{1} \mathrm{H}$ NMR (600 MHz, DMSO-d $d_{6} \delta 11.09(1 \mathrm{H}, \mathrm{s}), 9.88(2 \mathrm{H}, \mathrm{s}), 8.63(2 \mathrm{H}, \mathrm{d}, J=8.4 \mathrm{~Hz})$, $8.12(2 \mathrm{H}, \mathrm{d}, J=10.2 \mathrm{~Hz}), 7.76(2 \mathrm{H}, \mathrm{t}, J=6.6 \mathrm{~Hz}), 7.64-7.60(4 \mathrm{H}, \mathrm{m})$, $7.16(1 \mathrm{H}, \mathrm{dd}, J=6.6 \mathrm{~Hz}, J=1.2 \mathrm{~Hz}), 6.07(2 \mathrm{H}, \mathrm{s}), 3.89(3 \mathrm{H}, \mathrm{s}) ;{ }^{13} \mathrm{C}$ NMR (150 MHz, DMSO$d_{6)} \delta 178.9,165.8,149.0,142.5,141.8,138.3,130.4,127.2,126.1,125.8,125.0,124.6,124.3$, 12.18, 121.3, 113.0, 109.9, 104.1, 53.6, 52.4; IR (ATR): 3339, 2961, 1732, 1226, 1084, 765 $\mathrm{cm}^{-1}$; HRMS (FAB) $\mathrm{m} / z$ [M+H] $]^{+}$calcd for $\mathrm{C}_{30} \mathrm{H}_{20} \mathrm{NO}_{6}$ : 490.1291 , Found: 490.1287.

\section{5,9-Dihydroxy-5'-phenylspiro[dibenzo[c,h] xanthene-7,3'-indolin]-2'-one (5j):}

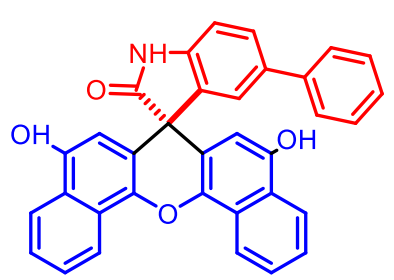

The compound was prepared according to the general procedure and purified by column chromatography (EtOAc/hexane $=30: 70)$. Yield: 83\% (210 mg); State: brown solid; mp: >300 ${ }^{\circ} \mathrm{C} ;{ }^{1} \mathrm{H}$ NMR $(600 \mathrm{MHz}$, DMSO- $\left.d_{6}\right) \delta 10.97(1 \mathrm{H}, \mathrm{s}), 9.90(2 \mathrm{H}, \mathrm{s}), 8.66(2 \mathrm{H}, \mathrm{d}, J=8.4 \mathrm{~Hz}), 8.14$ $(2 \mathrm{H}, \mathrm{d}, J=8.4 \mathrm{~Hz}), 7.76(2 \mathrm{H}, \mathrm{t}, J=7.8 \mathrm{~Hz}), 7.70(1 \mathrm{H}, \mathrm{dd}, J=8.4,1.8$ Hz), $7.61(2 \mathrm{H}, \mathrm{t}, J=7.8 \mathrm{~Hz}), 7.47(2 \mathrm{H}, \mathrm{d}, J=7.2 \mathrm{~Hz}), 7.30(1 \mathrm{H}, \mathrm{s}), 7.29-7.24(3 \mathrm{H}, \mathrm{m}), 7.18$ $(1 \mathrm{H}, \mathrm{t}, J=7.8 \mathrm{~Hz}), 6.18(2 \mathrm{H}, \mathrm{s}) ;{ }^{13} \mathrm{C}$ NMR (150 MHz, DMSO- $\left.d_{6}\right) \delta 179.4,148.9,141.8,139.4$, 138.4, 137.9, 135.2, 128.8, 127.5, 127.1, 126.9, 12.17, 126.0, 125.1, 124.7, 123.4, 122.2 , 121.3, 113.8, 110.5, 104.5, 53.7; IR (ATR): 3197, 1730, 1649, 1354, $1077 \mathrm{~cm}^{-1}$; HRMS (FAB) $\mathrm{m} / z$ $[\mathrm{M}+\mathrm{H}]^{+}$calcd for $\mathrm{C}_{34} \mathrm{H}_{22} \mathrm{NO}_{4}: 508.1549$, Found: 508.1545.

5,9-Dihydroxy-5' -(naphthalen-2-yl)spiro[dibenzo[c,h] xanthene-7,3'-indolin]-2'-one (5k):

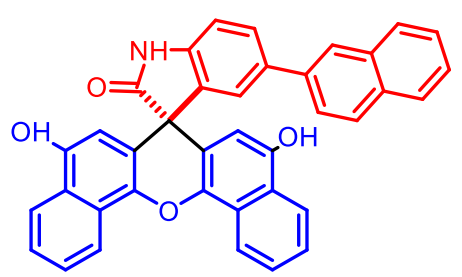

The compound was prepared according to the general procedure and purified by column chromatography $($ EtOAc/hexane $=30: 70)$. Yield: 86\% (240 mg); State: brown solid; mp: $>300{ }^{\circ} \mathrm{C} ;{ }^{1} \mathrm{H}$ NMR $\left(600 \mathrm{MHz}, \mathrm{DMSO}-d_{6}\right) \delta 10.98(1 \mathrm{H}, \mathrm{s}), 9.90(2 \mathrm{H}, \mathrm{s}), 8.66(2 \mathrm{H}, \mathrm{d}$, $J=8.4 \mathrm{~Hz}), 8.14(2 \mathrm{H}, \mathrm{d}, J=8.4 \mathrm{~Hz}), 8.06(1 \mathrm{H}, \mathrm{s}), 7.89-7.80$ $(4 \mathrm{H}, \mathrm{m}), 7.76(2 \mathrm{H}, \mathrm{t}, J=8.4 \mathrm{~Hz}), 7.72(1 \mathrm{H}, \mathrm{d}, J=9.0 \mathrm{~Hz}), 7.61(2 \mathrm{H}, \mathrm{t}, J=8.4 \mathrm{~Hz}), 7.50(1 \mathrm{H}$, s), $7.40(2 \mathrm{H}, \mathrm{t}, J=4.8 \mathrm{~Hz}), 7.30(1 \mathrm{H}, \mathrm{d}, J=7.2 \mathrm{~Hz}), 6.20(2 \mathrm{H}, \mathrm{s}) ;{ }^{13} \mathrm{C}$ NMR $(150 \mathrm{MHz}$, DMSO- $\left.d_{6}\right) \delta 179.3,148.9,141.9,138.4,137.9,136.6,134.8,133.3,131.9,128.3,128.0,127.8$, 127.2, 127.0, 126.1, 125.9, 125.7, 125.0, 124.7, 124.6, 124.2, 123.6, 122.1, 121.3, 113.7, 110.5, 
104.5, 53.7; IR (ATR): 3466, 3002, 1736, 1365, 1215, $817 \mathrm{~cm}^{-1}$; HRMS (FAB) $\mathrm{m} / \mathrm{z}$ $[\mathrm{M}+\mathrm{H}]^{+}$calcd for $\mathrm{C}_{38} \mathrm{H}_{24} \mathrm{NO}_{4}$ : 558.1705, Found: 558.1701.

\section{3-(2,5-dihydroxyphenyl)-3-methylindolin-2-one (7):}

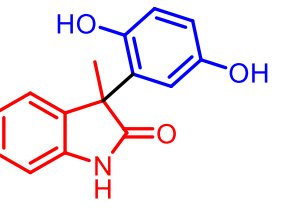

The compound was prepared according to the general procedure and purified by column chromatography (EtOAc/hexane $=60: 40)$. Yield: $30 \%$ (76 mg); State: off white solid; mp: $255-257{ }^{\circ} \mathrm{C}$; ${ }^{1} \mathrm{H}$ NMR $(600 \mathrm{MHz}$, DMSO- $\left.d_{6}\right) \delta 10.28(1 \mathrm{H}, \mathrm{s}), 8.71(1 \mathrm{H}, \mathrm{s}), 8.56(1 \mathrm{H}, \mathrm{s}), 7.10-7.06(1 \mathrm{H}, \mathrm{m})$, $6.87(1 \mathrm{H}, \mathrm{d}, J=2.4 \mathrm{~Hz}), 6.82-6.79(3 \mathrm{H}, \mathrm{m}), 6.49(1 \mathrm{H}, \mathrm{dd}, J=8.4,3.0 \mathrm{~Hz}), 6.41(1 \mathrm{H}, \mathrm{d}, J=$ $8.4 \mathrm{~Hz}), 1.49(3 \mathrm{H}, \mathrm{s}) ;{ }^{13} \mathrm{C}$ NMR (150 MHz, DMSO- $\left.d_{6}\right) \delta 181.5,149.5,147.3,142.0,136.2$, 128.0, 126.8, 122.3, 120.9, 115.5, 114.8, 114.0, 108.7, 23.5; IR (ATR): 3216, 2996, 1750, 1518, $716 \mathrm{~cm}^{-1}$; HRMS (EI) $\mathrm{m} / z$ [M] $]^{+}$calcd for $\mathrm{C}_{15} \mathrm{H}_{13} \mathrm{NO}_{3}$ : 255.0895, Found: 255.0897 . 
Copies of ${ }^{1} \mathrm{H}$ NMR and ${ }^{13} \mathrm{C}$ NMR spectra of the synthesized compounds

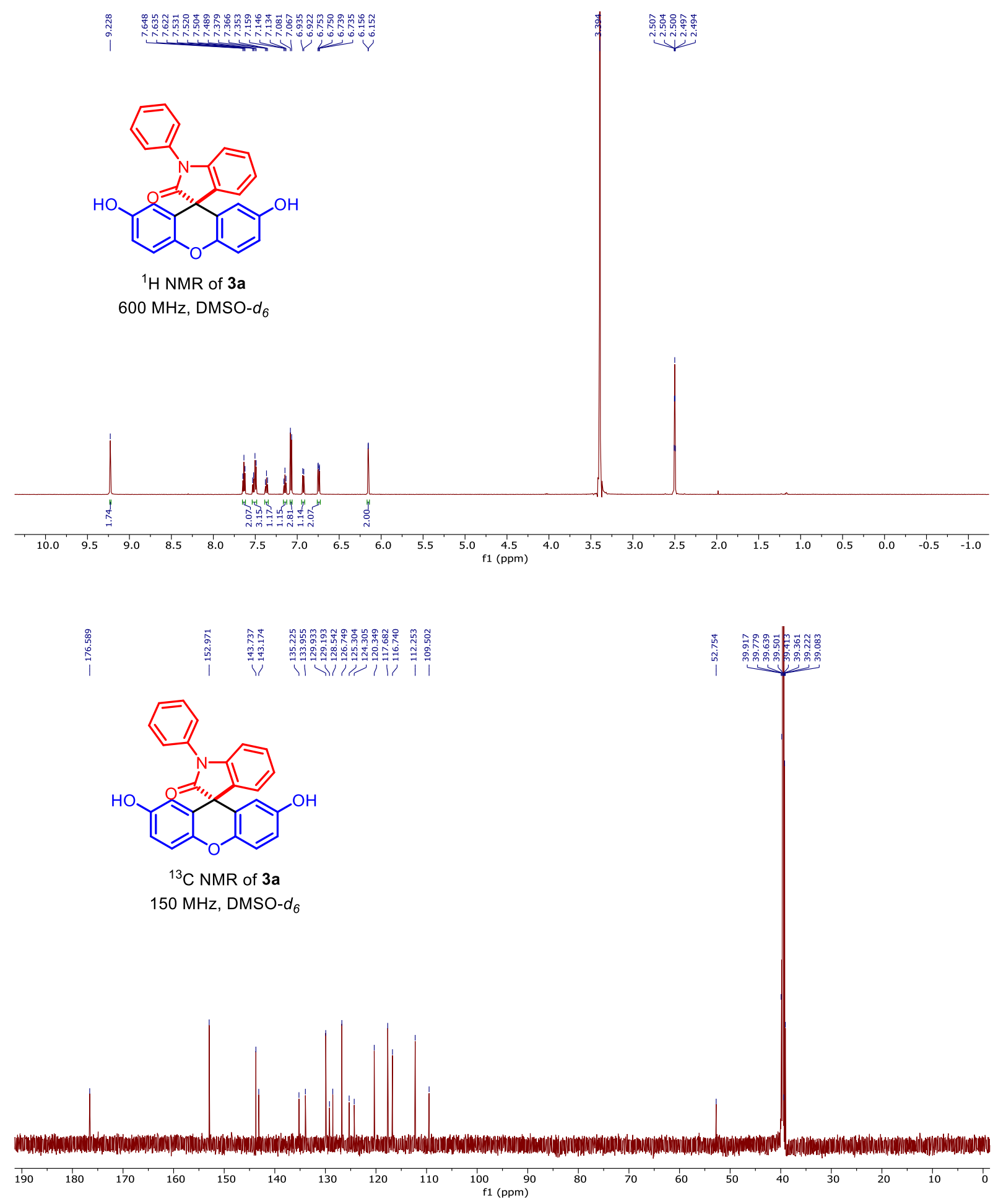




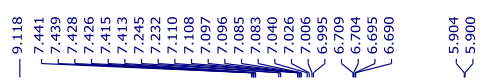<smiles>CN1C(=O)C2(c3ccccc3Oc3ccc(O)cc32)c2ccccc21</smiles>

${ }^{1} \mathrm{H}$ NMR of $\mathbf{3 b}$ $600 \mathrm{MHz}$, DMSO- $d_{6}$
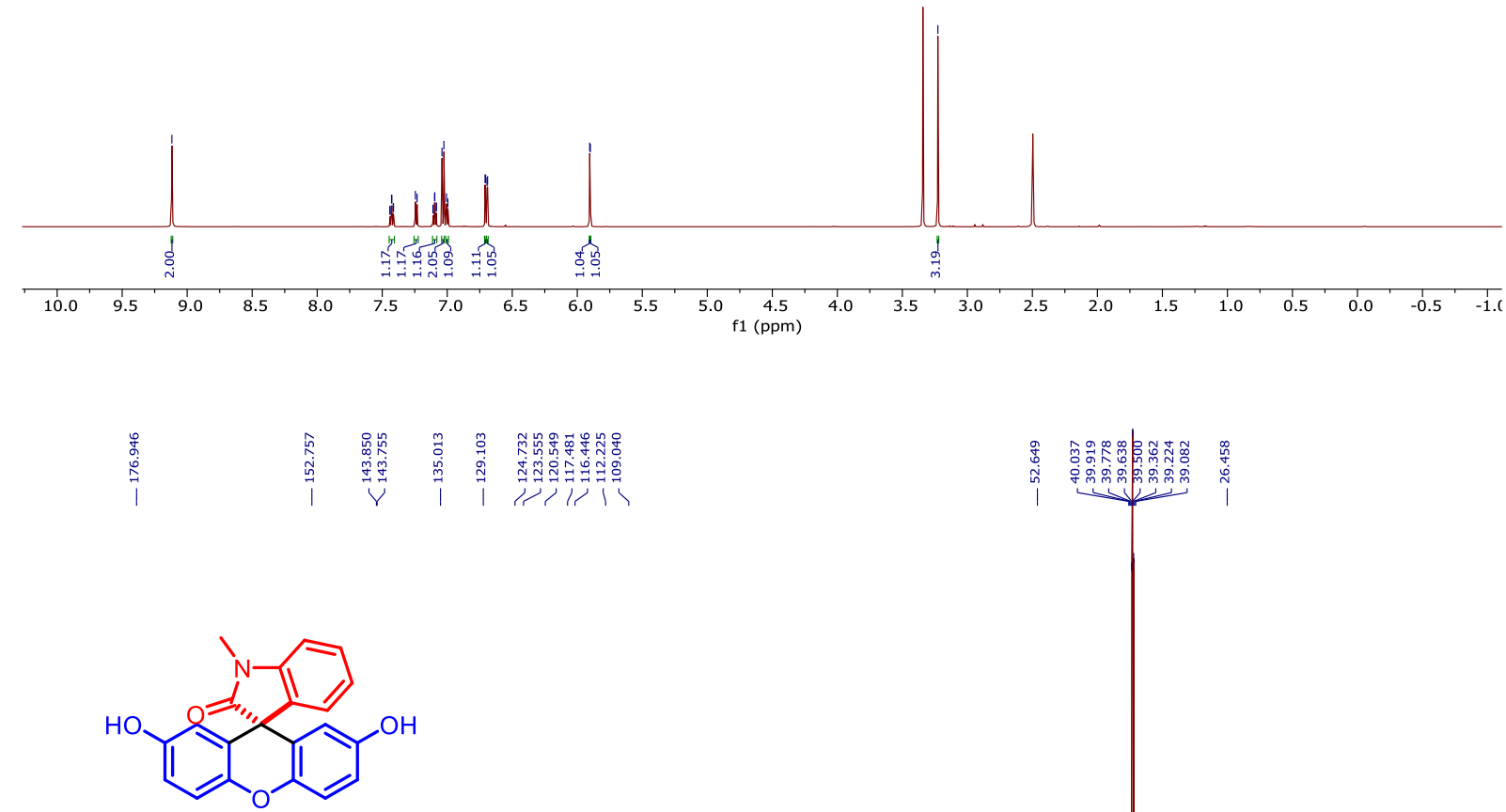

${ }^{13} \mathrm{C}$ NMR of $\mathbf{3 b}$

$150 \mathrm{MHz}$, DMSO- $d_{6}$

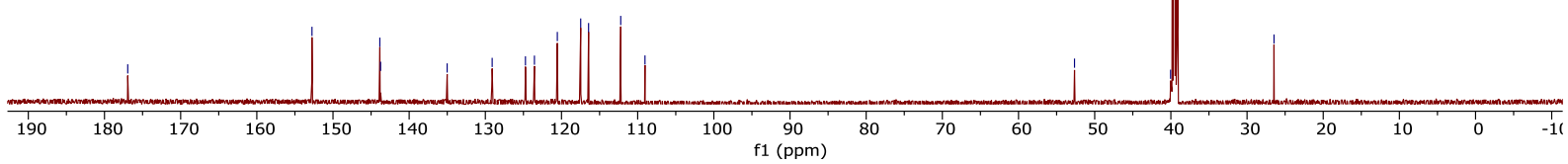




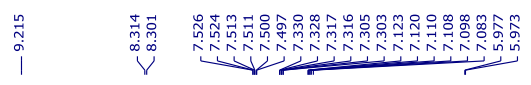<smiles>CC(=O)N1C(=O)[C@@]2(c3ccccc3Oc3ccc(O)cc32)c2ccccc21</smiles>

${ }^{1} \mathrm{H}$ NMR of $3 \mathrm{c}$

$600 \mathrm{MHz}, \mathrm{DMSO}-\mathrm{d}_{6}$

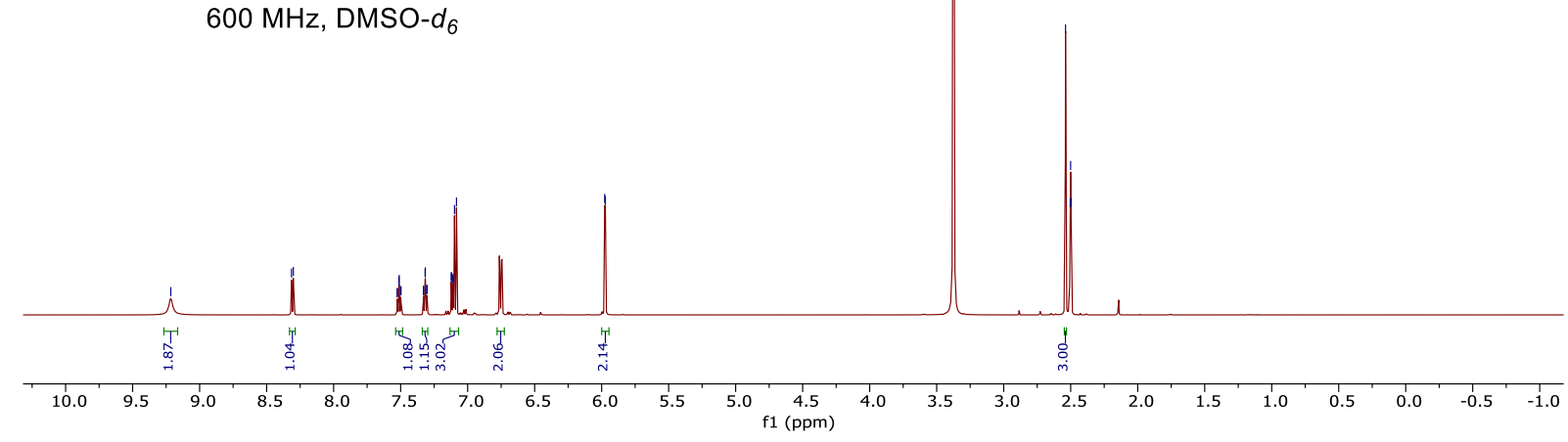

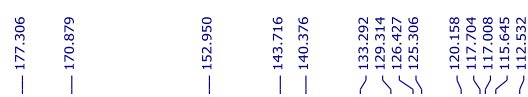

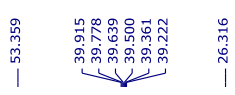<smiles>CC(=O)N1C(=O)[C@@]2(c3ccccc3Oc3ccc(O)cc32)c2ccccc21</smiles>

${ }^{13} \mathrm{C}$ NMR of $3 \mathrm{c}$

$150 \mathrm{MHz}$, DMSO- $d_{6}$

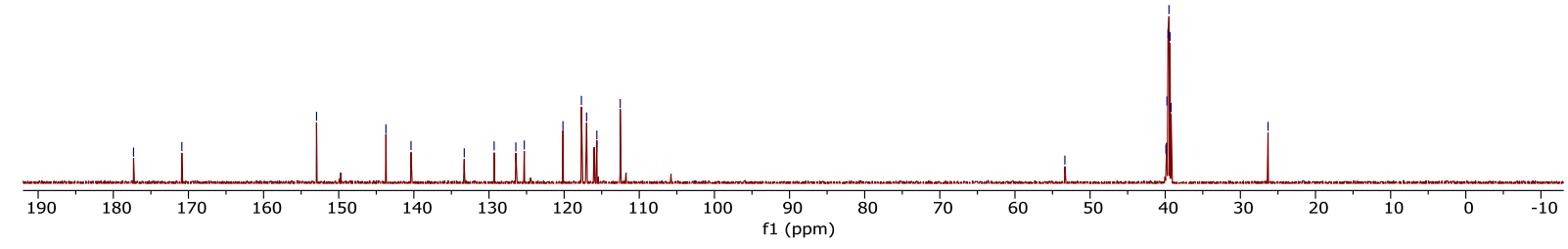



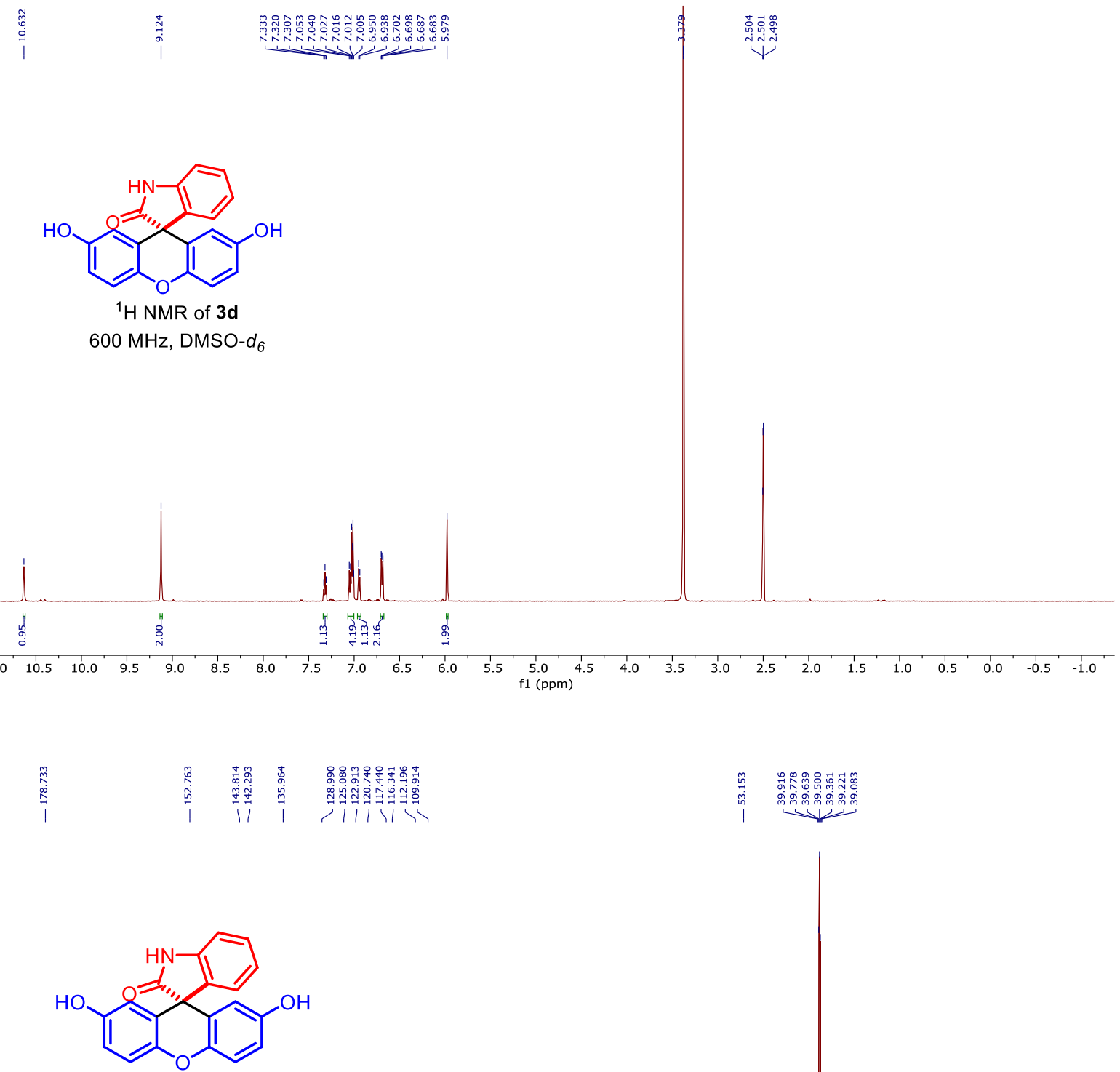

${ }^{1} \mathrm{H}$ NMR of $\mathbf{3 d}$

$600 \mathrm{MHz}, \mathrm{DMSO}-d_{6}$

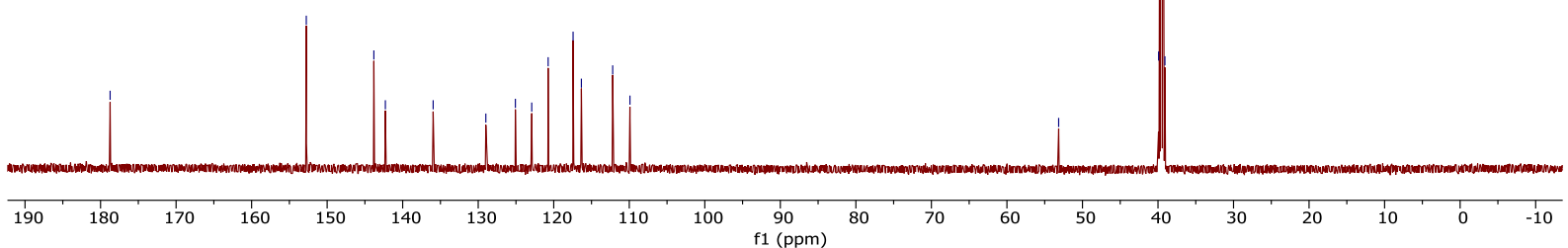




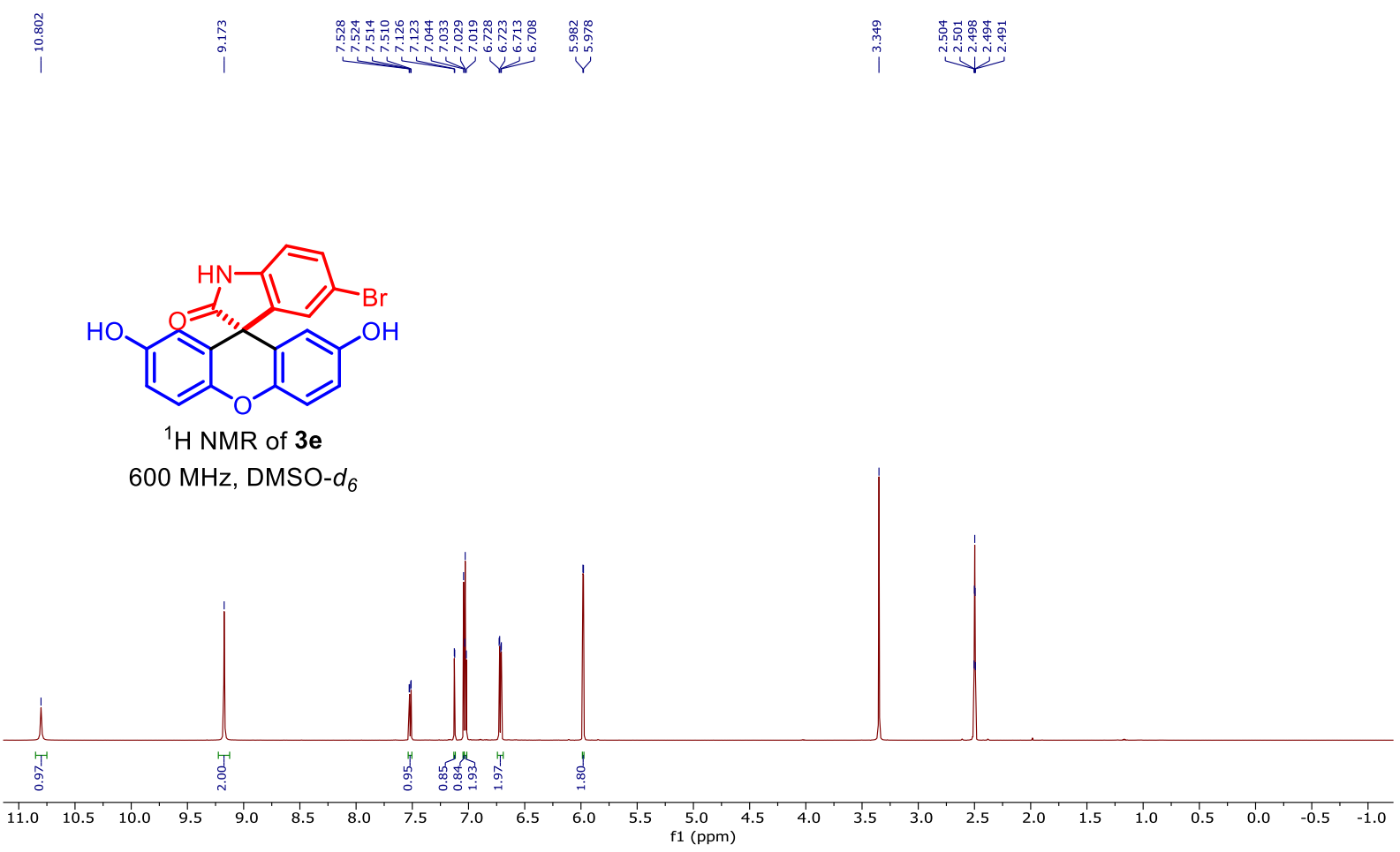

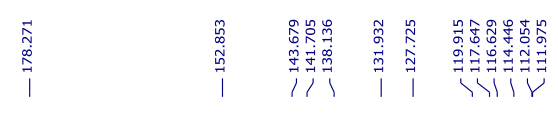
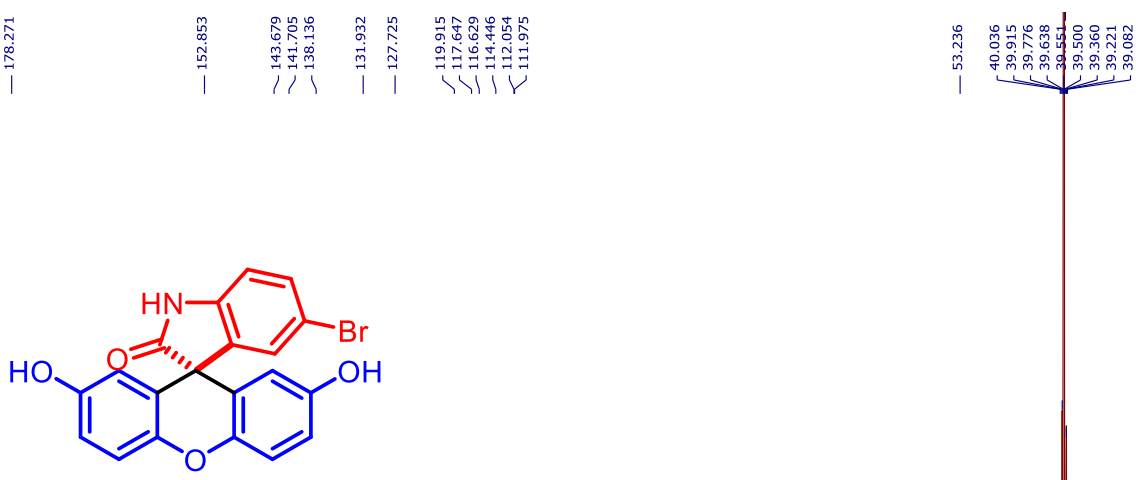

${ }^{13} \mathrm{C}$ NMR of $3 \mathbf{e}$

$150 \mathrm{MHz}, \mathrm{DMSO}-d_{6}$

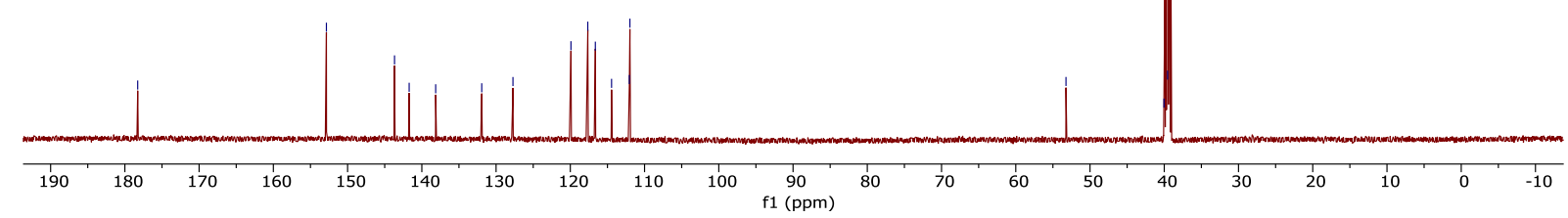


<smiles>O=C1Nc2ccc([N+](=O)[O-])cc2[C@]12C(=O)c1cc(O)ccc1Oc1ccc(O)cc12</smiles>

${ }^{1} \mathrm{H}$ NMR of $\mathbf{3 f}$ $600 \mathrm{MHz}, \mathrm{DMSO}-d_{6}$

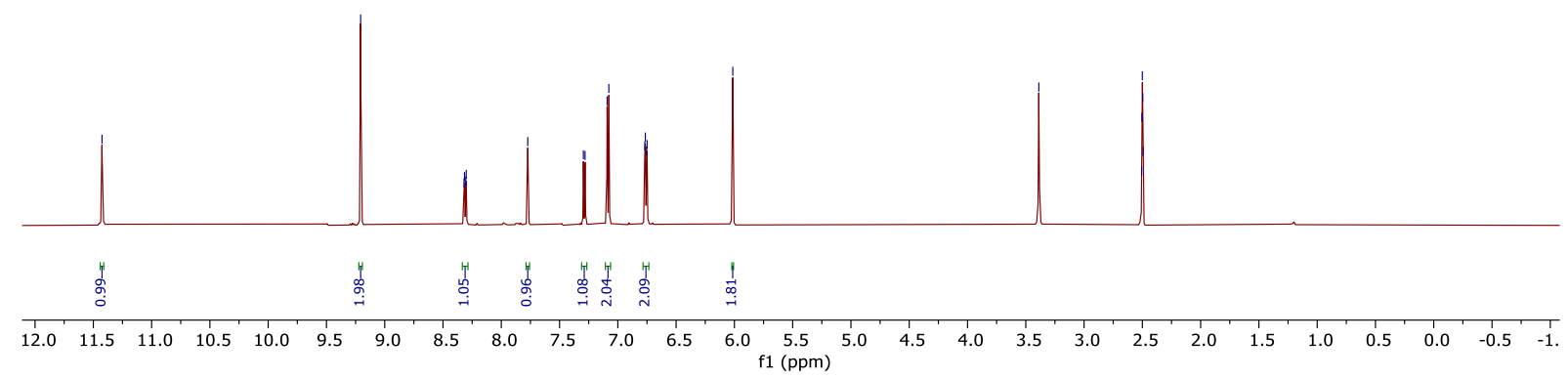<smiles>O=C1Nc2ccc([N+](=O)[O-])cc2[C@]12C(=O)c1cc(O)ccc1Oc1ccc(O)cc12</smiles>

${ }^{13} \mathrm{C}$ NMR of $3 \mathrm{f}$

$150 \mathrm{MHz}, \mathrm{DMSO}-d_{6}$

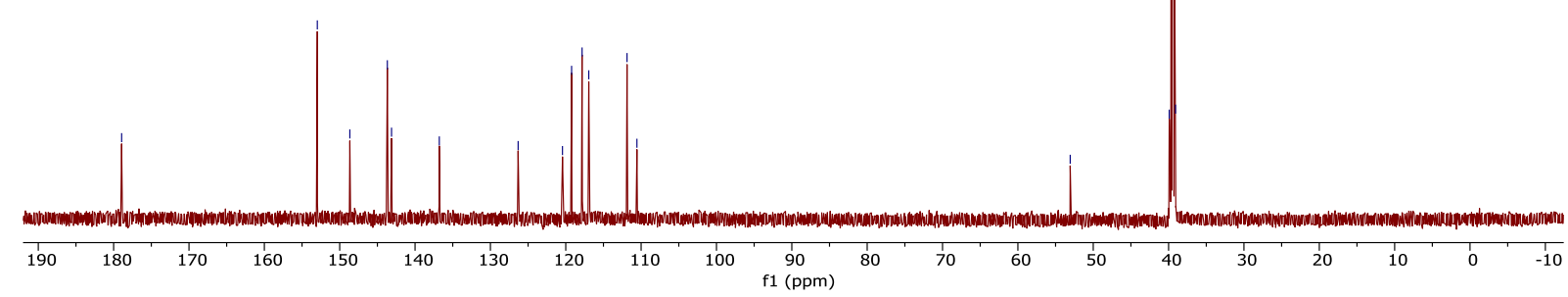


<smiles>O=C1Nc2ccc(-c3ccccc3)cc2C12c1cc(O)ccc1Oc1ccc(O)cc12</smiles>

${ }^{1} \mathrm{H}$ NMR of $\mathbf{3 g}$ $600 \mathrm{MHz}, \mathrm{DMSO}-d_{6}$

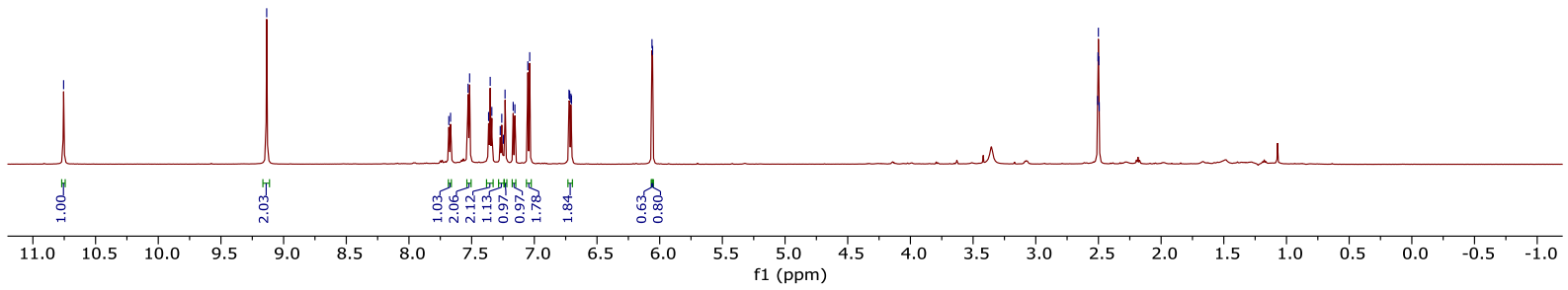<smiles>O=C1Nc2ccc(-c3ccccc3)cc2[C@@]12Oc1ccc(O)cc1C2=O</smiles>

${ }^{13} \mathrm{C}$ NMR of $\mathbf{3 g}$ $150 \mathrm{MHz}, \mathrm{DMSO}-d_{6}$

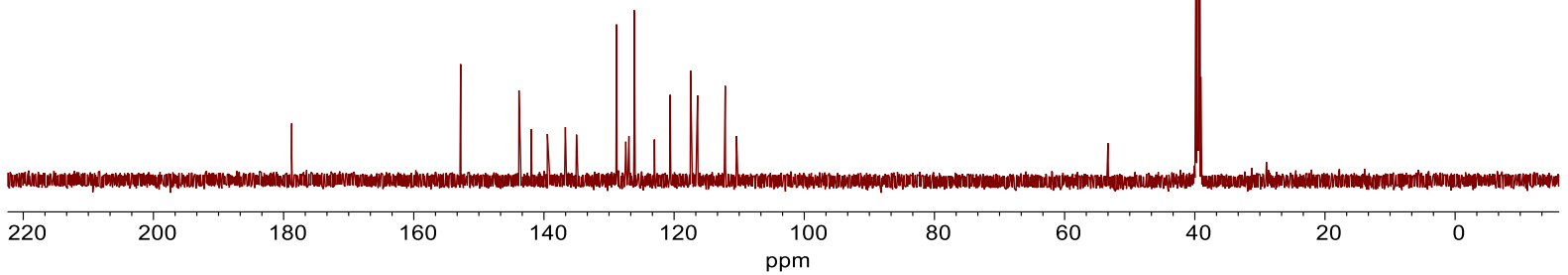



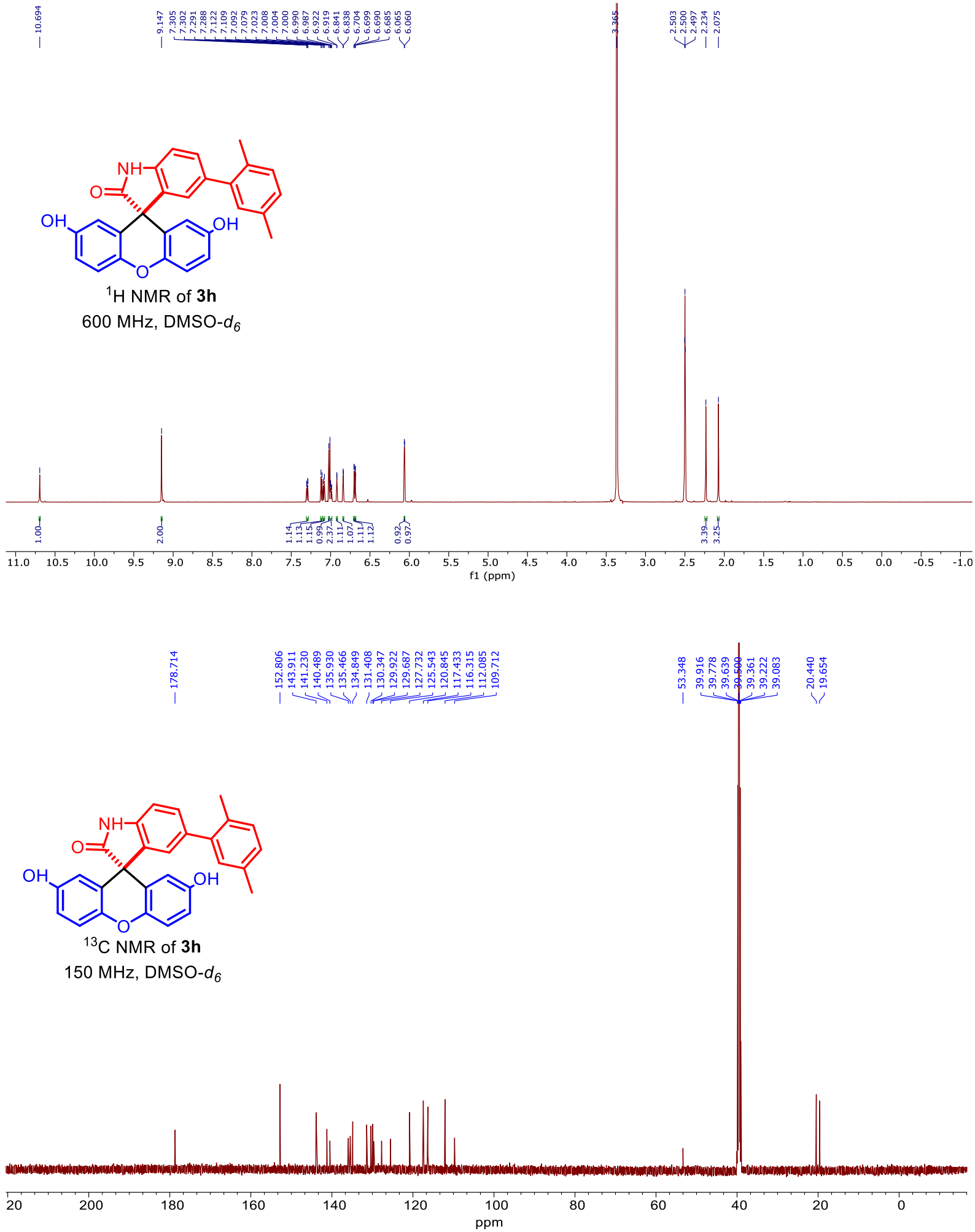


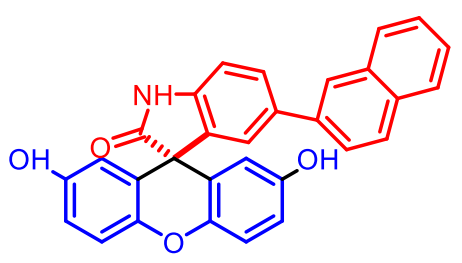

${ }^{1} \mathrm{H}$ NMR of $\mathbf{3 i}$

$600 \mathrm{MHz}$, DMSO- $d_{6}$
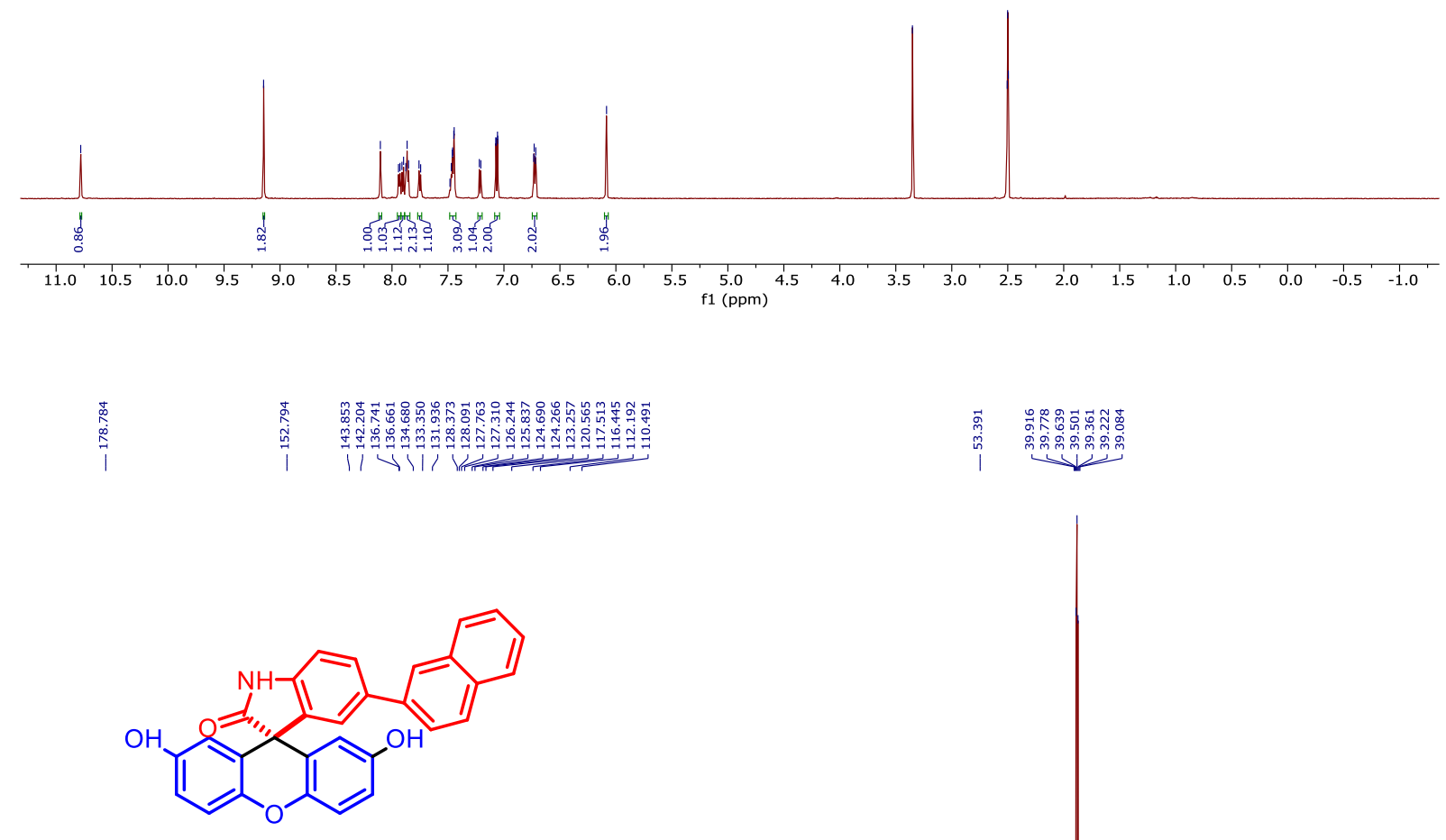

${ }^{13} \mathrm{C}$ NMR of $\mathbf{3 i}$

$150 \mathrm{MHz}, \mathrm{DMSO}-d_{6}$

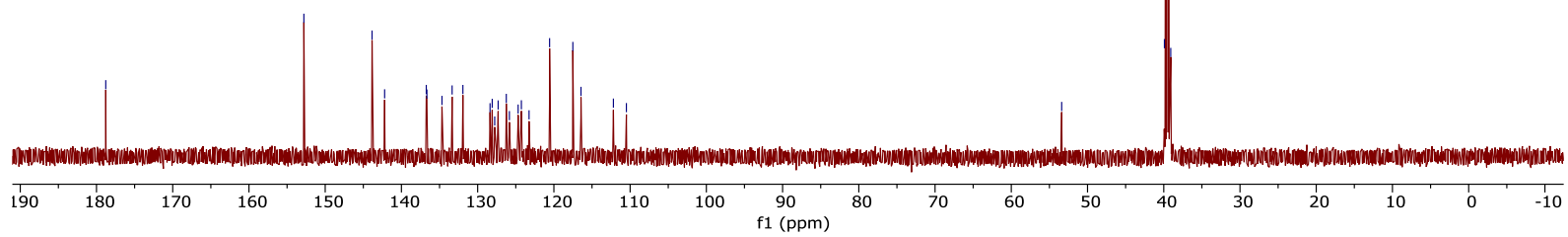




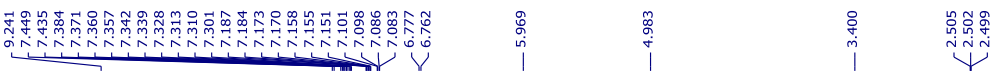

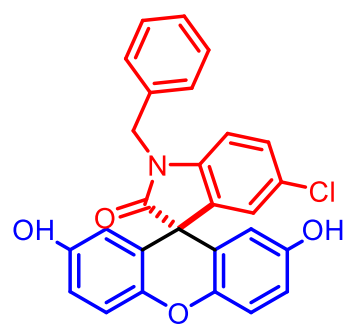

${ }^{1} \mathrm{H}$ NMR of $\mathbf{3 j}$

$600 \mathrm{MHz}, \mathrm{DMSO}-d_{6}$

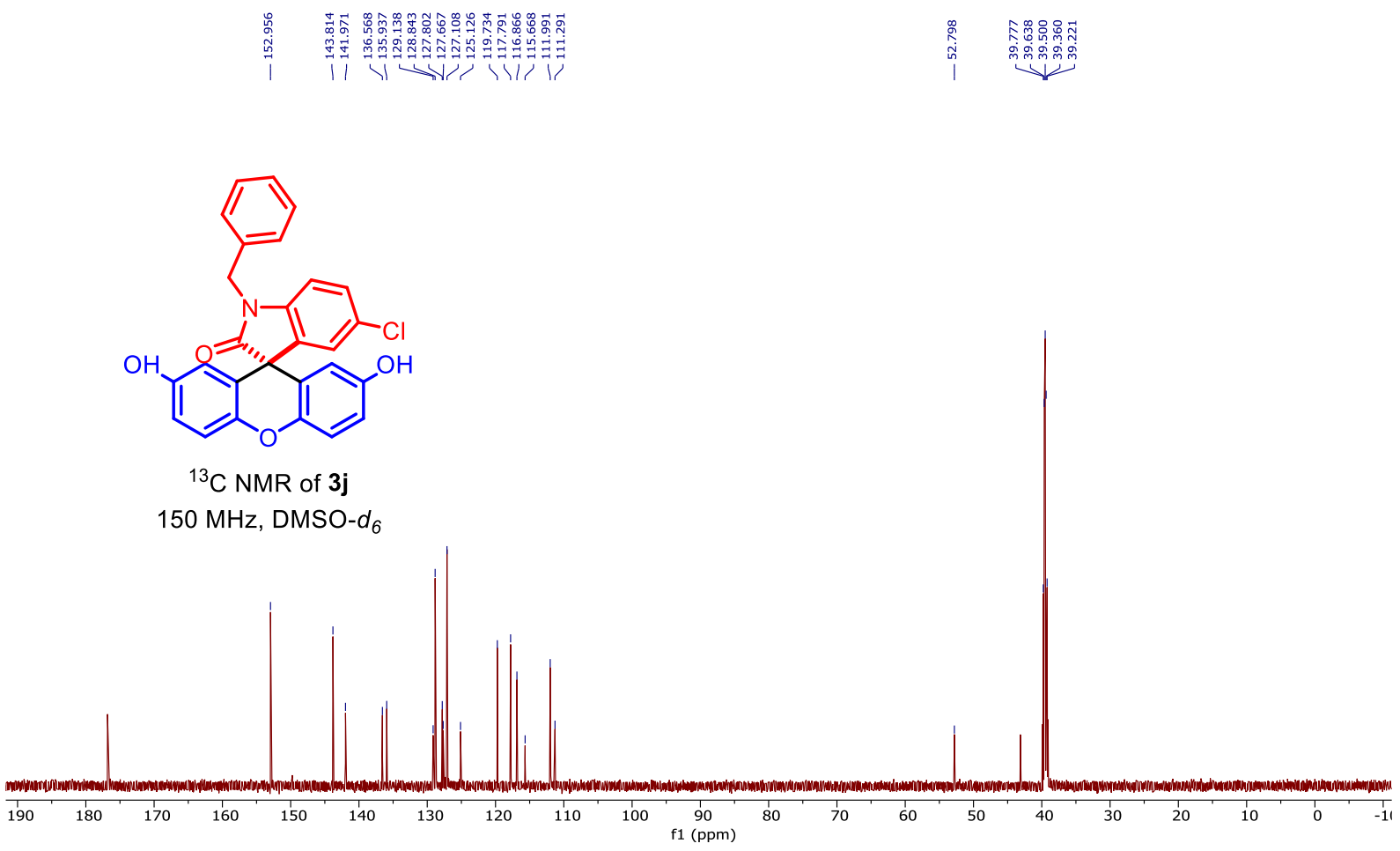

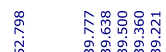

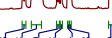

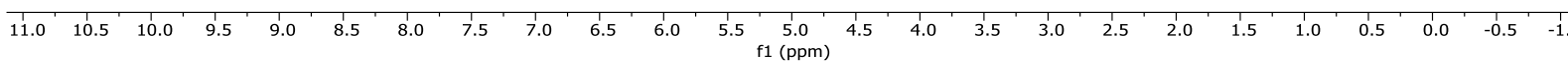




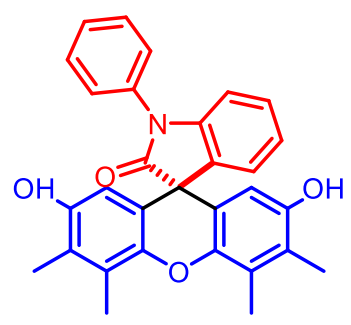

${ }^{1} \mathrm{H}$ NMR of $4 \mathrm{a}$

$600 \mathrm{MHz}$, DMSO- $d_{6}$

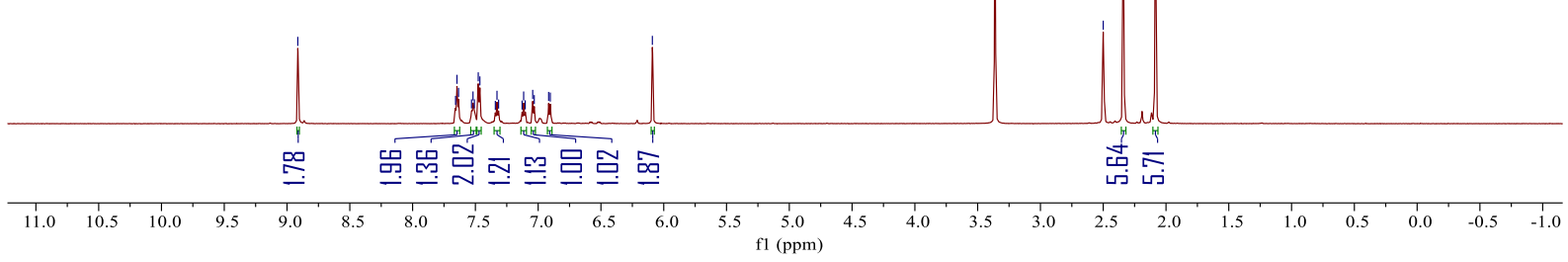<smiles>Cc1c(O)cc2c(c1C)Oc1c(cc(O)c(C)c1C)C21C(=O)N(c2ccccc2)c2ccccc21</smiles>

${ }^{13} \mathrm{C}$ NMR of $4 a$

$150 \mathrm{MHz}$, DMSO- $d_{6}$

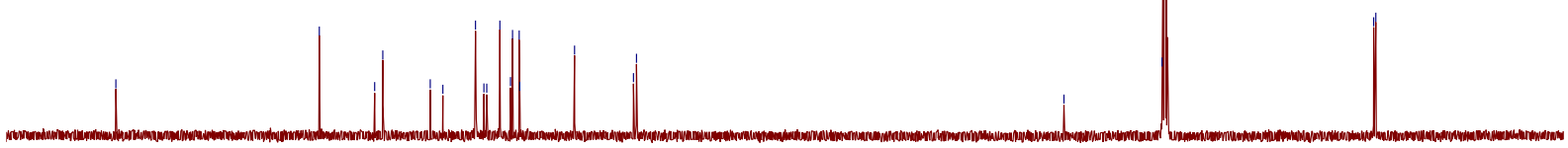




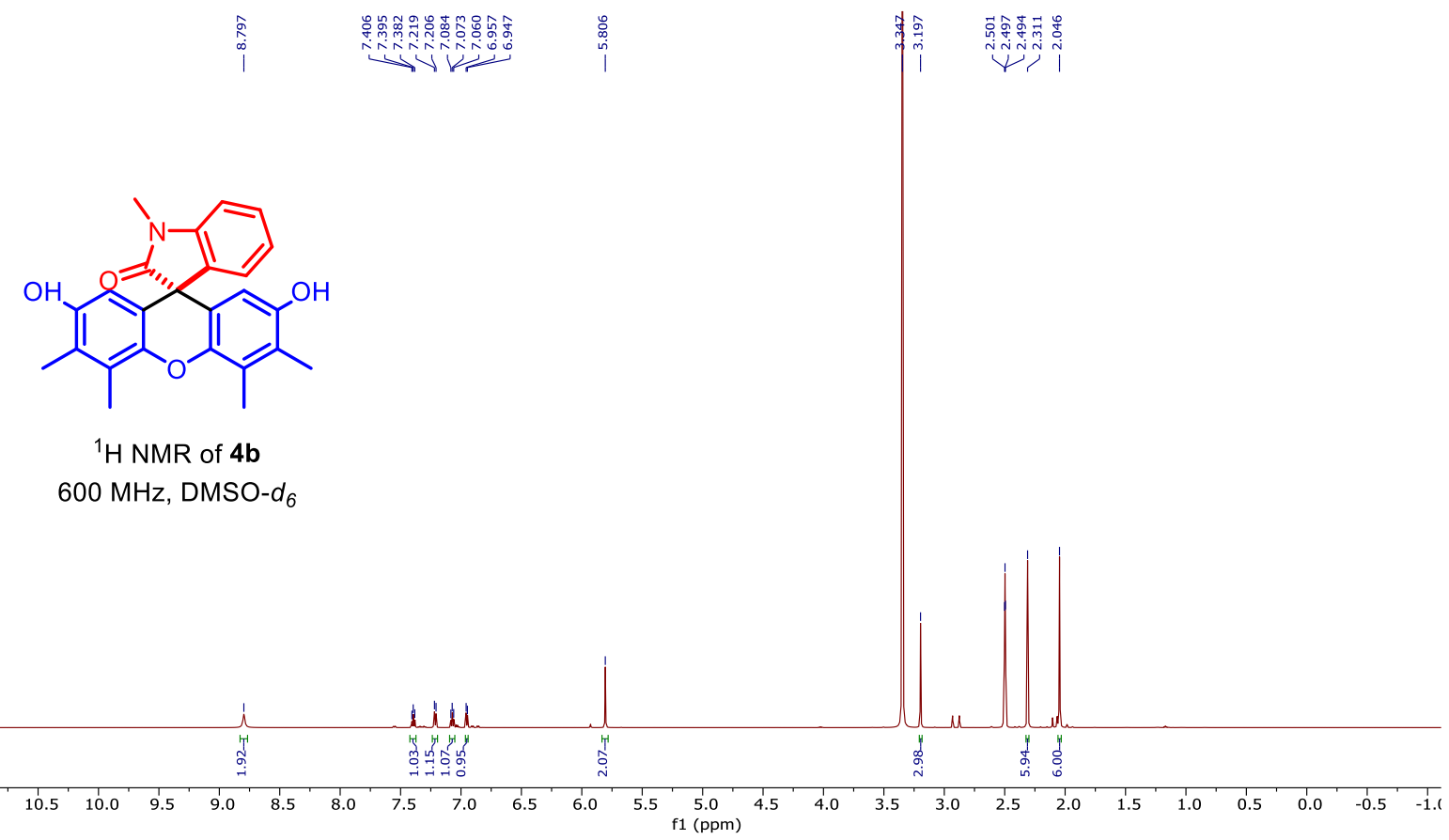

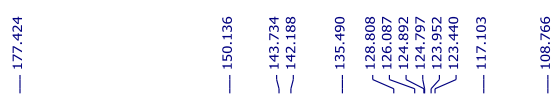

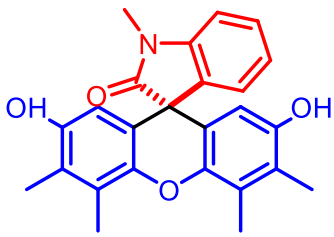

${ }^{13} \mathrm{C}$ NMR of $4 \mathrm{~b}$

$150 \mathrm{MHz}$, DMSO- $d_{6}$

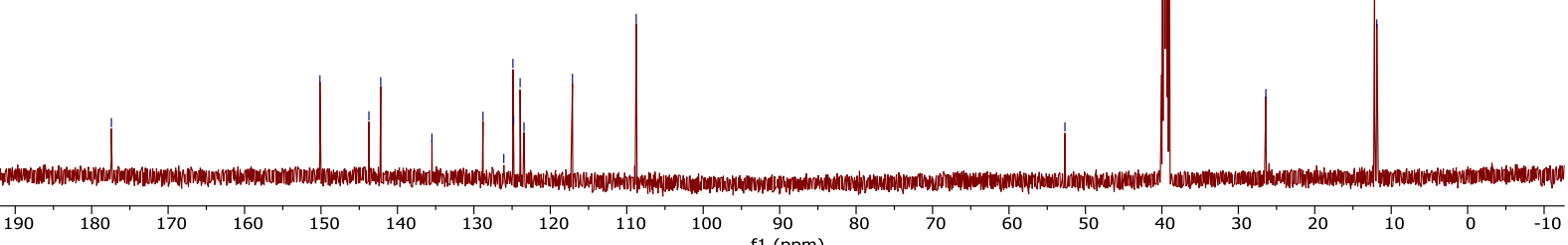




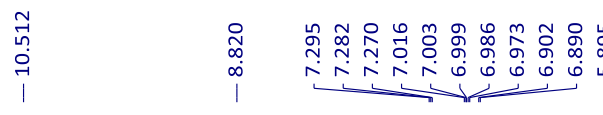

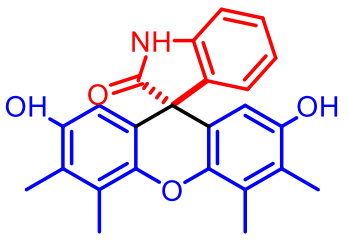

${ }^{1} \mathrm{H}$ NMR of $4 \mathrm{c}$

$600 \mathrm{MHz}$, DMSO- $d_{6}$

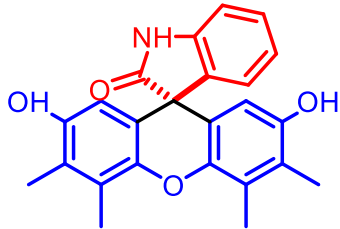

${ }^{13} \mathrm{C}$ NMR of $4 \mathrm{c}$

$150 \mathrm{MHz}, \mathrm{DMSO}-d_{6}$

\section{ill}

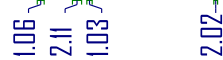

品密

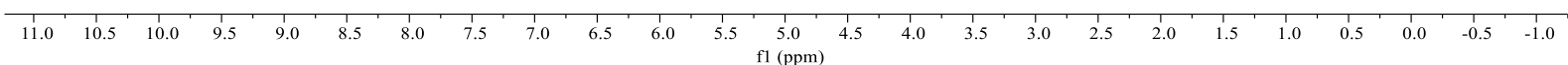

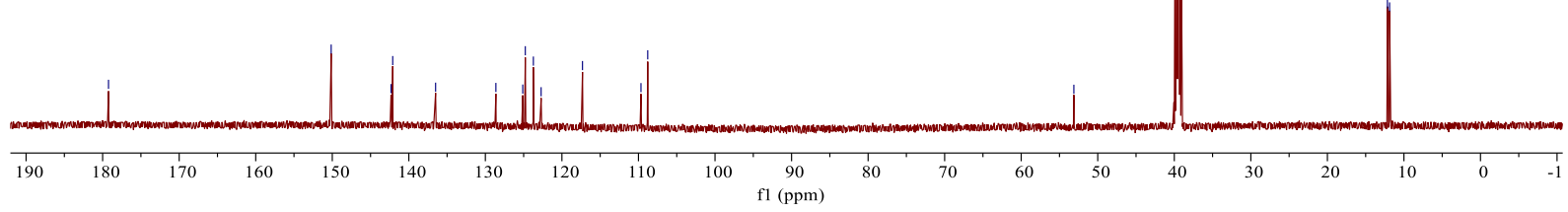




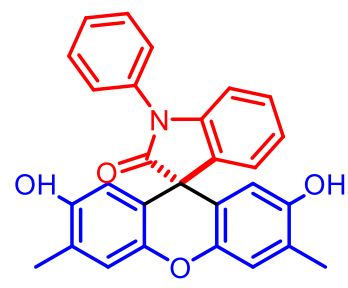

${ }^{1} \mathrm{H}$ NMR of $4 \mathbf{d}$ $600 \mathrm{MHz}, \mathrm{DMSO}-d_{6}$
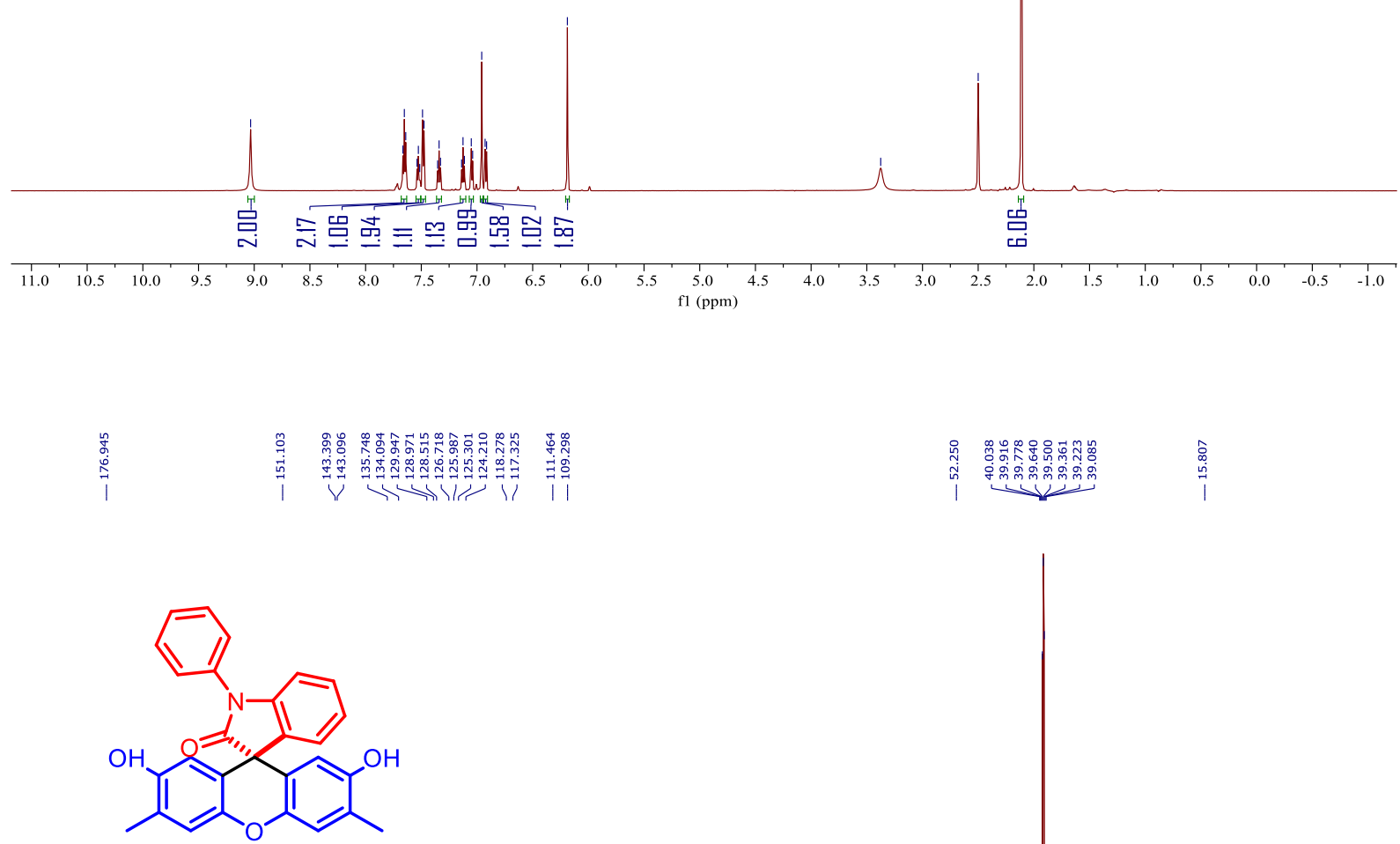

${ }^{13} \mathrm{C}$ NMR of $4 d$ $150 \mathrm{MHz}, \mathrm{DMSO}-d_{6}$

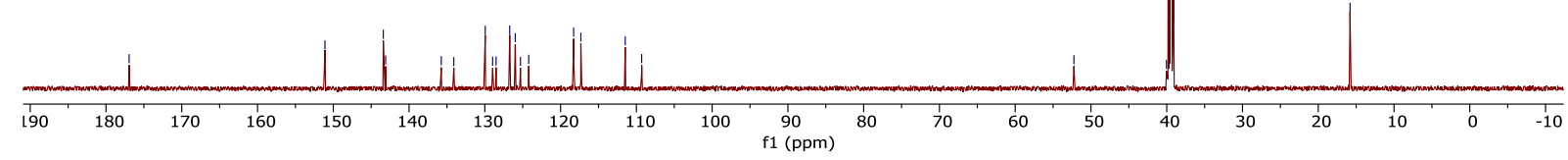




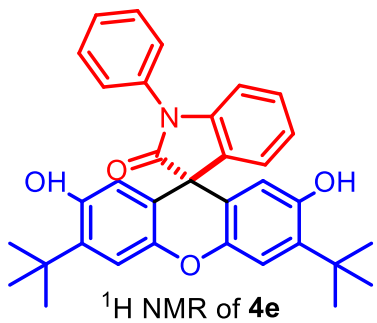

$600 \mathrm{MHz}, \mathrm{DMSO}-d_{6}$

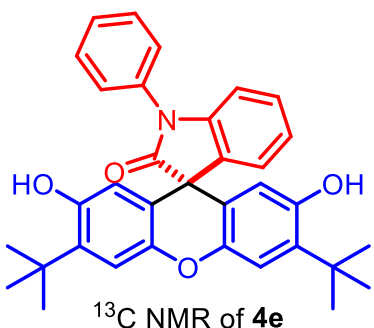

$150 \mathrm{MHz}, \mathrm{DMSO}-d_{6}$

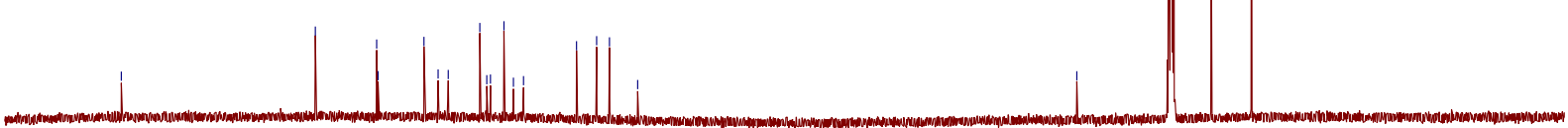

190
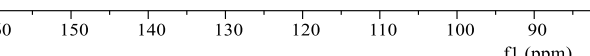


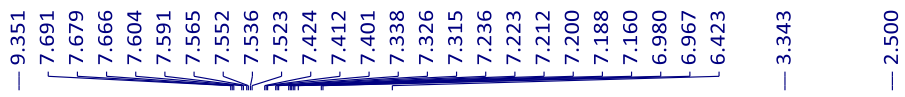

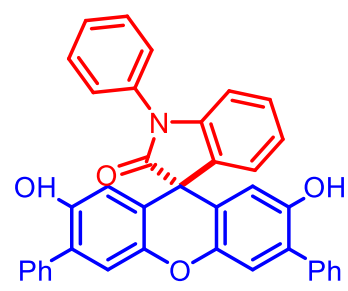

${ }^{1} \mathrm{H}$ NMR of $\mathbf{4 f}$

$600 \mathrm{MHz}, \mathrm{DMSO}-d_{6}$

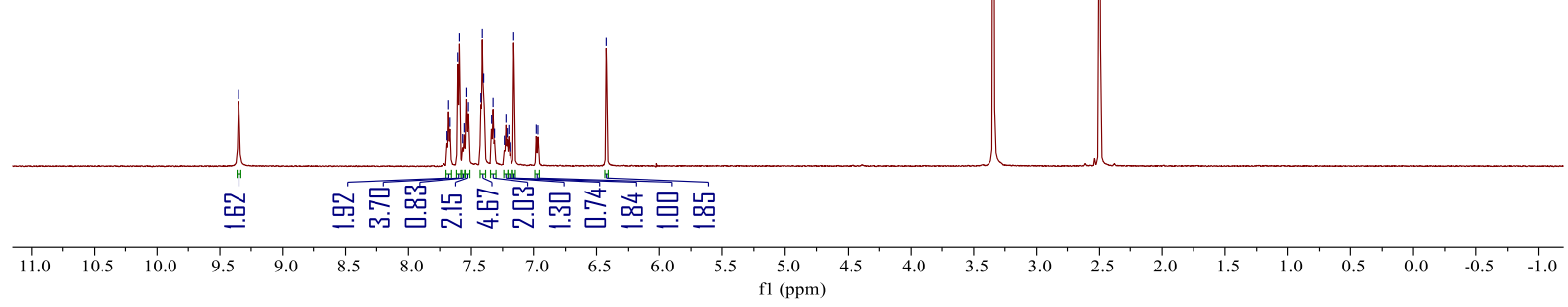

草

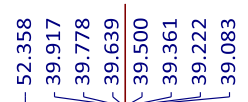

(c)

${ }^{13} \mathrm{C}$ NMR of $\mathbf{4 f}$

$150 \mathrm{MHz}, \mathrm{DMSO}-d_{6}$

$\underset{190}{180} \quad 170 \quad 160 \quad 150$

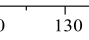

$\begin{array}{lll}120 & 110 & 100\end{array}$ 


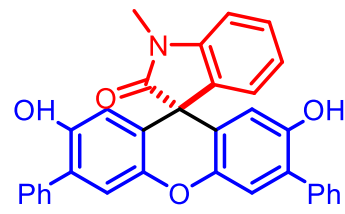

${ }^{1} \mathrm{H}$ NMR of $\mathbf{4 g}$

$600 \mathrm{MHz}, \mathrm{DMSO}-d_{6}$

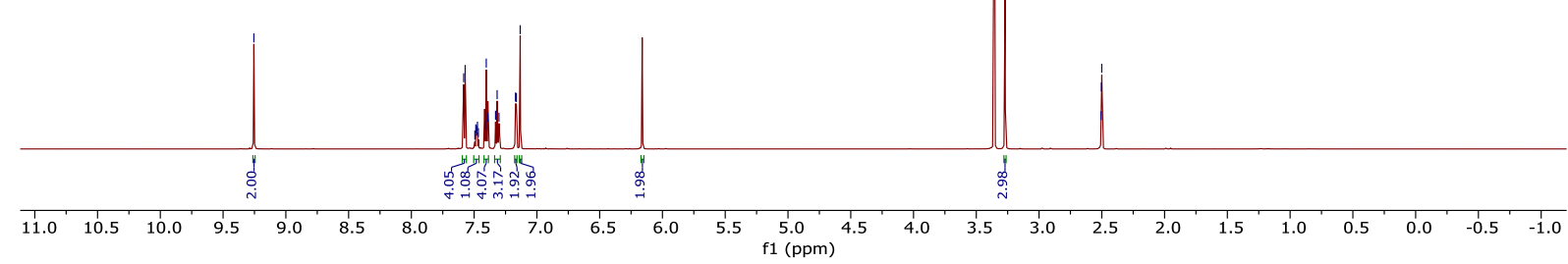

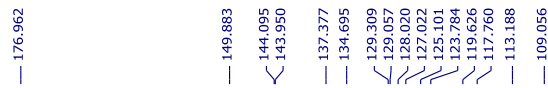

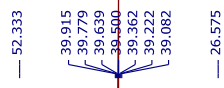

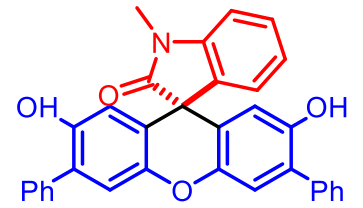

${ }^{13} \mathrm{C}$ NMR of $\mathbf{4 g}$

$150 \mathrm{MHz}, \mathrm{DMSO}-d_{6}$

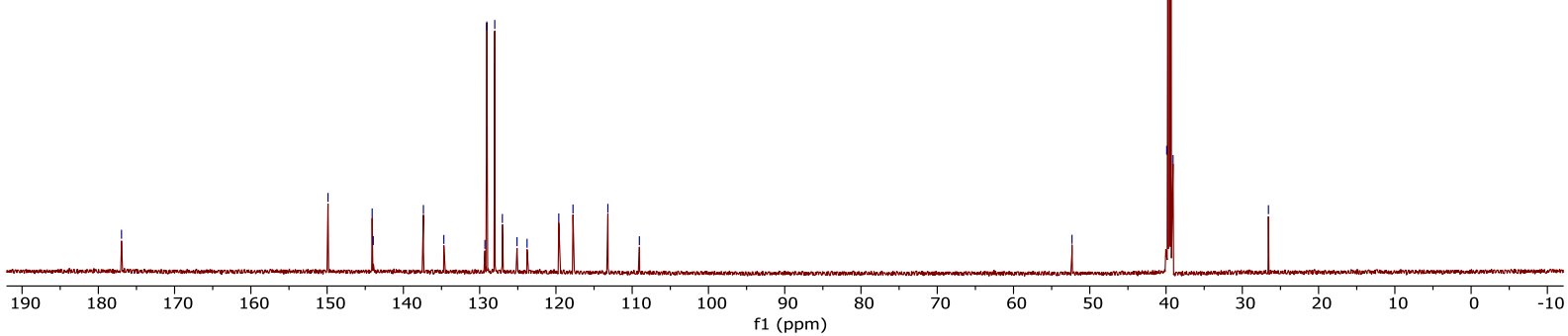


|

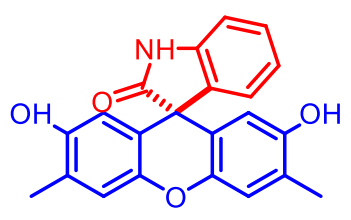

${ }^{1} \mathrm{H}$ NMR of $\mathbf{4 h}$

$600 \mathrm{MHz}, \mathrm{DMSO}-d_{6}$

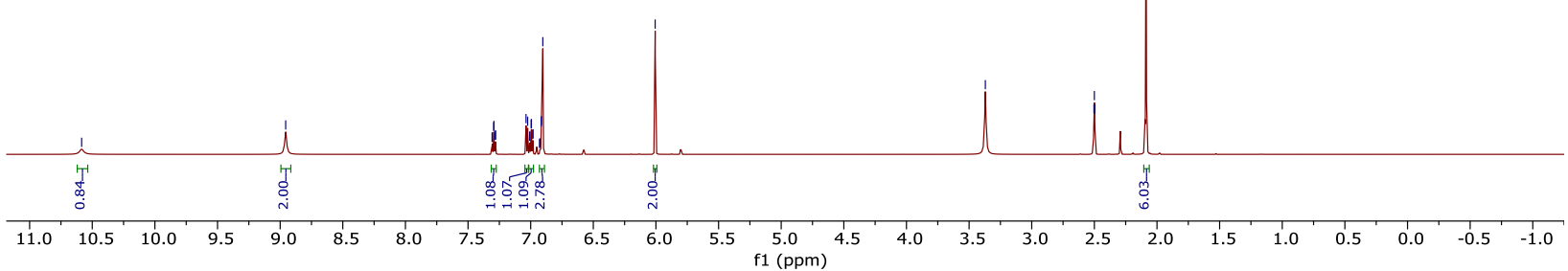

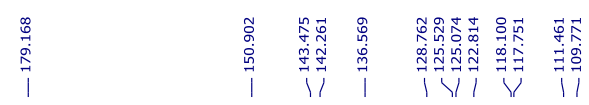

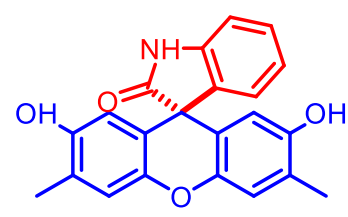

${ }^{13} \mathrm{C}$ NMR of $\mathbf{4 h}$

$150 \mathrm{MHz}, \mathrm{DMSO}-d_{6}$

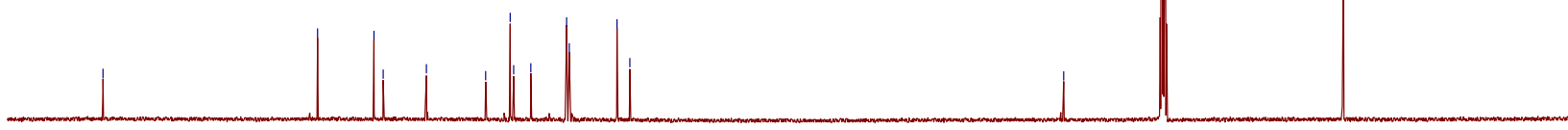

190

180

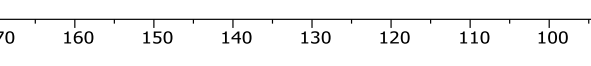

f1 $(\mathrm{ppm})$ 


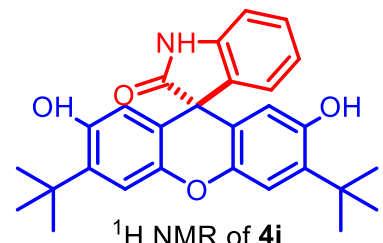

$600 \mathrm{MHz}$, DMSO-d 6

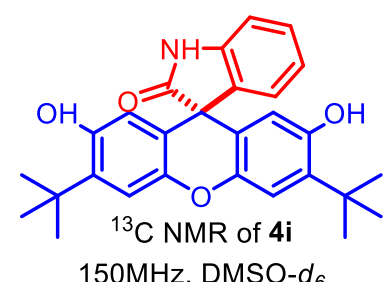

$150 \mathrm{MHz}$, DMSO- $d_{6}$

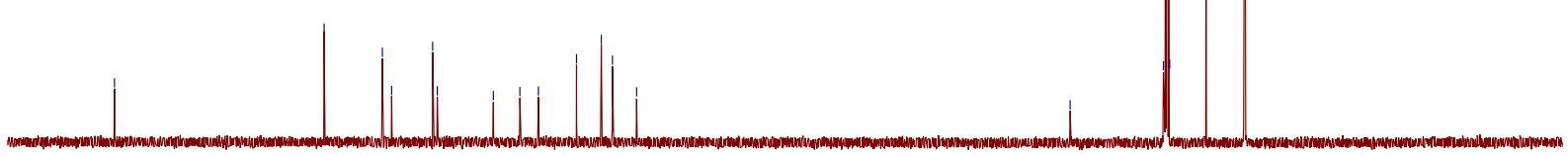




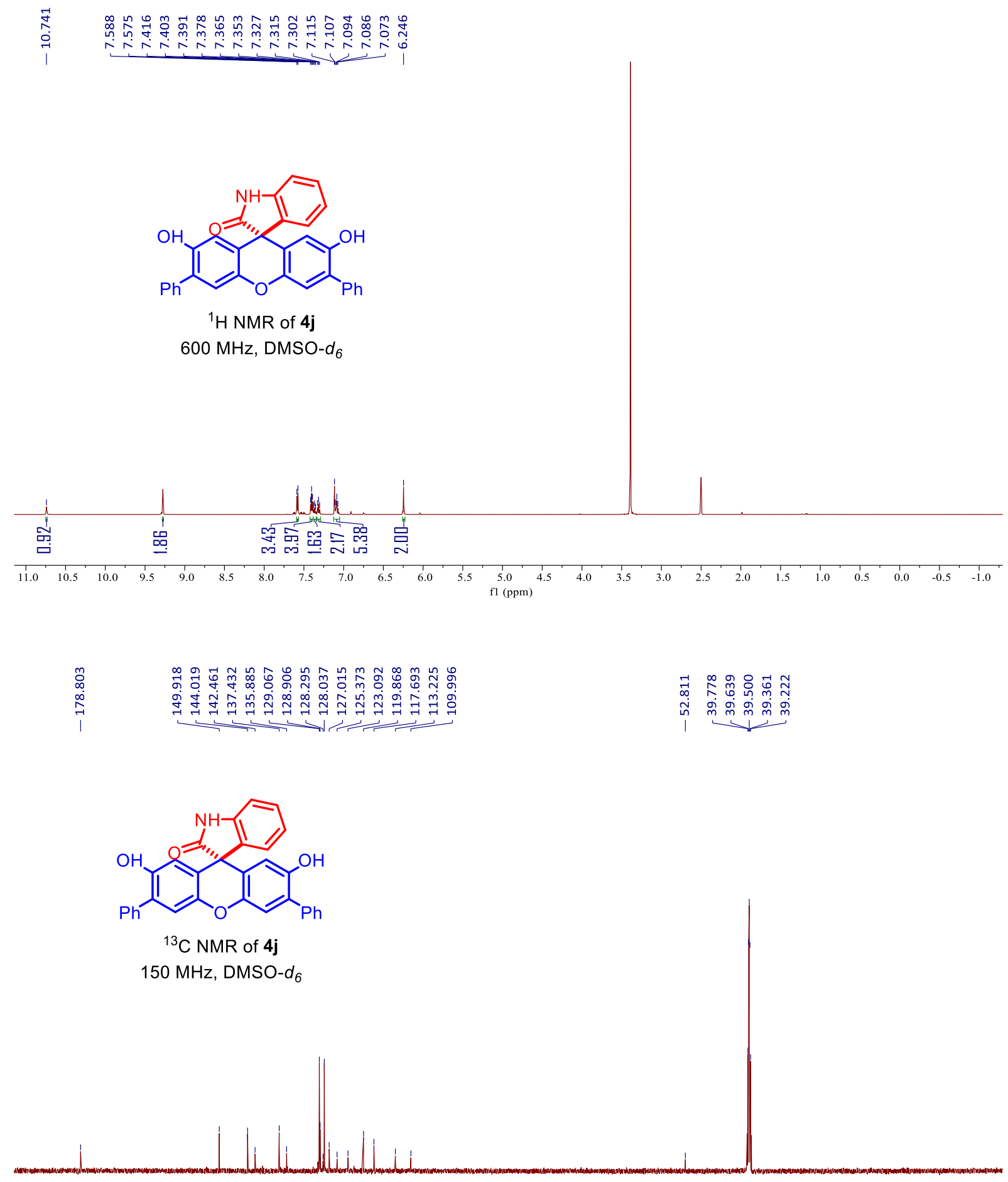

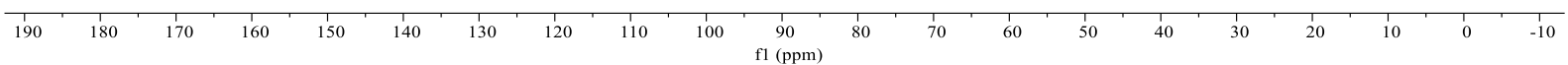




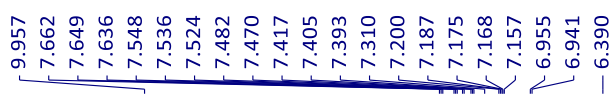

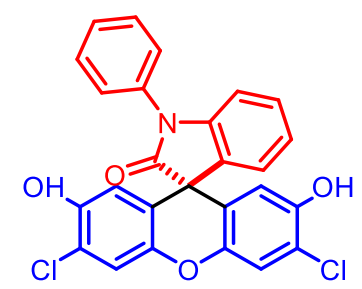

${ }^{1} \mathrm{H}$ NMR of $\mathbf{4 k}$

$600 \mathrm{MHz}, \mathrm{DMSO}-d_{6}$
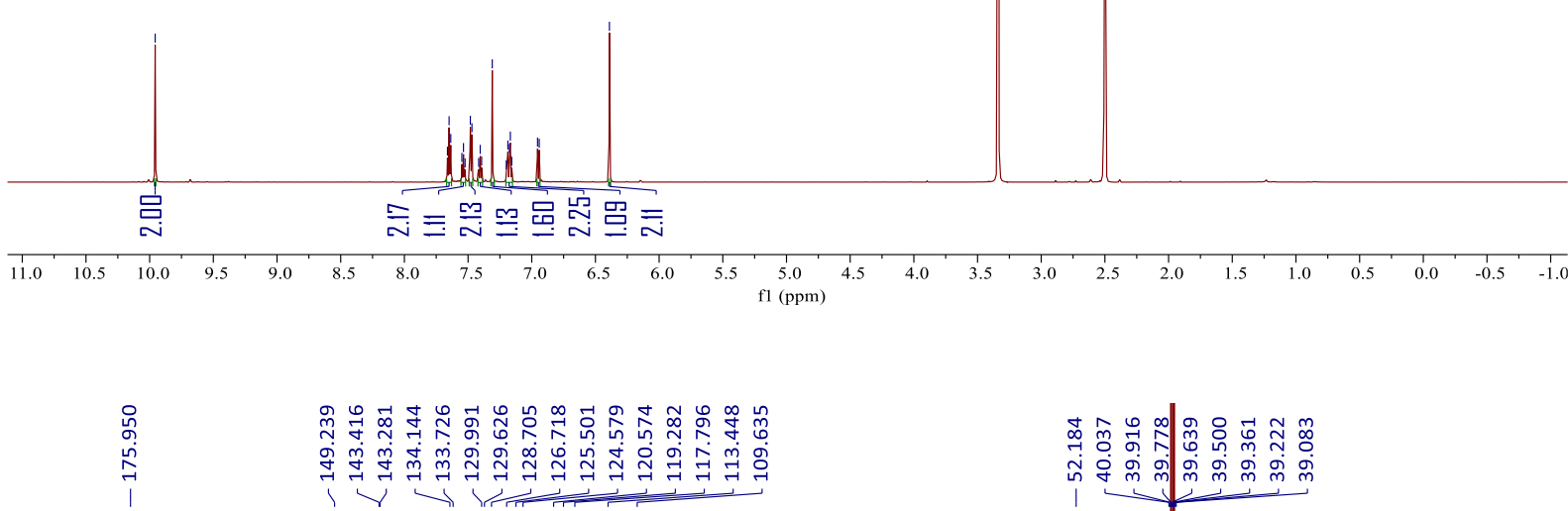

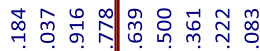

तै 宇<smiles>O=C1c2cc(O)c(Cl)cc2Oc2cc(Cl)c(O)cc2[C@]12C(=O)N(c1ccccc1)c1ccccc12</smiles>

${ }^{13} \mathrm{C}$ NMR of $4 \mathbf{k}$

$150 \mathrm{MHz}, \mathrm{DMSO}-d_{6}$

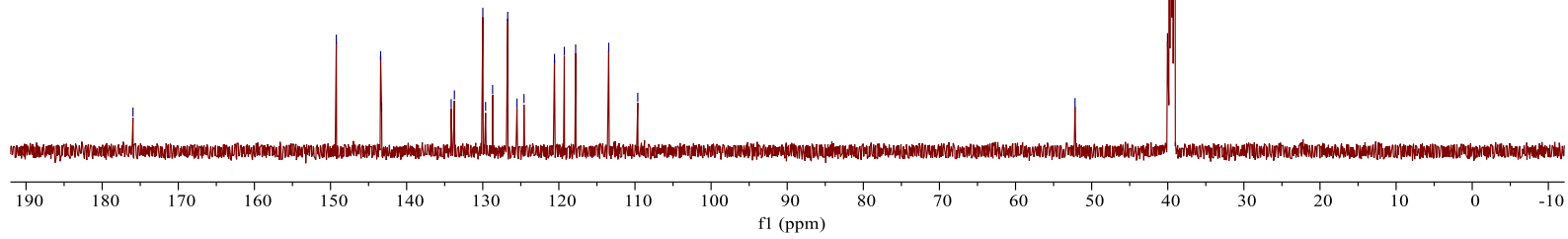


|<smiles>O=C1c2cc(O)c(Br)cc2Oc2cc(Br)c(O)cc2[C@]12C(=O)N(c1ccccc1)c1ccccc12</smiles>

${ }^{1} \mathrm{H}$ NMR of 4 I $600 \mathrm{MHz}, \mathrm{DMSO}-d_{6}$

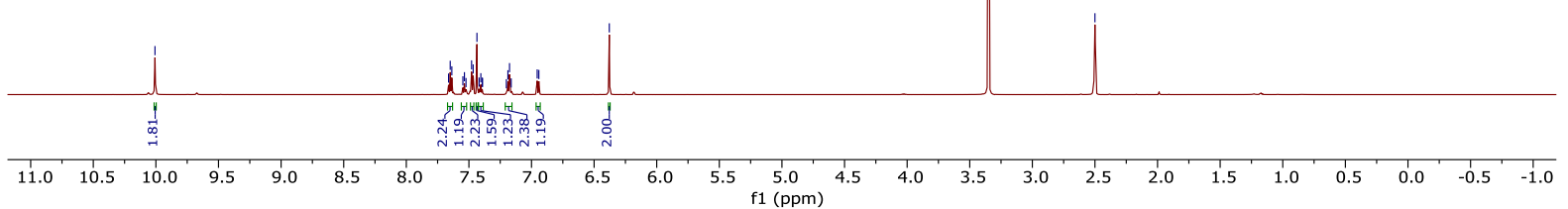

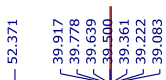

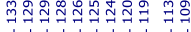

परा1/ ।

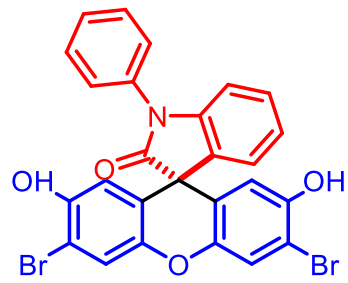

${ }^{13} \mathrm{C}$ NMR of 4 I

$150 \mathrm{MHz}, \mathrm{DMSO}-d_{6}$

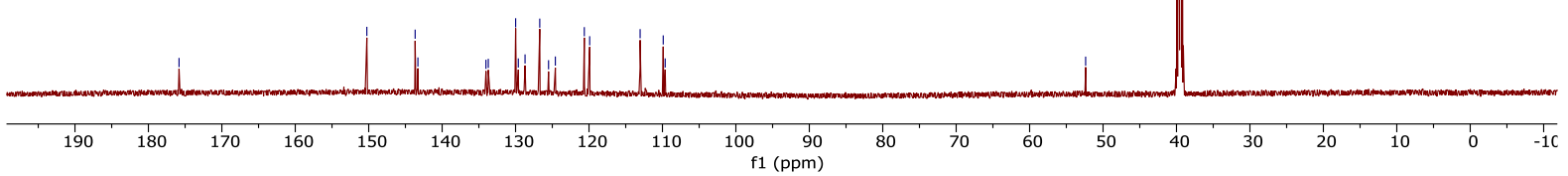




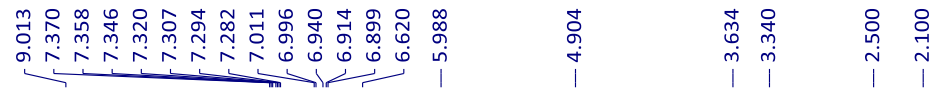

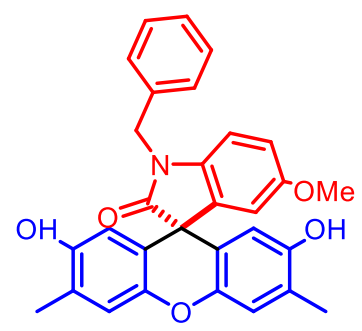

${ }^{1} \mathrm{H}$ NMR of $4 \mathrm{~m}$

$600 \mathrm{MHz}, \mathrm{DMSO}-d_{6}$

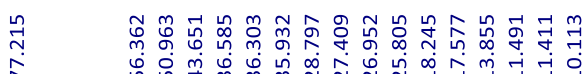

年 $\quad \underbrace{\circ}$

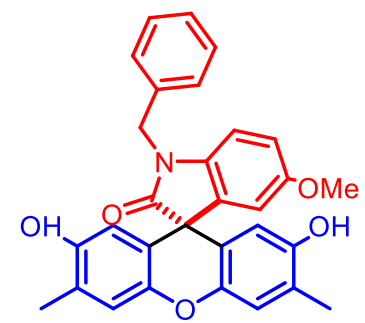

${ }^{13} \mathrm{C}$ NMR of $4 \mathrm{~m}$

$150 \mathrm{MHz}, \mathrm{DMSO}-d_{6}$
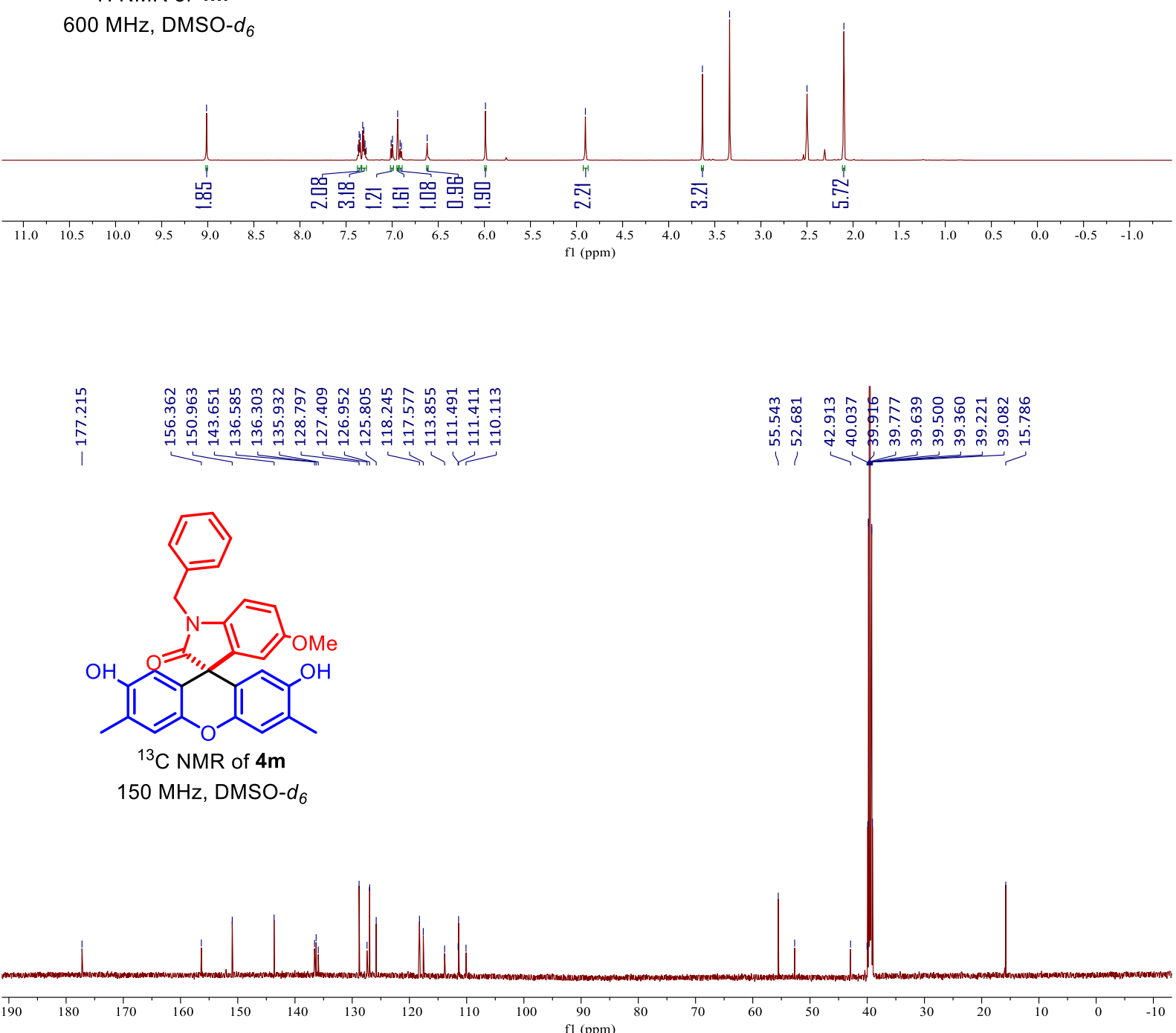


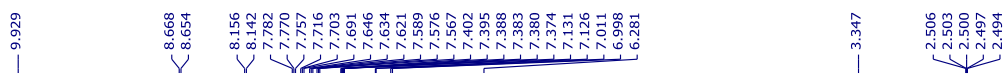<smiles>O=C1N(c2ccccc2)c2ccccc2C12c1ccccc1Oc1c2cc(O)c2ccccc12</smiles>

${ }^{1} \mathrm{H}$ NMR of $5 \mathbf{a}$ $600 \mathrm{MHz}, \mathrm{DMSO}-d_{6}$
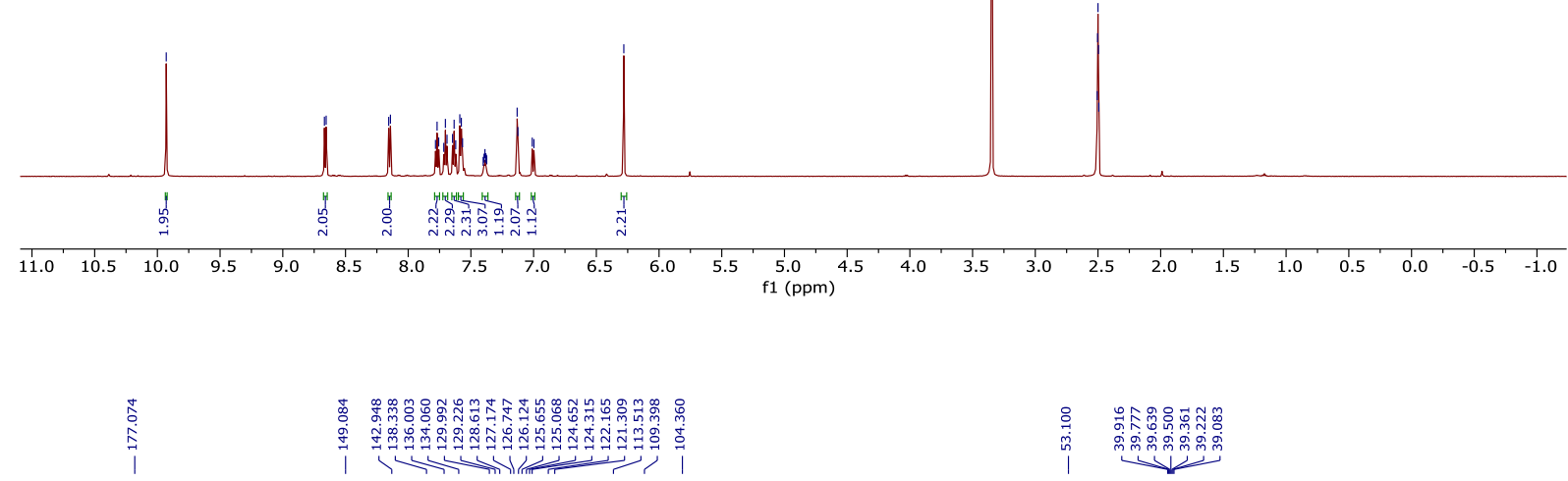

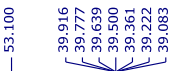<smiles>O=C1c2c(cc(O)c3ccccc23)Oc2ccccc2C12C(=O)N(c1ccccc1)c1ccccc12</smiles>

${ }^{13} \mathrm{C}$ NMR of $5 a$

$150 \mathrm{MHz}$, DMSO- $d_{6}$

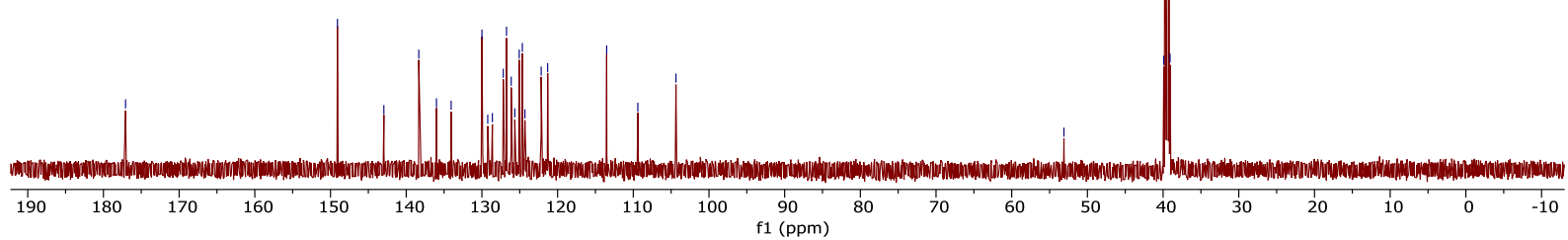


<smiles>O=C1c2cc(O)c3ccccc3c2Oc2ccccc2C12C(=O)N(c1c(Cl)cccc1Cl)c1ccccc12</smiles>

${ }^{1} \mathrm{H}$ NMR of $\mathbf{5 b}$ $600 \mathrm{MHz}, \mathrm{DMSO}-d_{6}$

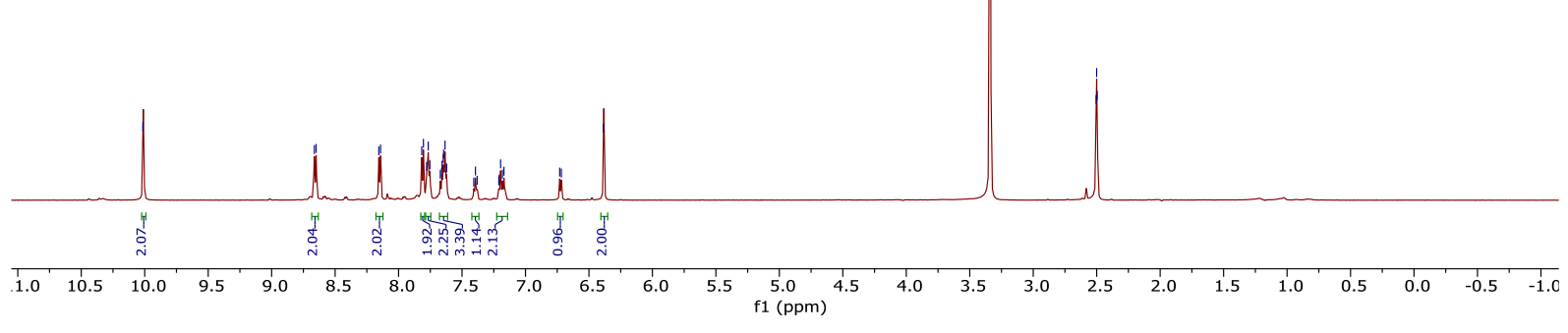<smiles>O=C1N(c2c(Cl)cccc2Cl)c2ccccc2C12c1ccc3c(O)cccc3c1Oc1c2cc(O)c2ccccc12</smiles>

${ }^{13} \mathrm{C}$ NMR of $5 \mathbf{b}$

$150 \mathrm{MHz}$, DMSO-d $d_{6}$

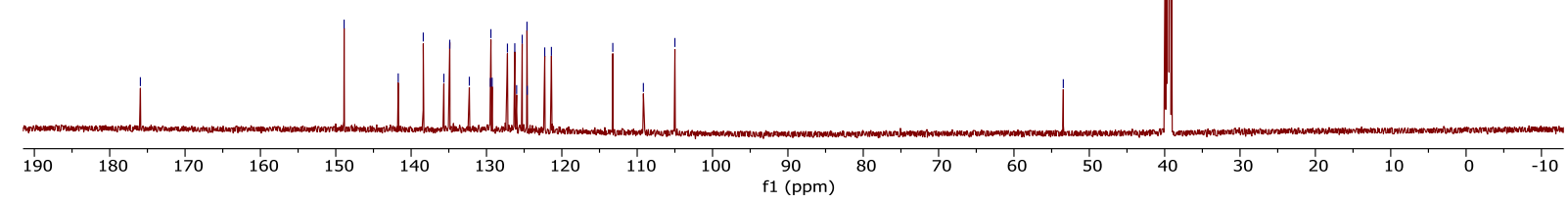




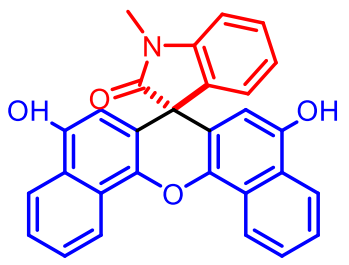

${ }^{1} \mathrm{H}$ NMR of $5 \mathrm{c}$ $600 \mathrm{MHz}, \mathrm{DMSO}-d_{6}$

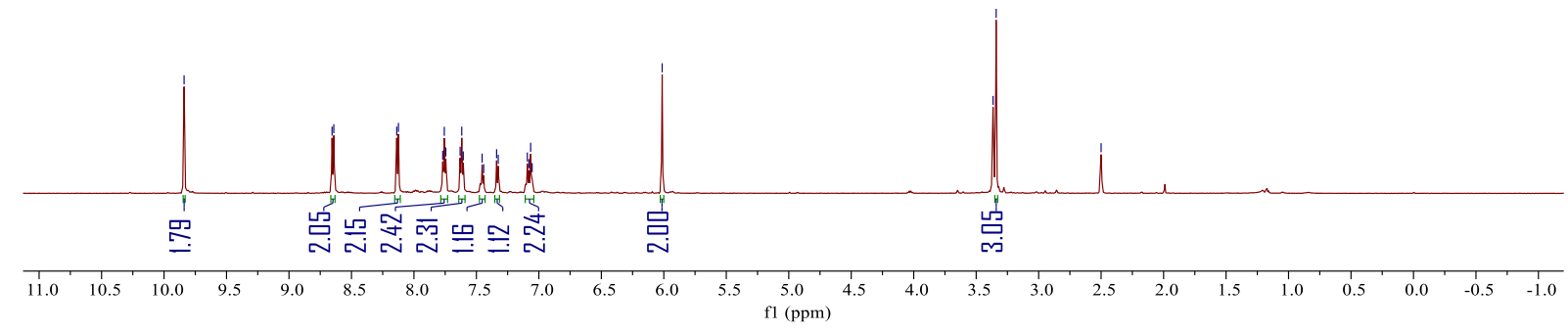

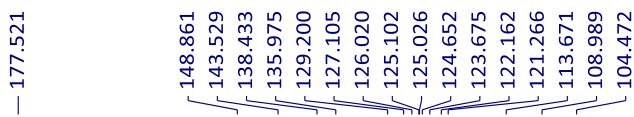<smiles>CN1C(=O)C2(c3ccccc3Oc3ccc(O)cc32)c2ccccc21</smiles>

${ }^{13} \mathrm{C}$ NMR of $5 \mathrm{c}$

$150 \mathrm{MHz}, \mathrm{DMSO}-\mathrm{d}_{6}$

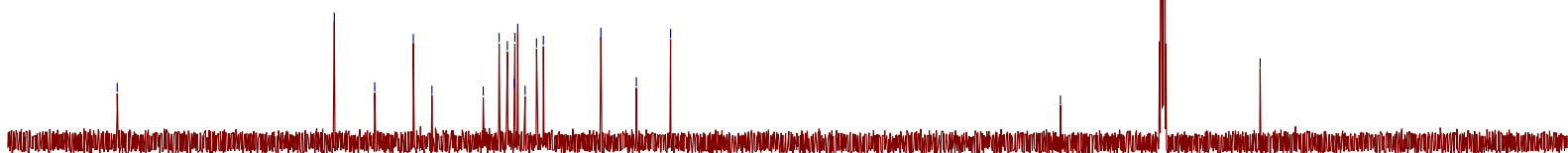

$\begin{array}{rllllllllllllllllllll}190 & 180 & 170 & 160 & 150 & 140 & 130 & 120 & 110 & 100 & 90 & 80 & 70 & 60 & 50 & 40 & 30 & 20 & 10 & 0 & -10\end{array}$ 


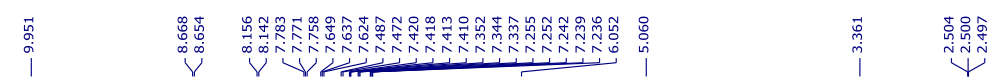<smiles>O=C1c2cc(O)c3ccccc3c2Oc2ccccc2[C@@]12C(=O)N(Cc1ccccc1)c1ccc(Cl)cc12</smiles>

${ }^{1} \mathrm{H}$ NMR of $5 \mathrm{~d}$

$600 \mathrm{MHz}$, DMSO-d 6

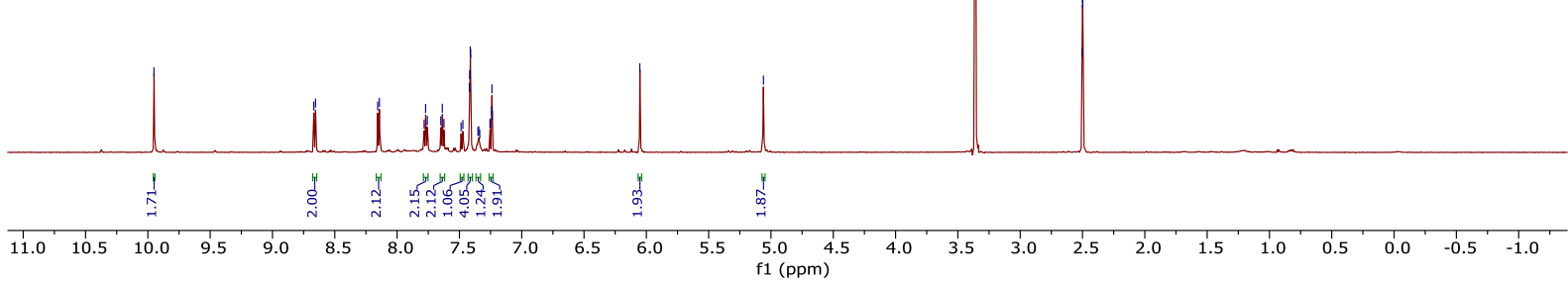

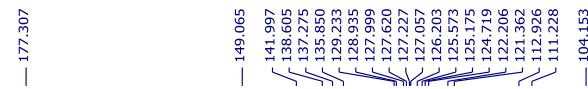

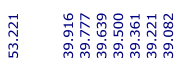<smiles>O=C1c2cc(O)c3ccccc3c2Oc2ccccc2[C@@]12C(=O)N(Cc1ccccc1)c1ccc(Cl)cc12</smiles>

${ }^{13} \mathrm{C}$ NMR of $5 \mathbf{d}$

$150 \mathrm{MHz}, \mathrm{DMSO}-d_{6}$

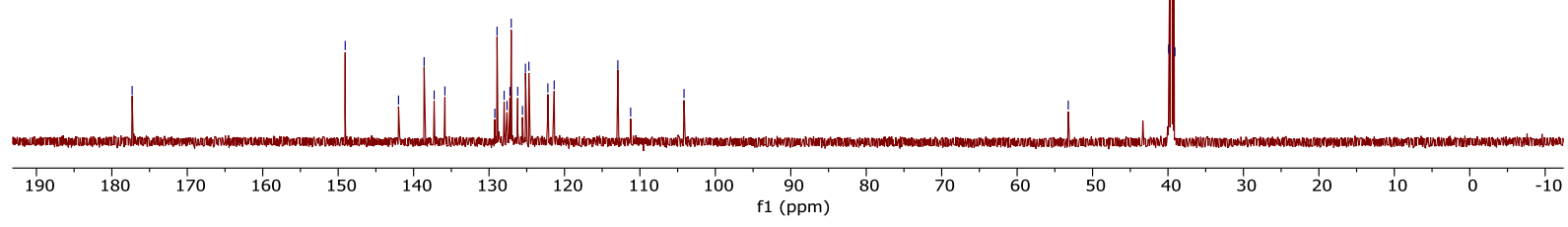


<smiles></smiles>

${ }^{1} \mathrm{H}$ NMR of $5 \mathbf{e}$ $600 \mathrm{MHz}$, DMSO-d 6

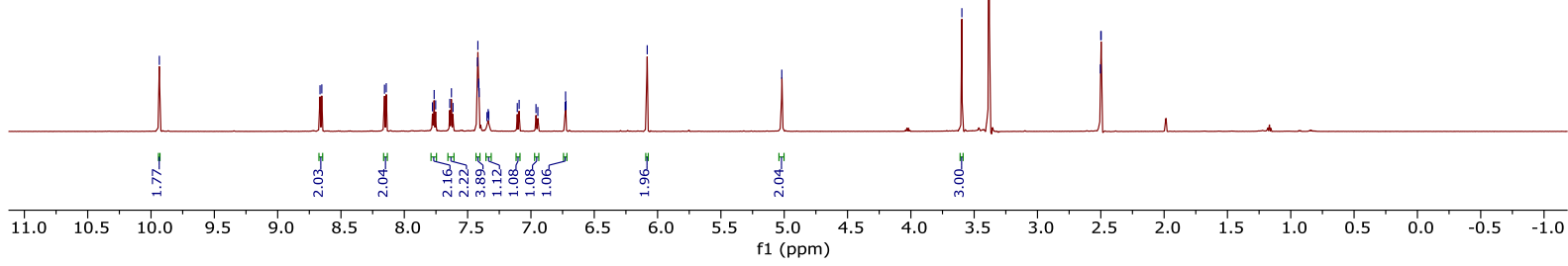

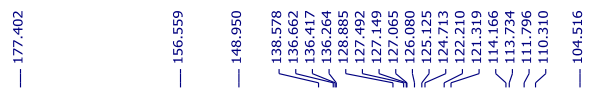

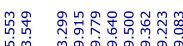

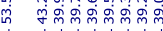<smiles></smiles>

${ }^{13} \mathrm{C}$ NMR of $5 \mathbf{e}$

$150 \mathrm{MHz}$, DMSO-d

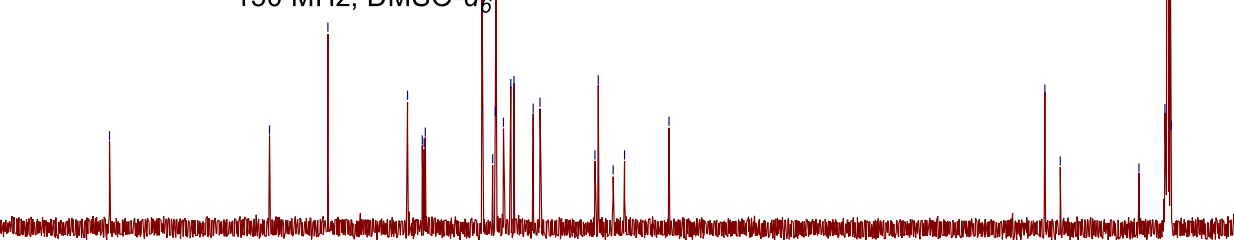

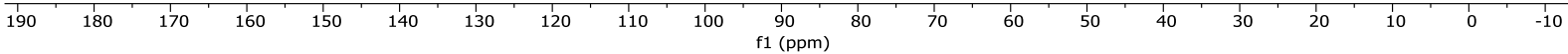



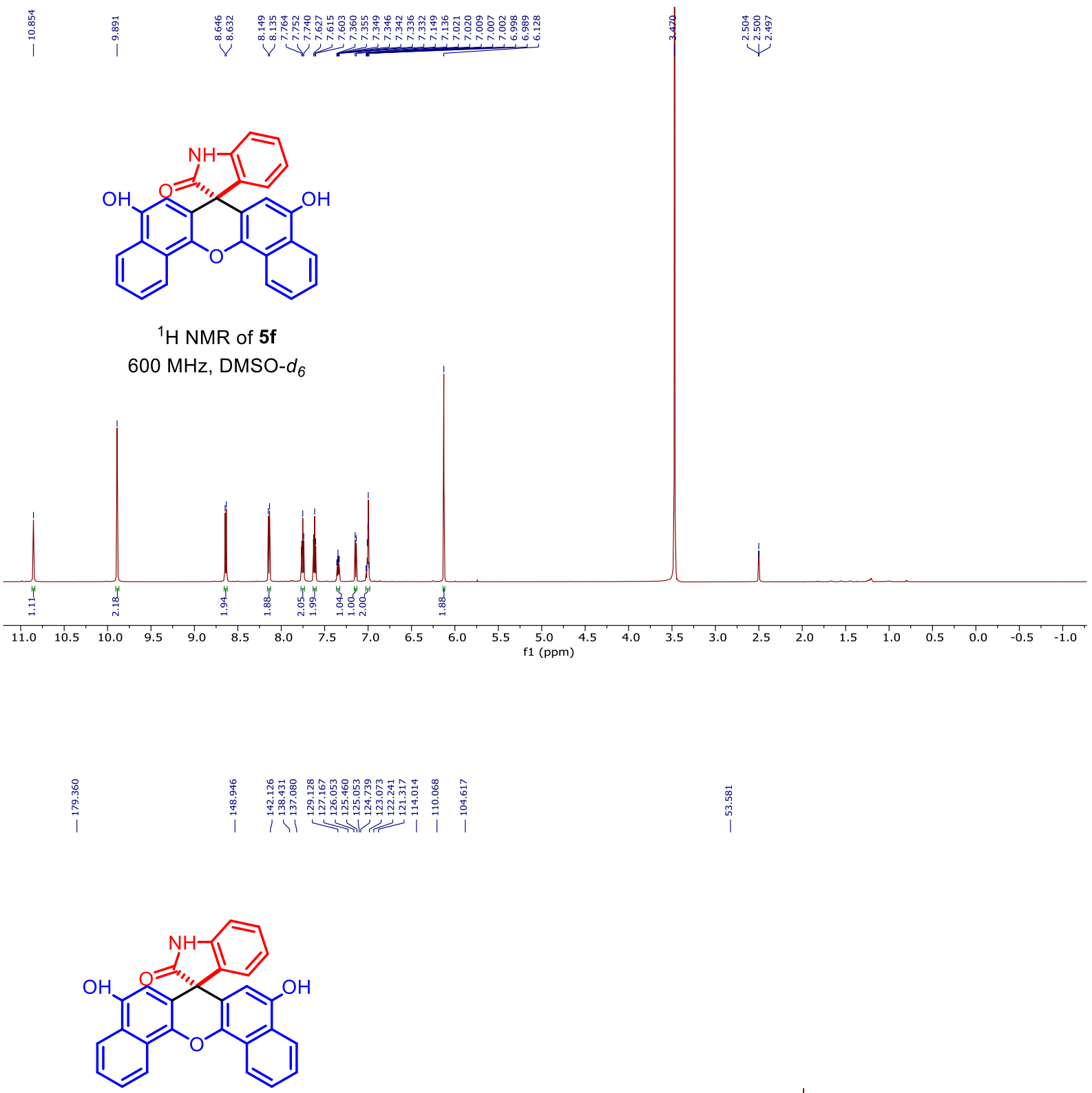

${ }^{13} \mathrm{C}$ NMR of $\mathbf{5 f}$

$150 \mathrm{MHz}, \mathrm{DMSO}-d_{6}$

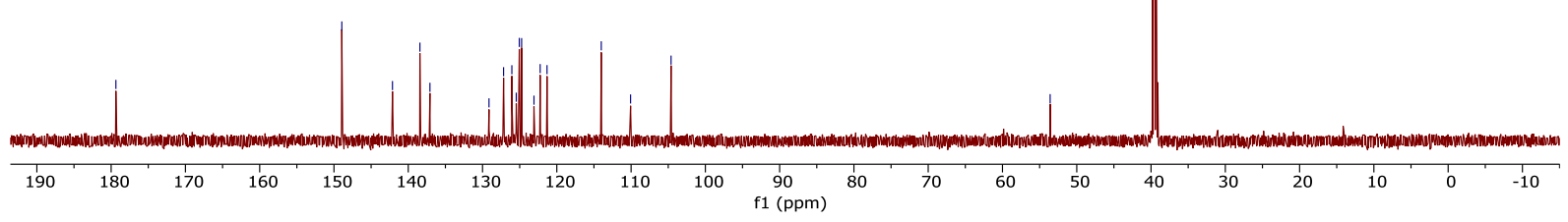



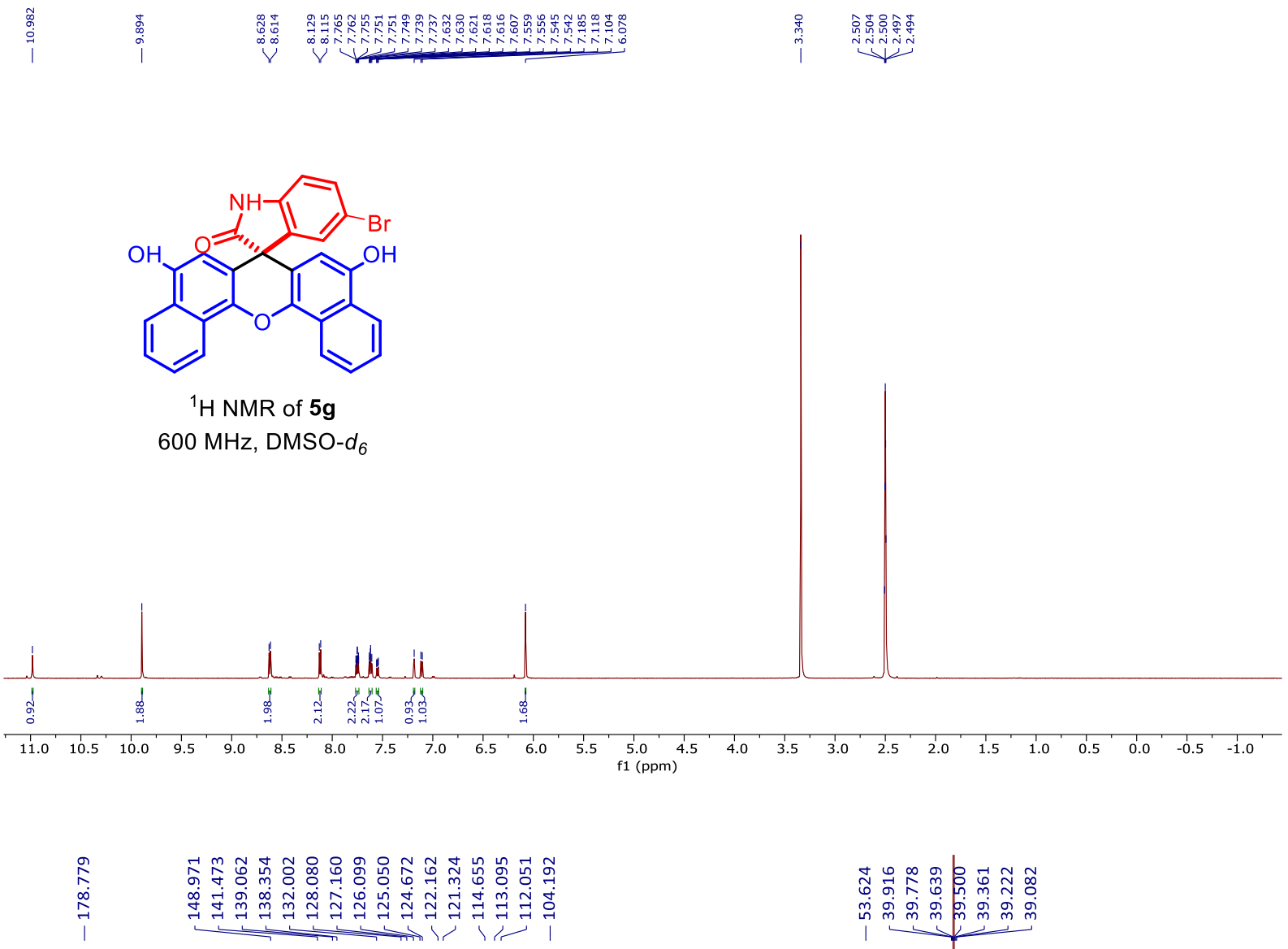

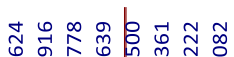

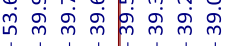

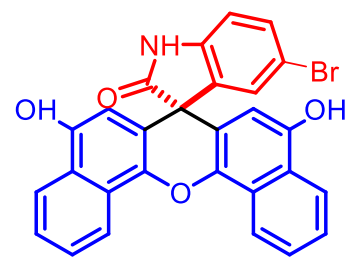

${ }^{13} \mathrm{C}$ NMR of $\mathbf{5 g}$

$150 \mathrm{MHz}, \mathrm{DMSO}-d_{6}$

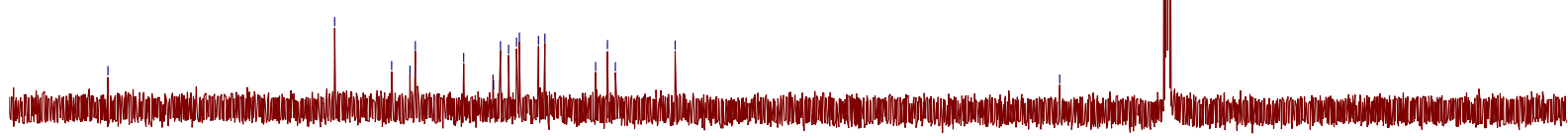

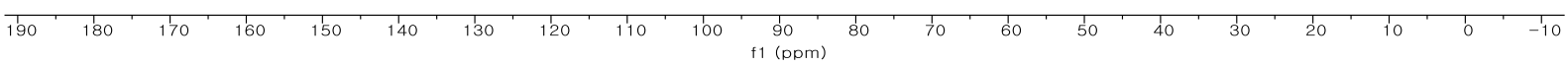




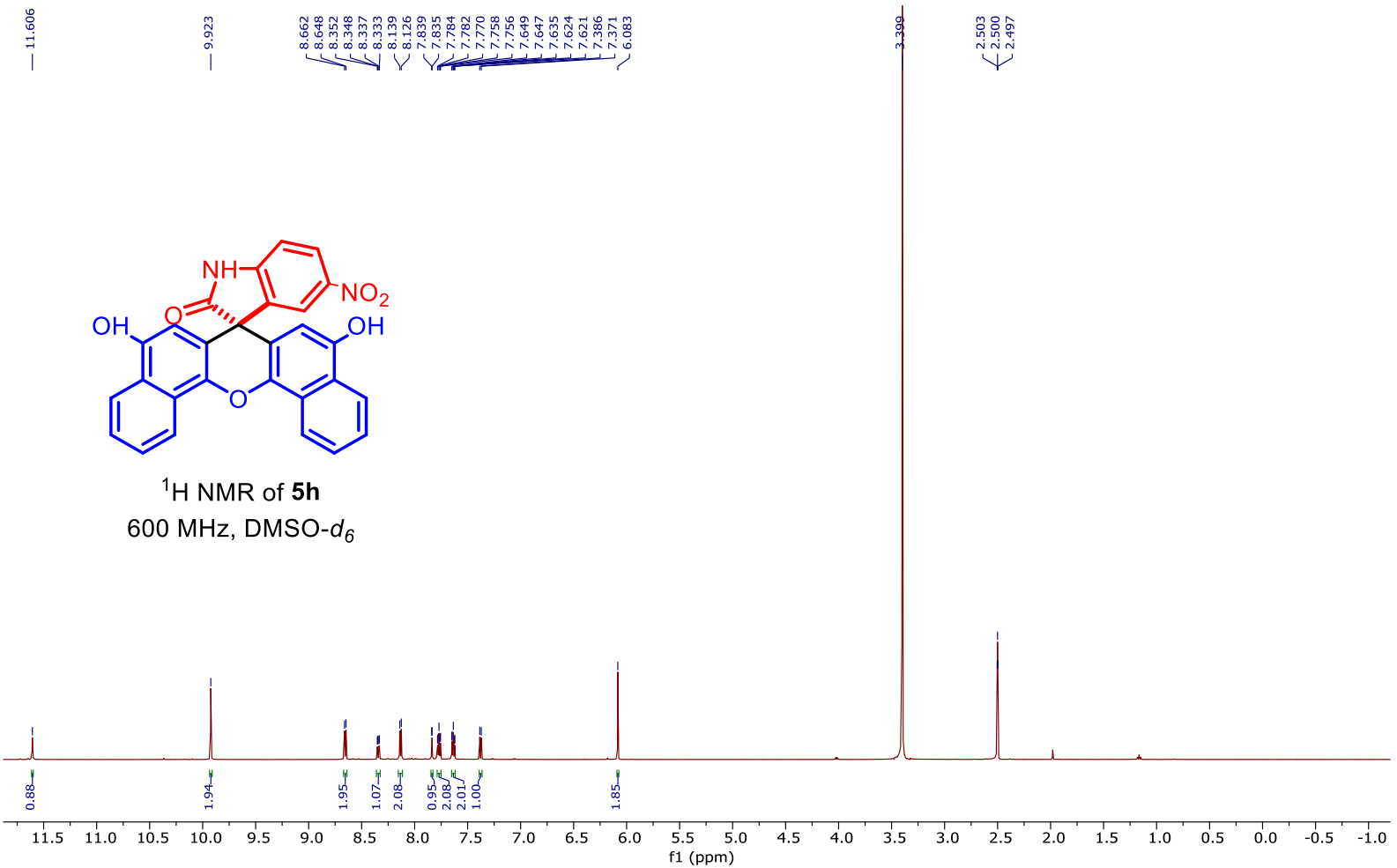

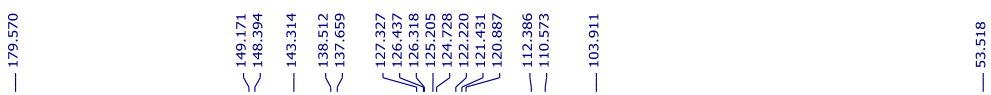

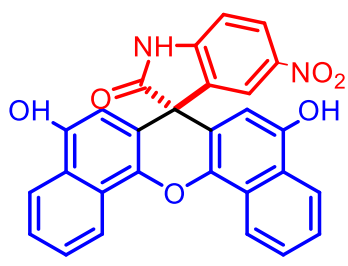

${ }^{13} \mathrm{C}$ NMR of $\mathbf{5 h}$

$150 \mathrm{MHz}, \mathrm{DMSO}-d_{6}$

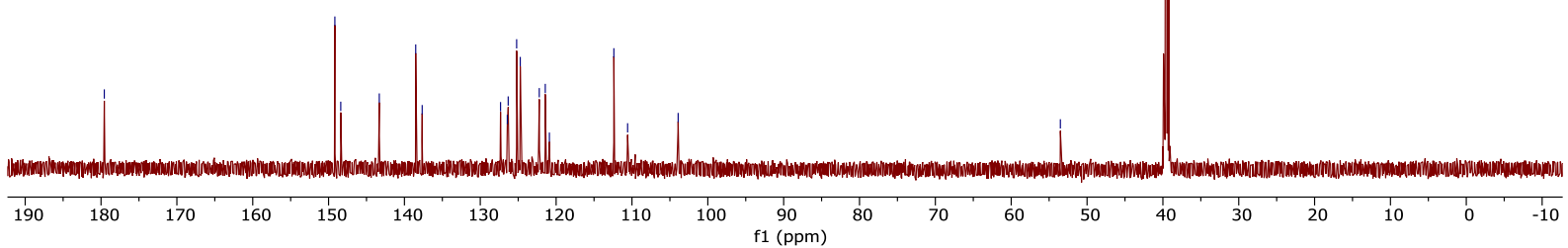




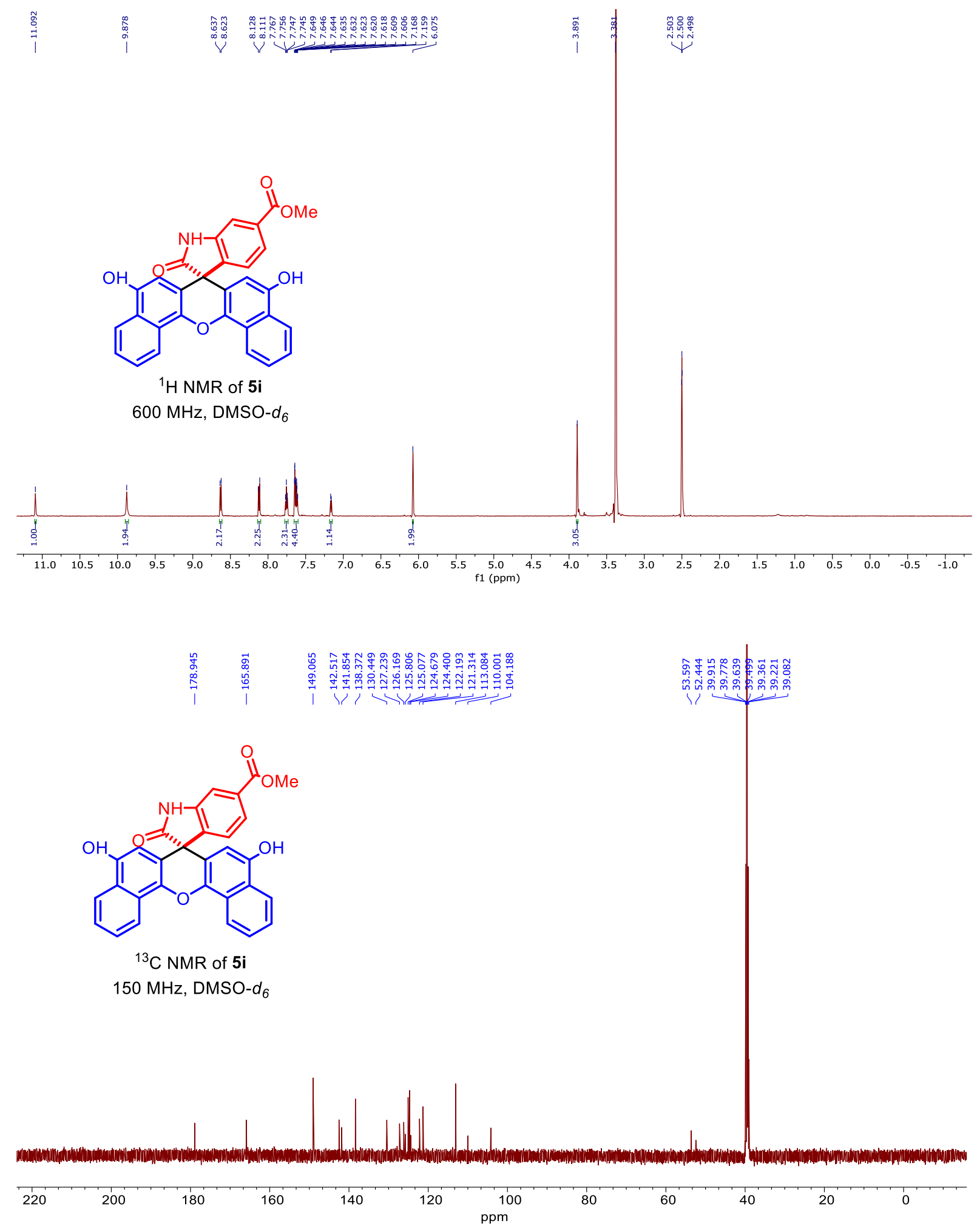




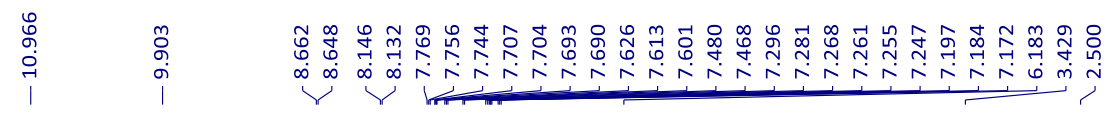<smiles>O=C1Nc2ccc(-c3ccccc3)cc2C12c1ccccc1Oc1c2ccc2ccccc12</smiles>

${ }^{1} \mathrm{H}$ NMR of $5 \mathbf{j}$

$600 \mathrm{MHz}, \mathrm{DMSO}-d_{6}$<smiles>O=C1Nc2ccc(-c3ccccc3)cc2C12c1ccccc1Oc1c2cc(O)c2ccccc12</smiles>

${ }^{13} \mathrm{C}$ NMR of $5 \mathbf{j}$

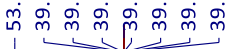

$150 \mathrm{MHz}$, DMSO- $d_{6}$

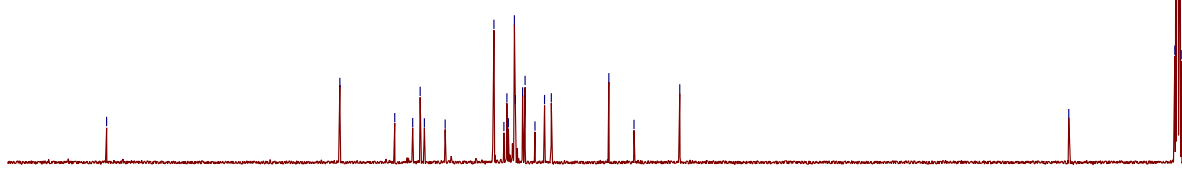

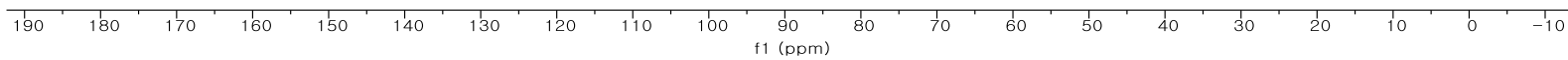




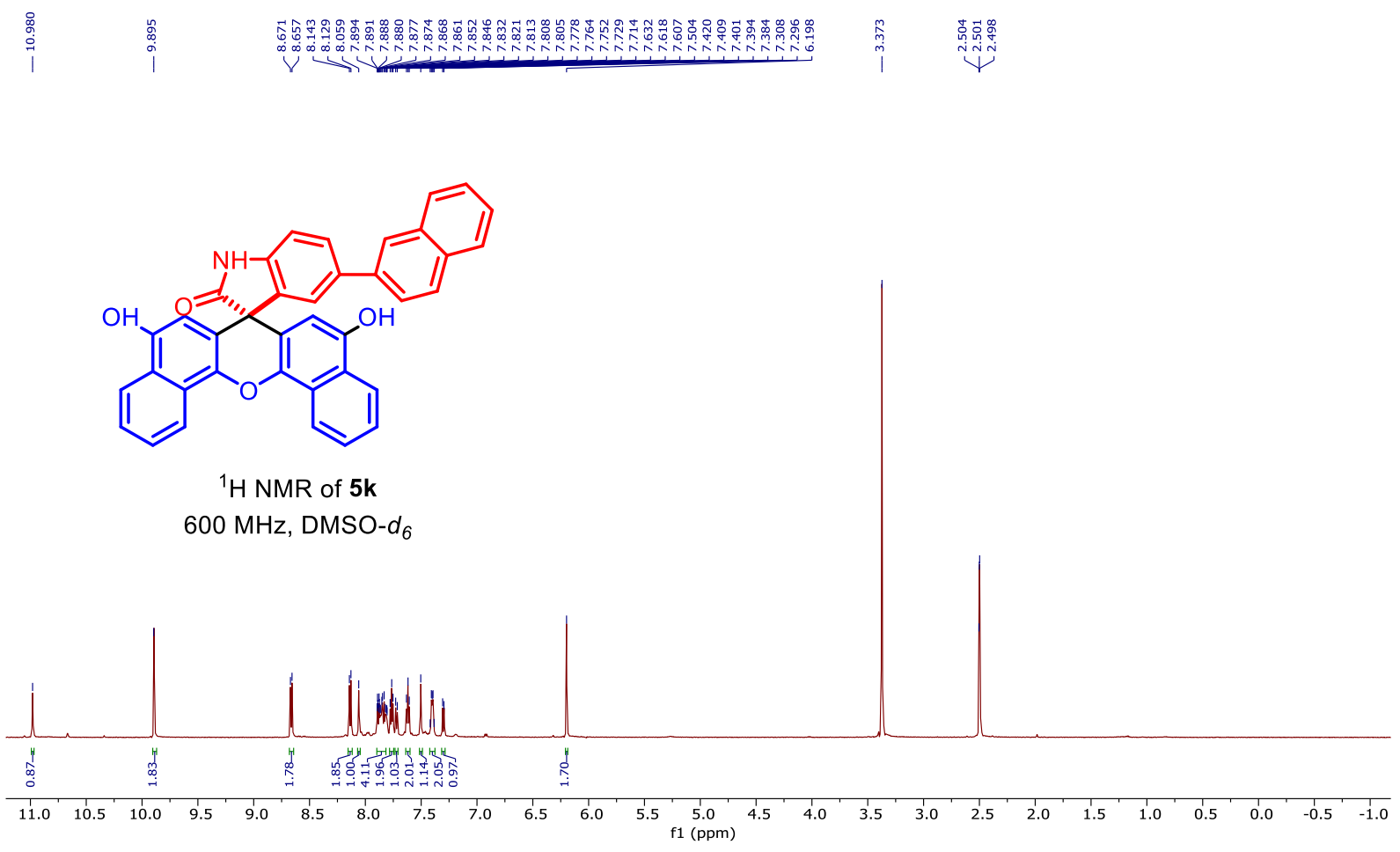

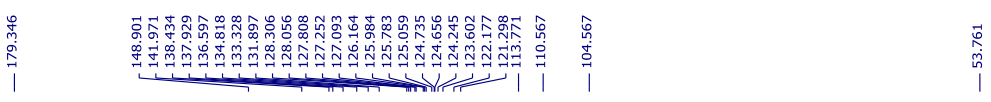

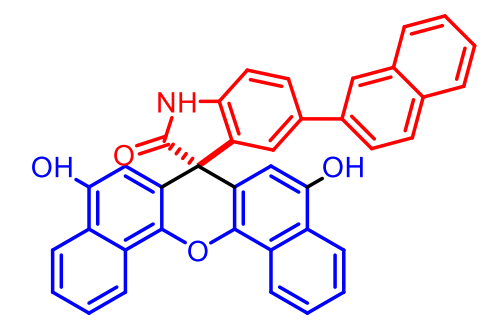

${ }^{13} \mathrm{C}$ NMR of $\mathbf{5 k}$

$150 \mathrm{MHz}$, DMSO-d 6

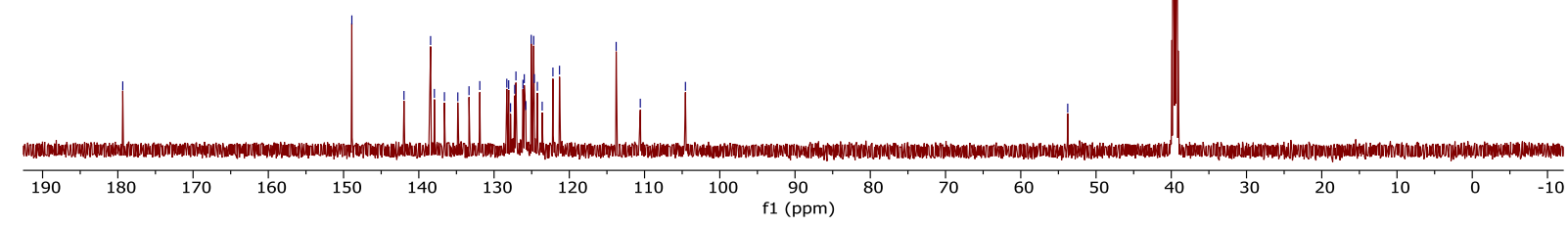



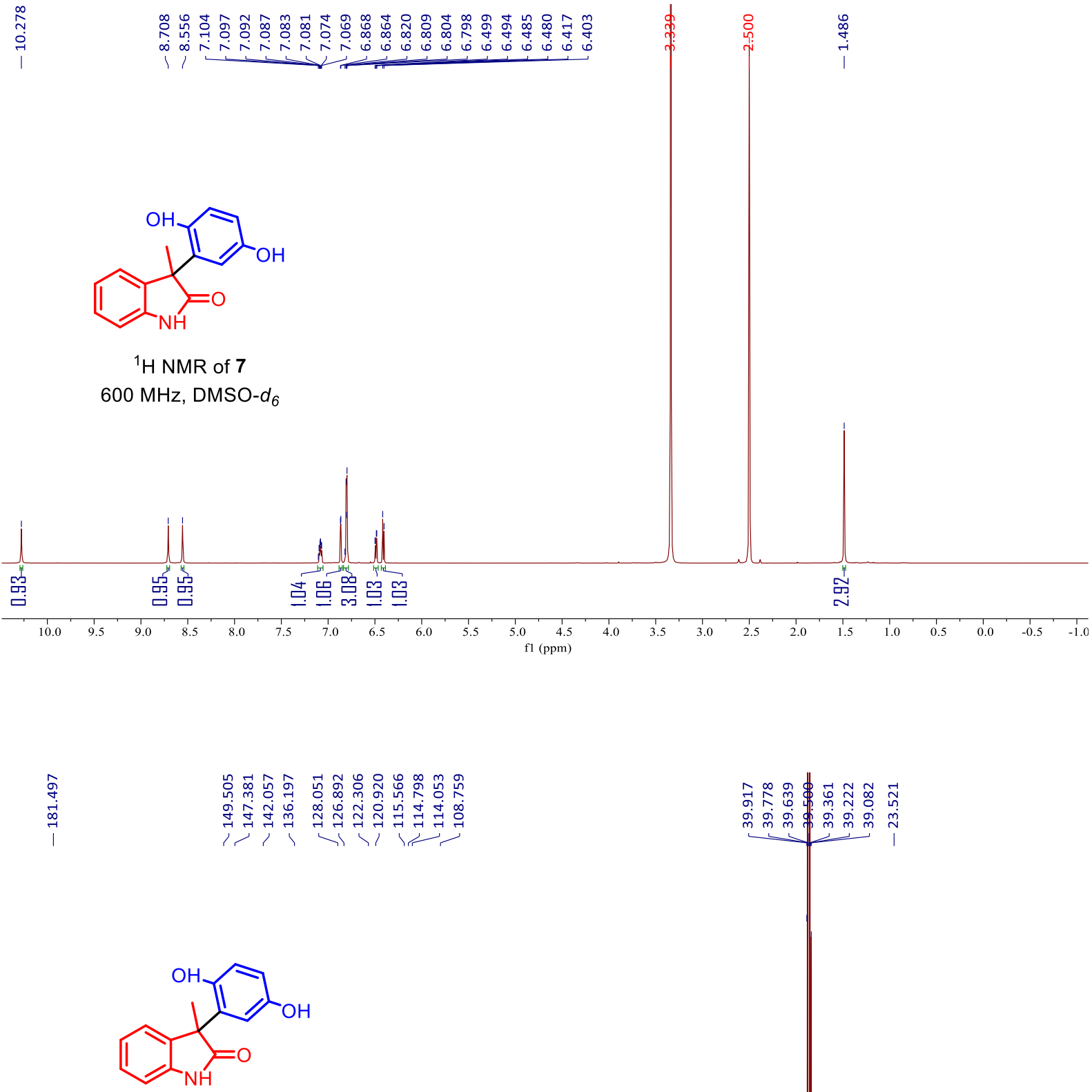

${ }^{13} \mathrm{C}$ NMR of 7

$150 \mathrm{MHz}, \mathrm{DMSO}-d_{6}$
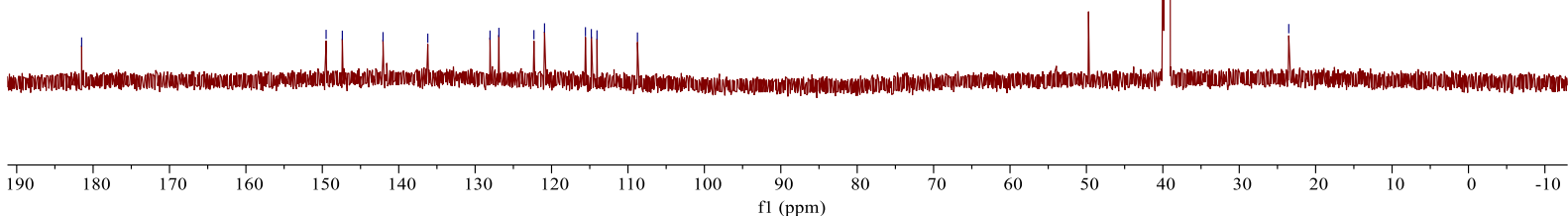


\section{Details of fluorophore analysis for metal sensing}

\section{Procedure for sensing measurements}

UV-Vis and fluorescence spectra were recorded using a UV 3220 spectrometer (Optizen) and spectrofluorometer (HITACHI) F-2700 equipped with a Xe arc lamp, respectively. A stock solution of $\mathbf{3 a}, \mathbf{4 g}$, and $\mathbf{5 c}\left(1 \times 10^{-4} \mathrm{M}\right)$ was prepared in DMSO. Stock solutions of various cations $\left(10 \mathrm{mM}\right.$; $\mathrm{Ag}^{+}, \mathrm{Ba}^{2+}, \mathrm{Ca}^{2+}, \mathrm{Cd}^{2+}, \mathrm{Ce}^{3+}, \mathrm{Cu}^{2+}, \mathrm{Co}^{2+}, \mathrm{Fe}^{3+}, \mathrm{Hg}^{2+}, \mathrm{Mn}^{2+}, \mathrm{Na}^{+}, \mathrm{Ni}^{2+}, \mathrm{Pb}^{2+}$, $\mathrm{Sn}^{2+}, \mathrm{Sr}^{2+}, \mathrm{Ti}^{3+}$, and $\mathrm{Zn}^{2+}$ ) were prepared in deionized water. Before spectroscopic measurements, test solutions were prepared in $1.950 \mu \mathrm{L}$ of DMSO mixing $25 \mu \mathrm{L}$ stock solution of $\mathbf{3 a}, \mathbf{4 g}$, and $\mathbf{5 c}$ and $25 \mu \mathrm{L}$ of each metal ions stock into cuvettes with the final volume of $2.0 \mathrm{~mL}$ respectively. $\mathrm{Fe}^{3+}$ and $\mathrm{Cu}^{2+}$ ions were detected by adding different aliquot of stock solution of $\mathrm{Fe}^{3+}(2.0-10 \mathrm{mM})$ and $\mathrm{Cu}^{2+}(0.5-10 \mathrm{mM})$ with $\mathbf{3 a}, \mathrm{Fe}^{3+}(0.1-10 \mathrm{mM})$ with $\mathbf{4 g}$, and $\mathrm{Fe}^{3+}(0.1-10 \mathrm{mM})$ with 5c. All UV-Vis and fluorescence spectra were recorded at room temperature after the addition of samples for a few seconds. The fluorescence spectra were acquired from 300 to $600 \mathrm{~nm}$ with the excitation wavelength set as $316 \mathrm{~nm}, 332 \mathrm{~nm}$, and 344 $\mathrm{nm}$.

\section{Chemosensors}

Heavy metal ions toxicity has proven to be a major threat and there are several health risks associated with it. ${ }^{5}$ Their medical and technological applications must raise concerns over their potential effects on human health and the environment. Among these heavy metals, iron and copper are among the most commonly present in our body but lethal in high concentration. ${ }^{6,7}$ The optical properties are tested for absorption (Fig. S1a-c) and fluorescence (Fig. S1d-f) properties of 3a-j, 4a-j, and 5a-k products commonly known to bind with metal ions due to the presence of hydroxyl, carbonyl, and amine groups. In this regard, we have studied the fluorescent properties of representative compounds $\mathbf{3 a}, \mathbf{4 g}$, and $\mathbf{5 c}$ bearing 1,4naphthoquinones, 1,4-benzoquinones, and oxindoles with various active sites for its ability to selectively detect heavy metals. From the absorption and fluorescence response of the chemosensor $\mathbf{3 a}, \mathbf{4 g}$, and $\mathbf{5 c}$ toward 17 different metal ions in aqueous solutions, a shifted maxima with enhancing the absorption and quenching in fluorescence intensity for $\mathbf{3 a}, \mathbf{4 g}$, and $\mathbf{5 c}$ was observed following the addition of $\mathrm{Fe}^{3+}$ and $\mathrm{Cu}^{2+}$ ions (Fig. S2a-f). Conversely, no effect on the absorption and fluorescence of $\mathbf{3 a}, \mathbf{4 g}$, and $\mathbf{5 c}$ was observed following addition of other 
metal ions, such as $\mathrm{Ag}^{+}, \mathrm{Ba}^{2+}, \mathrm{Ca}^{2+}, \mathrm{Cd}^{2+}, \mathrm{Ce}^{3+}, \mathrm{Co}^{2+}, \mathrm{Hg}^{2+}, \mathrm{Mn}^{2+}, \mathrm{Na}^{+}, \mathrm{Ni}^{2+}, \mathrm{Pb}^{2+}, \mathrm{Sn}^{2+}, \mathrm{Sr}^{2+}$, $\mathrm{Ti}^{3+}$, and $\mathrm{Zn}^{2+}$, indicating that the sensor is highly-selective for $\mathrm{Fe}^{3+}$ and $\mathrm{Cu}^{2+}$ ions in aqueous solutions.

In this regard, the fluorescence analysis of compounds $\mathbf{3 a}, \mathbf{4 g}$, and $\mathbf{5 c}$ having the key components of the chelating unit and binding interactions with metal ions $\left(\mathrm{Fe}^{3+}\right.$ and $\left.\mathrm{Cu}^{2+}\right)$ was studied. With the incremental addition of the $\mathrm{Fe}^{3+}$ and $\mathrm{Cu}^{2+}$ metal ions in the fluorescence spectra of 3a, $\mathbf{4 g}$, and $\mathbf{5 c}$ significantly quenched the intensity at $10 \mathrm{mM}$ of $\mathrm{Fe}^{3+}$ and $\mathrm{Cu}^{2+}$, which indicates that the probe is strongly binding to the metal ions. ${ }^{6,7}$ The gradual decrease with increase in the concentration of $\mathrm{Fe}^{3+}(2.0$ to $10 \mathrm{mM})$ and $\mathrm{Cu}^{2+}(0.5$ to $10 \mathrm{mM})$ with $\mathbf{3 a}, \mathrm{Fe}^{3+}$ (0.1 to $10 \mathrm{mM})$ with $\mathbf{4 g}$, and $\mathrm{Fe}^{3+}(0.1$ to $10 \mathrm{mM})$ with $\mathbf{5 c}$ was observed (see Fig. S3a-d). According to the linear Stern-Volmer equation, ${ }^{8}$ the measured fluorescence intensity $\left[\mathrm{F} / \mathrm{F}_{0}\right]$ varied as a function of $\left[\mathrm{Fe}^{3+}\right]$ and $\left[\mathrm{Cu}^{2+}\right]$ concentration that showed good linearity, confirming the formation of $\mathbf{3 a}-\mathrm{Fe}^{3+}, \mathbf{3 a}-\mathrm{Cu}^{2+}, \mathbf{4} \mathbf{g}-\mathrm{Fe}^{3+}$, and $\mathbf{5} \mathbf{c}-\mathrm{Fe}^{3+}$, respectively (Fig. S4a-d). Based on the equation of $\mathrm{LOD}=\mathrm{K} \times \mathrm{SD} / \mathrm{S},{ }^{9}$ the detection limits of metal complexes $\mathbf{3 a}-\mathrm{Fe}^{3+}, \mathbf{3} \mathbf{a}-\mathrm{Cu}^{2+}$, $\mathbf{4 g}-\mathrm{Fe}^{3+}$, and $\mathbf{5 c}-\mathrm{Fe}^{3+}$ were calculated to be $3.81 \mu \mathrm{M}, 3.86 \mu \mathrm{M}, 4.37 \mu \mathrm{M}$, and $2.48 \mu \mathrm{M}$, respectively (Fig. S5a-d). 

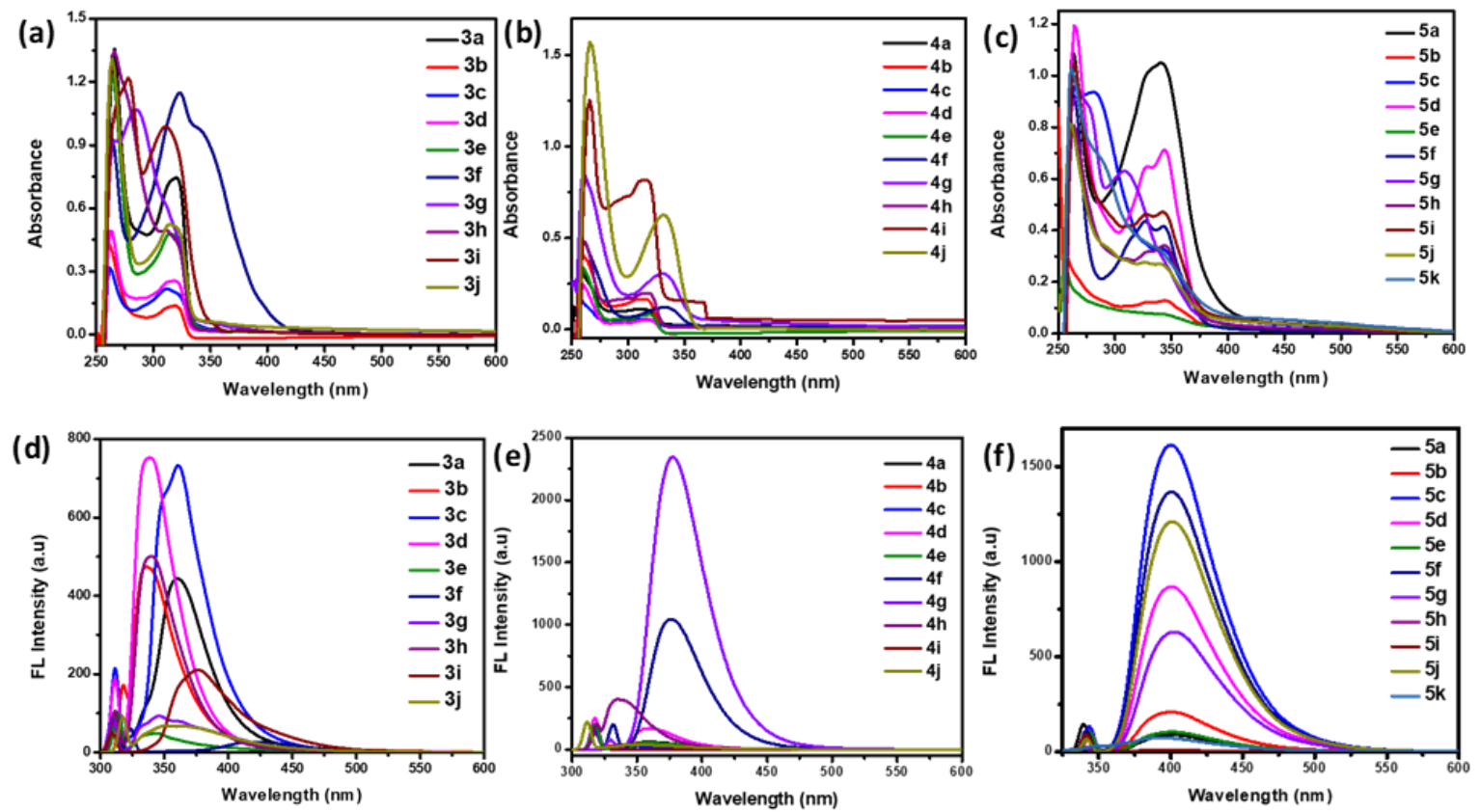

Fig. S1. (a-c) Absorption and (d-f) Fluorescence spectral properties of $\mathbf{3 a - j}, \mathbf{4 a - j}$, and $\mathbf{5 a - k}$.
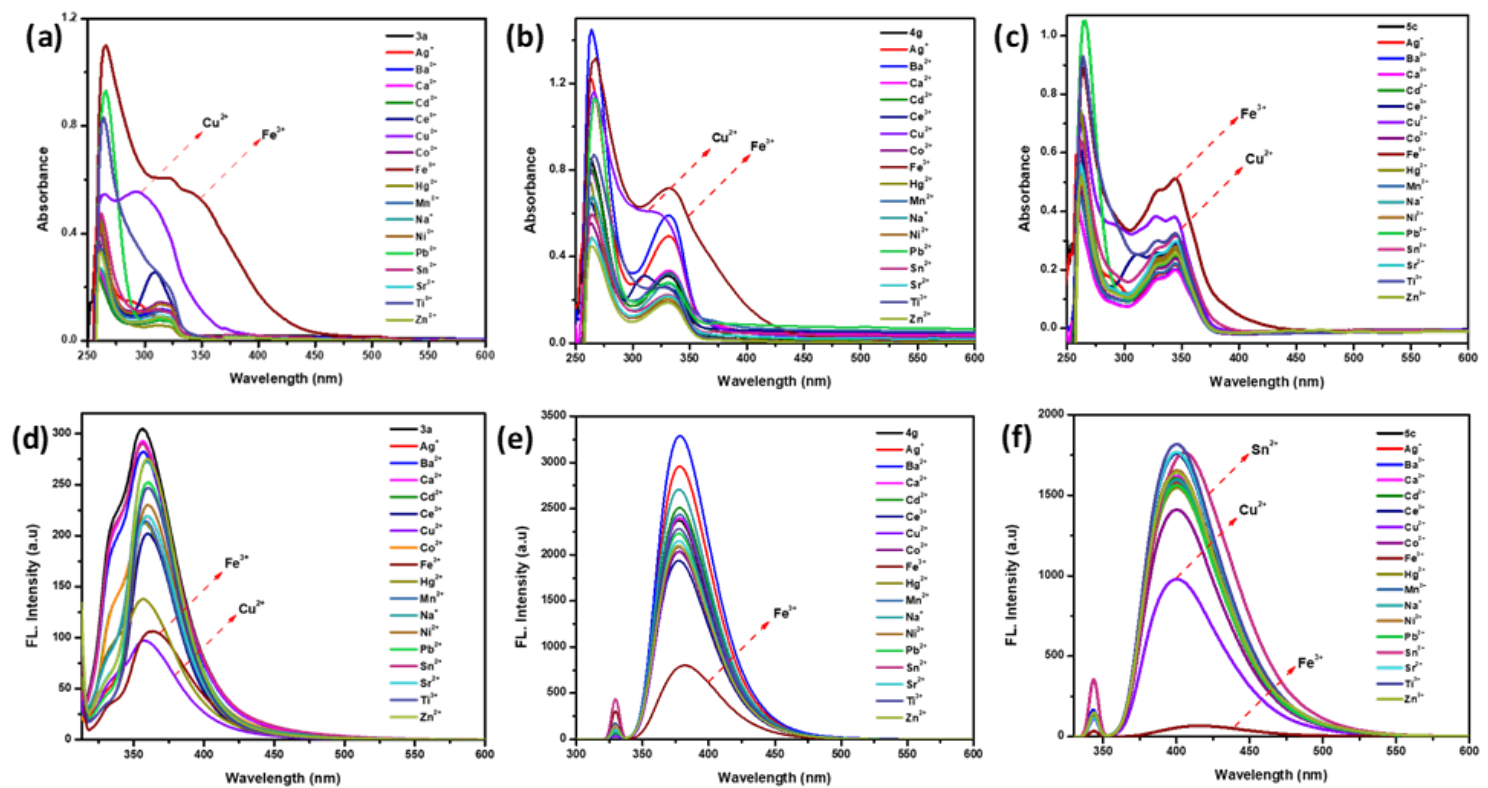

Fig. S2. (a-c) Absorption and (d-f) Fluorescence spectral properties of 3a, 4g, and 5c system in the presence of various metal ions $\left(\mathrm{Ag}^{+}, \mathrm{Ba}^{2+}, \mathrm{Ca}^{2+}, \mathrm{Cd}^{2+}, \mathrm{Ce}^{3+}, \mathrm{Cu}^{2+}, \mathrm{Co}^{2+}, \mathrm{Fe}^{3+}, \mathrm{Hg}^{2+}, \mathrm{Mn}^{2+}\right.$, $\mathrm{Na}^{+}, \mathrm{Ni}^{2+}, \mathrm{Pb}^{2+}, \mathrm{Sn}^{2+}, \mathrm{Sr}^{2+}, \mathrm{Ti}^{3+}$, and $\left.\mathrm{Zn}^{2+}\right)$ at $10 \mathrm{mM}$. 

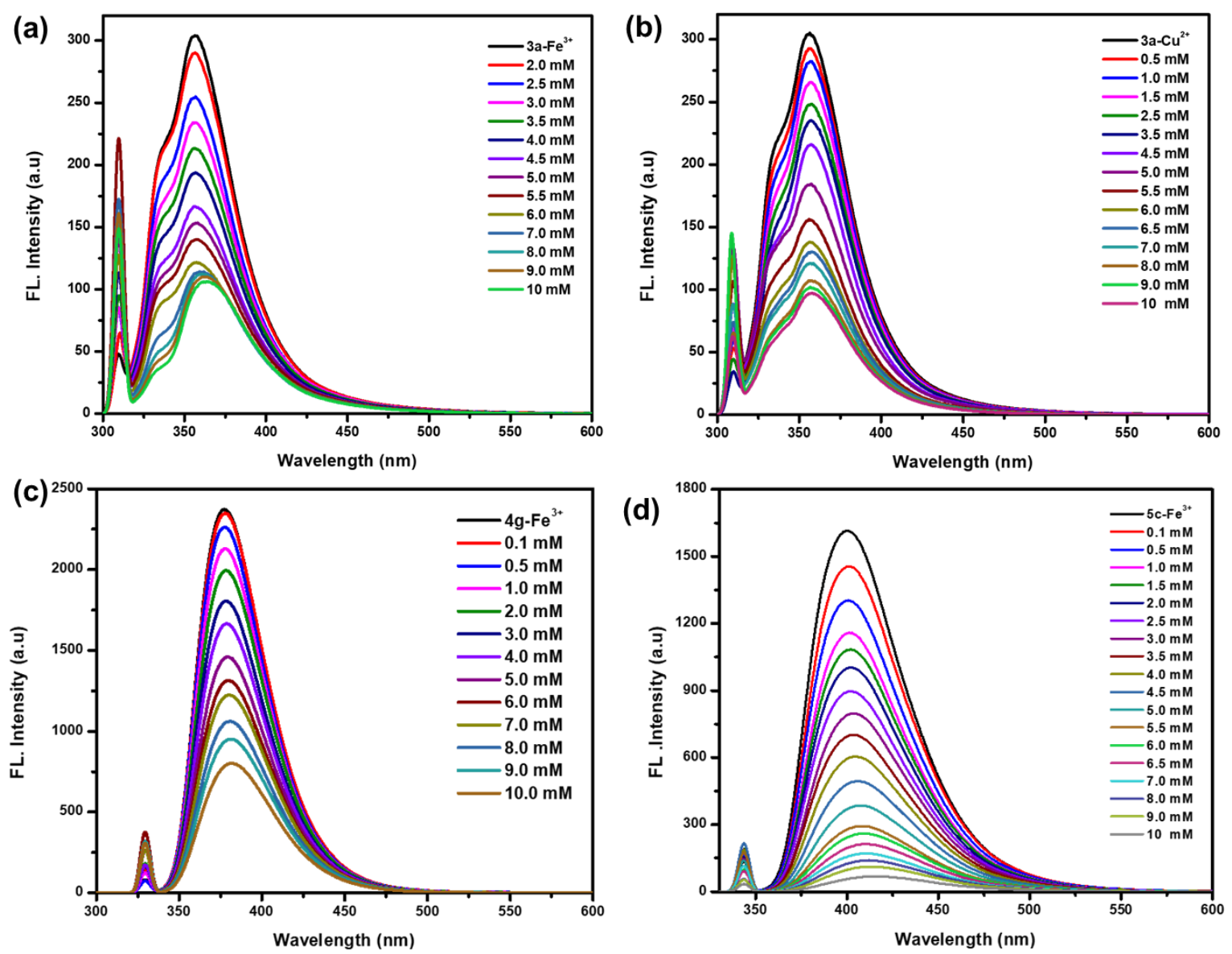

Fig. S3. (a,b) Fluorescence spectra of 3a in DMSO:water medium containing various $\mathrm{Fe}^{3+}(2.0$ to $10 \mathrm{mM})$ or $\mathrm{Cu}^{2+}(0.5$ to $10 \mathrm{mM})$ concentrations. (c) Fluorescence spectra of $\mathbf{4 g}$ in DMSO:water medium containing different $\mathrm{Fe}^{3+}$ concentrations $(0.1$ to $10 \mathrm{mM})$. (d) Fluorescence spectra of $\mathbf{5 c}$ in DMSO:water medium containing different $\mathrm{Fe}^{3+}$ concentrations (0.1 to $10 \mathrm{mM})$. 

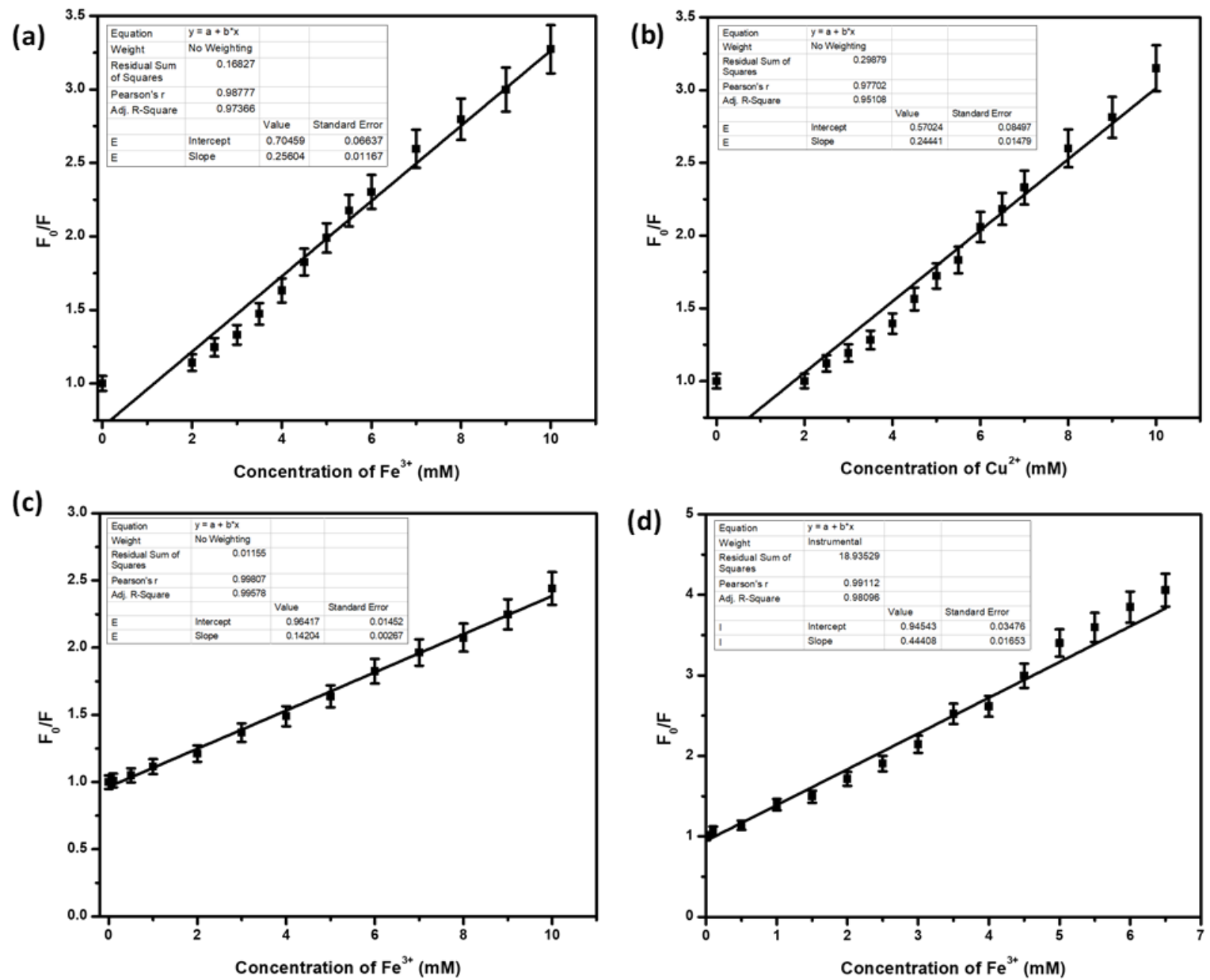

Fig. S4. Stern-Volmer plot based on the relative fluorescence signal $\left[\mathrm{F}_{0} / \mathrm{F}\right]$ vs. $\left[\mathrm{Fe}^{3+}\right]$ and $\left[\mathrm{Cu}^{2+}\right]$ concentrations. (a) $\mathbf{3 a}-\mathrm{Fe}^{3+}$, (b) $\mathbf{3 a}-\mathrm{Cu}^{2+}$, (c) $\mathbf{4} \mathbf{g}-\mathrm{Fe}^{3+}$, and (d) $\mathbf{5} \mathbf{c}-\mathrm{Fe}^{3+}$ systems. 

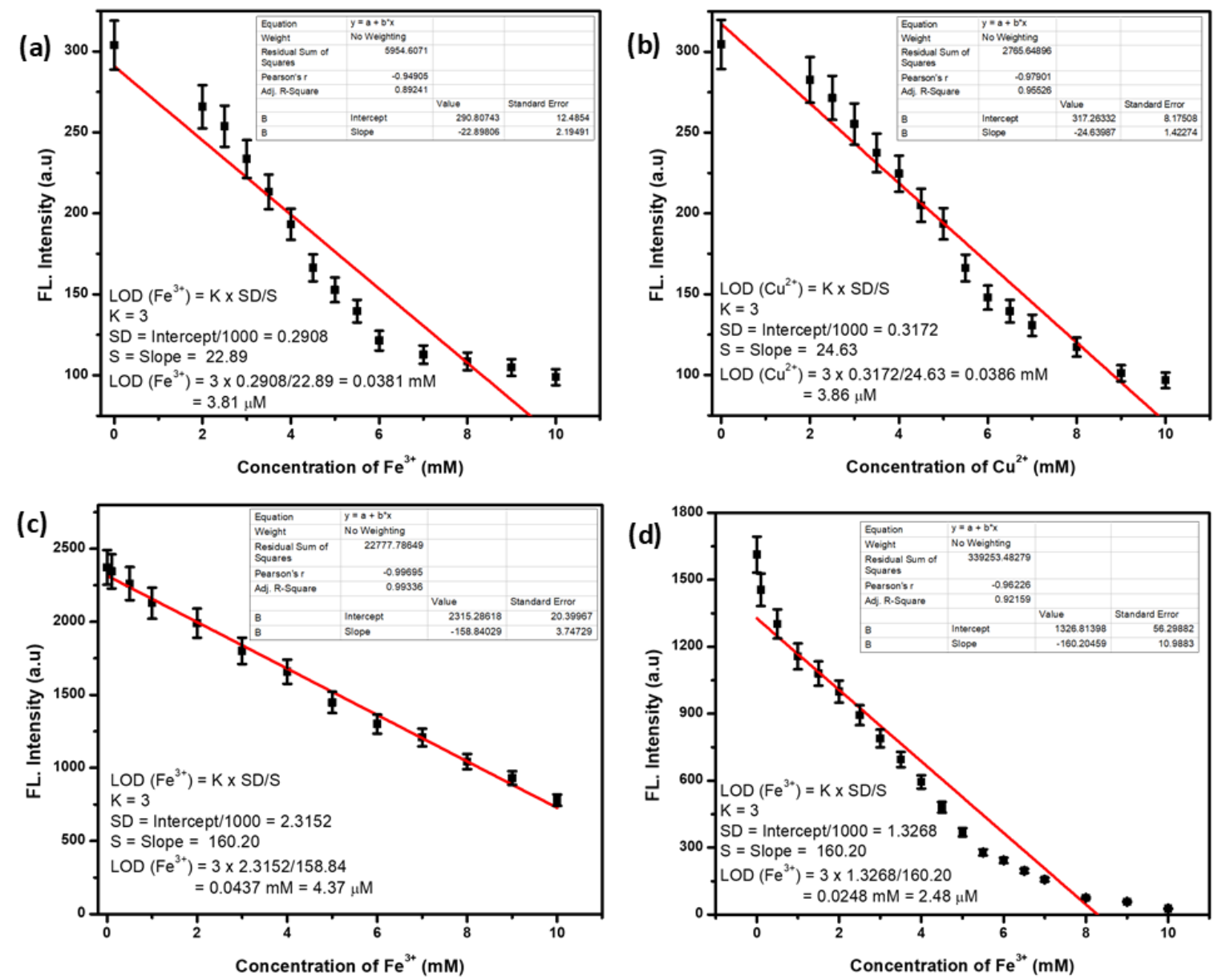

Fig. S5. Calibration curve of $\mathbf{3 a}, \mathbf{4 g}$, and $\mathbf{5 c}$ in the presence of $\mathrm{Fe}^{3+}$ and $\mathrm{Cu}^{2+}$ ions using the monitored emission wavelength at (a) $365 \mathrm{~nm} ; \mathbf{3 a}-\mathrm{Fe}^{3+}$, (b) $365 \mathrm{~nm} ; \mathbf{3 a}-\mathrm{Cu}^{2+}$, (c) $385 \mathrm{~nm} ; \mathbf{4 g}-$ $\mathrm{Fe}^{3+}$, and (d) $400 \mathrm{~nm} ; \mathbf{5 c}-\mathrm{Fe}^{3+}$ systems. The detection limit (LOD) was determined from the following equation: $\mathrm{LOD}=\mathrm{K} \times \mathrm{SD} / \mathrm{S}$, where $\mathrm{K}=3$; $\mathrm{SD}$ is the standard deviation of the blank solution; $\mathrm{S}$ is the slope of the calibration curve. 


\section{Details of cell imaging experiments}

\section{Cell culture}

The parental human colorectal carcinoma cell line (HCT116) was purchased from ATCC, Manassas, VA, USA. HCT116 cells were grown in McCoy's 5A medium supplemented with $10 \%$ fetal bovine serum (FBS) and antibiotics. Cells were cultured at the density of $1 \times 10^{6}$ cells $/ \mathrm{cm}^{2}$ in a $5 \% \mathrm{CO}_{2}$ atmosphere condition at $37{ }^{\circ} \mathrm{C}$ for $24 \mathrm{~h}$.

\section{Cell viability assay}

In this study, the cell viability was assessed by WST-1 assay. HCT116 cells were seeded in a 96-well microplate at the density of $1 \times 10^{6}$ cells $/ \mathrm{cm}^{2}$. Fluorescent probes $\mathbf{3 a}, \mathbf{4 g}$, and $\mathbf{5 c}, \mathbf{3 a}$ $\mathrm{Fe}^{3+}, \mathbf{3 a}-\mathrm{Cu}^{2+}, \mathbf{4 g}-\mathrm{Fe}^{3+}$ and $\mathbf{5 c}-\mathrm{Fe}^{3+}$ in different concentration $(25,50$ and $100 \mu \mathrm{g} / \mathrm{mL})$ were incubated with cells at $37^{\circ} \mathrm{C}$ for $24 \mathrm{~h}$. The experiment was conducted three times for each sample and the cells without treatment of probe served as a control. Add, $10 \mu \mathrm{L}$ of WST-1 solution to each sample and incubated the cells at $37{ }^{\circ} \mathrm{C}$ for $30 \mathrm{~min}$. The absorbance was recorded at $450 \mathrm{~nm}$ using a microplate reader (EL-800, Bio Tek Instruments, Winooski, VT USA). The cell viability was calculated using the following formulae.

$$
\text { Cell viability }(\%)=\frac{\text { Absorbance of test sample }}{\text { Absorbance of control }}
$$

\section{Cellular uptake}

The effect of $\mathbf{3 a}, \mathbf{4 g}$, and $\mathbf{5 c}$ on sensitive and selective detection of $\mathrm{Fe}^{3+}$ and $\mathrm{Cu}^{2+}$ ions in living cells were evaluated by a fluorescence microscopic analysis. Briefly, HCT116 cells were seeded in a 24 well microplate and the cells independently incubated with the highest concentration of each probe $(100 \mu \mathrm{g} / \mathrm{mL})$ at $37^{\circ} \mathrm{C}$ for $12 \mathrm{~h}$. Over the incubation period, the cells were washed with 1X PBS (phosphate buffer solution, $\mathrm{pH}$ 7.4) and fixed in methanol:acetic acid (3:1, v/v). Subsequently, the cells were stained with DAPI (4',6-diamidino-2-phenylindole) for 20 min under the dark condition and then, washed with 1X PBS. The cell imaging was visualized by a Nikon microscope (ECLIPSE, Ts2R-FL, Tokyo, Japan). 


\section{Cytotoxicity and imaging applications}

The cell viability of $\mathbf{3 a}, \mathbf{4 g}$, and $\mathbf{5 c}$ with $\mathrm{Fe}^{3+}$ and $\mathrm{Cu}^{2+}$ was tested against HCT116 cells in DMSO using WST-1 assay (Fig. S6). ${ }^{10,11}$ Although the cell viabilities were decreased with the increase of concentrations $(25-100 \mu \mathrm{g} / \mathrm{mL})$ of $\mathbf{3 a}, \mathbf{4 g}$, and $\mathbf{5 c}$ and $\mathbf{3 a}-\mathrm{Fe}^{3+}, \mathbf{3 a}-\mathrm{Cu}^{2+}, \mathbf{4 g}-\mathrm{Fe}^{3+}$, and $\mathbf{5 c}-\mathrm{Fe}^{3+}$ at the treatment of $12 \mathrm{~h}$. Furthermore, cell imaging experiments of $\mathbf{3 a}, \mathbf{4 g}$, and $\mathbf{5 c}$ for sensing $\mathrm{Fe}^{3+}$ and $\mathrm{Cu}^{2+}$ ions in living cells at the intracellular level were examined. Initially, the HCT116 cells were incubated with $\mathbf{3 a}, \mathbf{4 g}$, and $\mathbf{5 c}(100 \mu \mathrm{g} / \mathrm{mL})$ alone for $30 \mathrm{~min}$ at $37^{\circ} \mathrm{C}$ in PBS solution showed strong blue fluorescence emission in the cytoplasmic region (Fig. S7S9), indicating the $\mathbf{3 a}, \mathbf{4 g}$, and $\mathbf{5 c}$ has good cell membrane penetrability at the cytoplasm level of HCT116 cells. On further incubation with $\mathbf{3 a}-\mathrm{Fe}^{3+}, \mathbf{3 a}-\mathrm{Cu}^{2+}, \mathbf{4 g}-\mathrm{Fe}^{3+}$, and $\mathbf{5 c}-\mathrm{Fe}^{3+}$, the remarkable intracellular blue fluorescence of the system was obviously quenched (Fig. S7-S9) and this result was in good agreement with fluorescence intensity observed sensing system. ${ }^{10,11}$
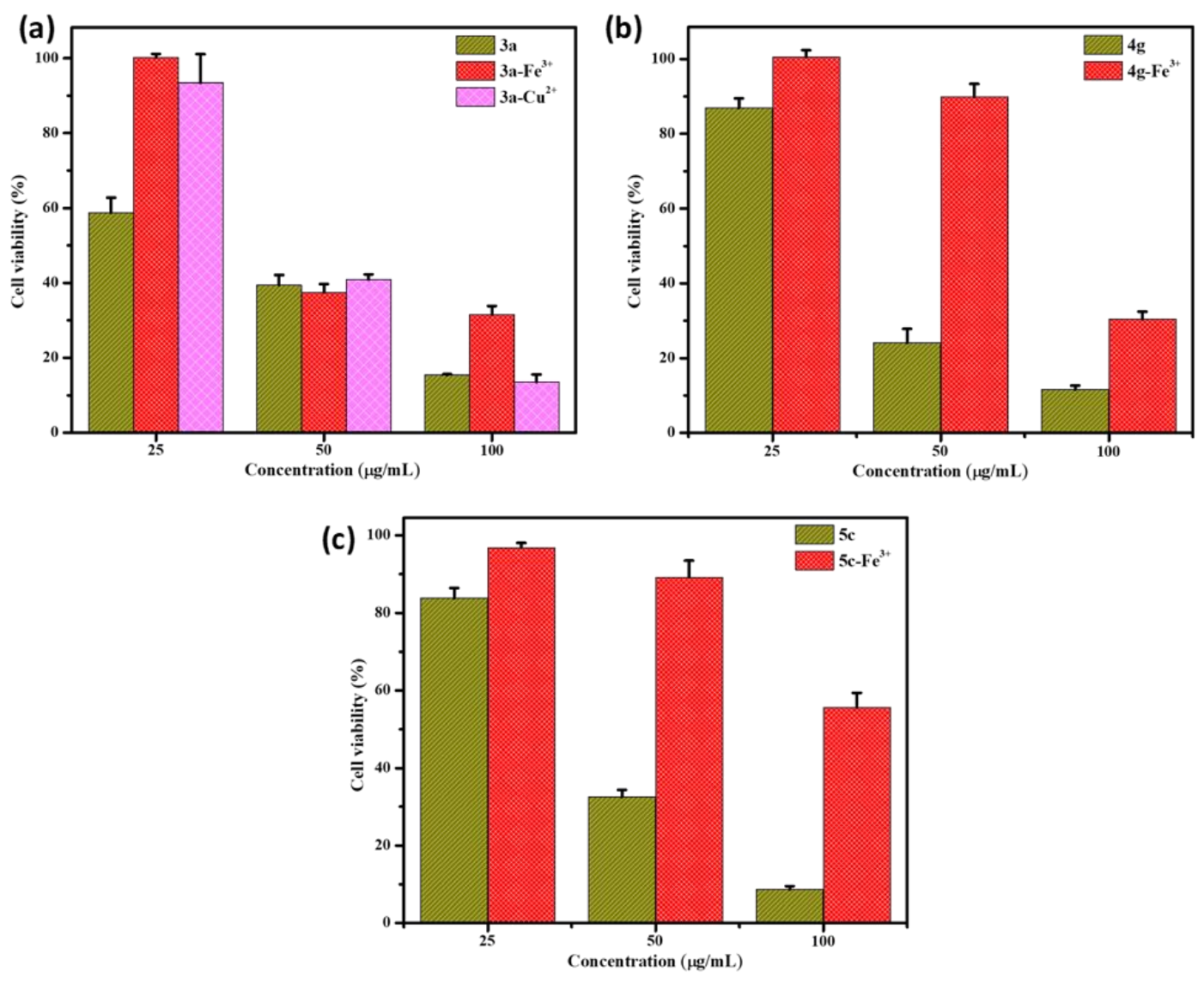

Fig. S6. Cell viability of HCT116 cells (human colon cancer cell line) treated with different concentrations of $\mathbf{3 a}, \mathbf{4 g}$, and $\mathbf{5 c}$ in the presence of $\mathrm{Fe}^{3+}$ and $\mathrm{Cu}^{2+}$ ions $(25,50,100 \mu \mathrm{g} / \mathrm{mL})$ at $37^{\circ} \mathrm{C}$ for $24 \mathrm{~h}$. 


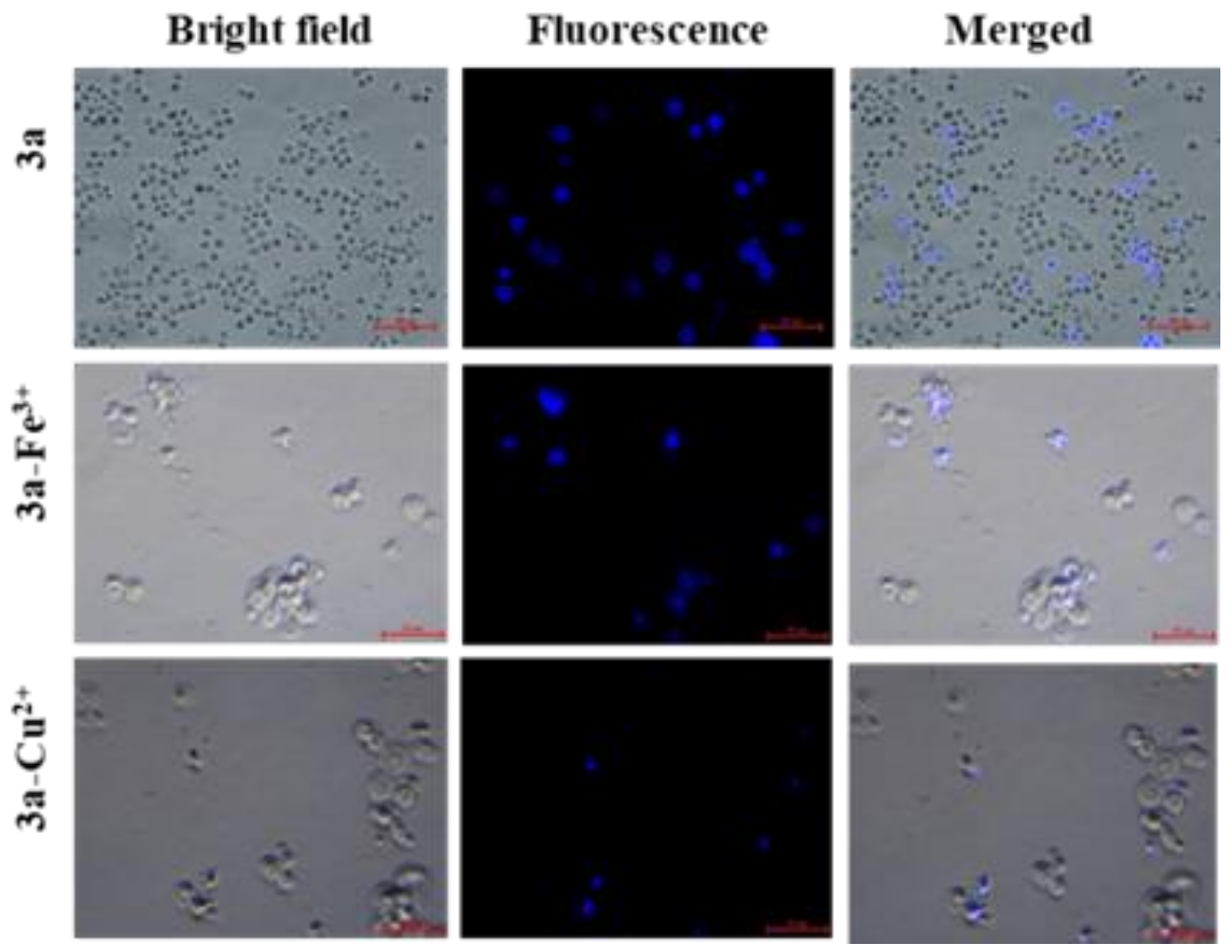

Fig. S7. Fluorescence images and corresponding bright-field and merged transmission images of HCT116 cells (a human colon cancer cell line) incubated with $\mathbf{3 a}(100 \mu \mathrm{g} / \mathrm{mL})$ in the absence or presence of $\mathrm{Fe}^{3+}$ or $\mathrm{Cu}^{2+}(100 \mu \mathrm{g} / \mathrm{mL})$ for $12 \mathrm{~h}$ at $37^{\circ} \mathrm{C}$. 

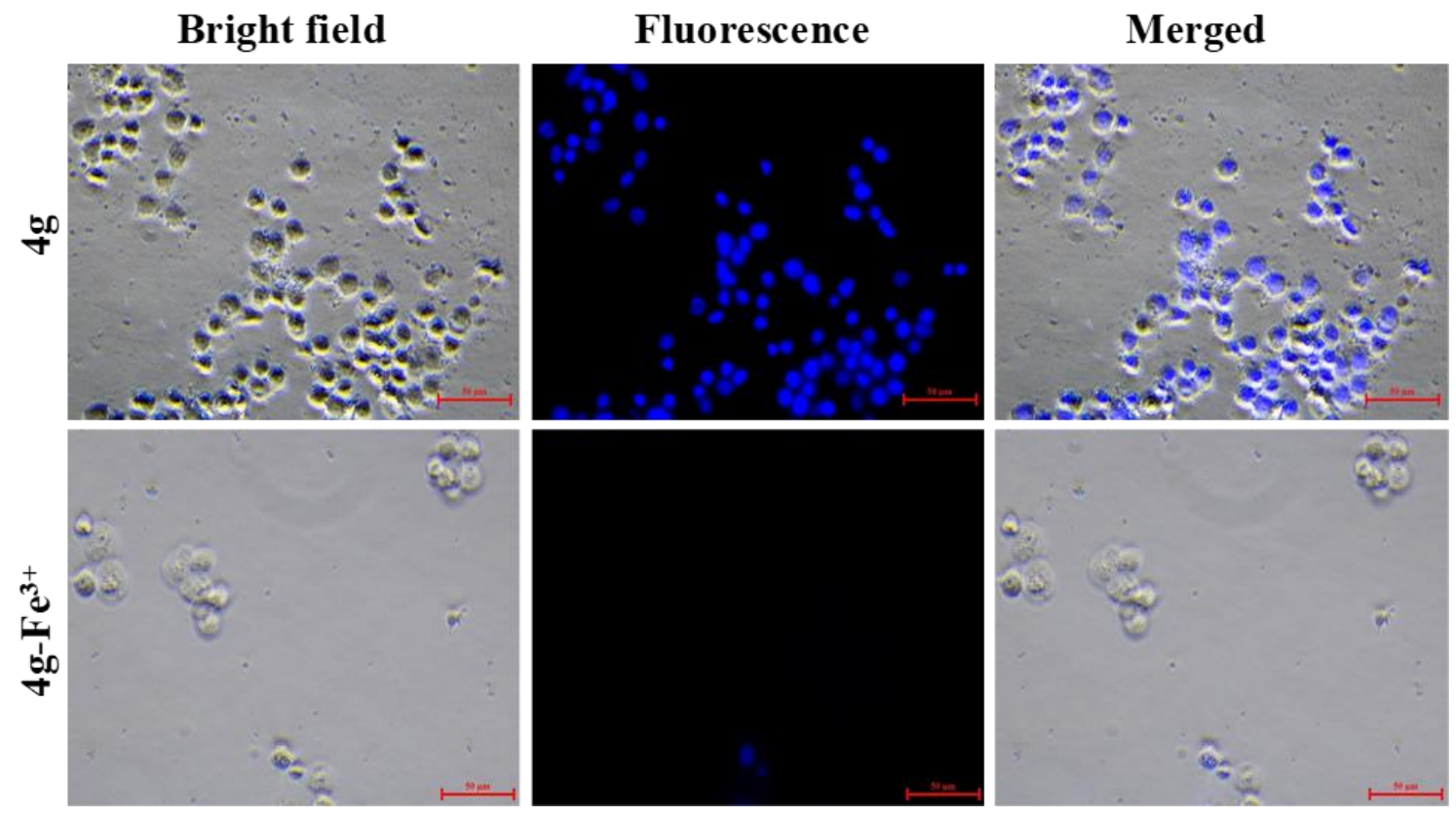

Fig. S8. Fluorescence images and their corresponding bright-field and merged transmission images of HCT116 cells (human colon cancer cell line) incubated with $\mathbf{4 g}(100 \mu \mathrm{g} / \mathrm{mL}$ ) in the absence or presence of $\mathrm{Fe}^{3+}(100 \mu \mathrm{g} / \mathrm{mL})$ at $37^{\circ} \mathrm{C}$ for $12 \mathrm{~h}$.

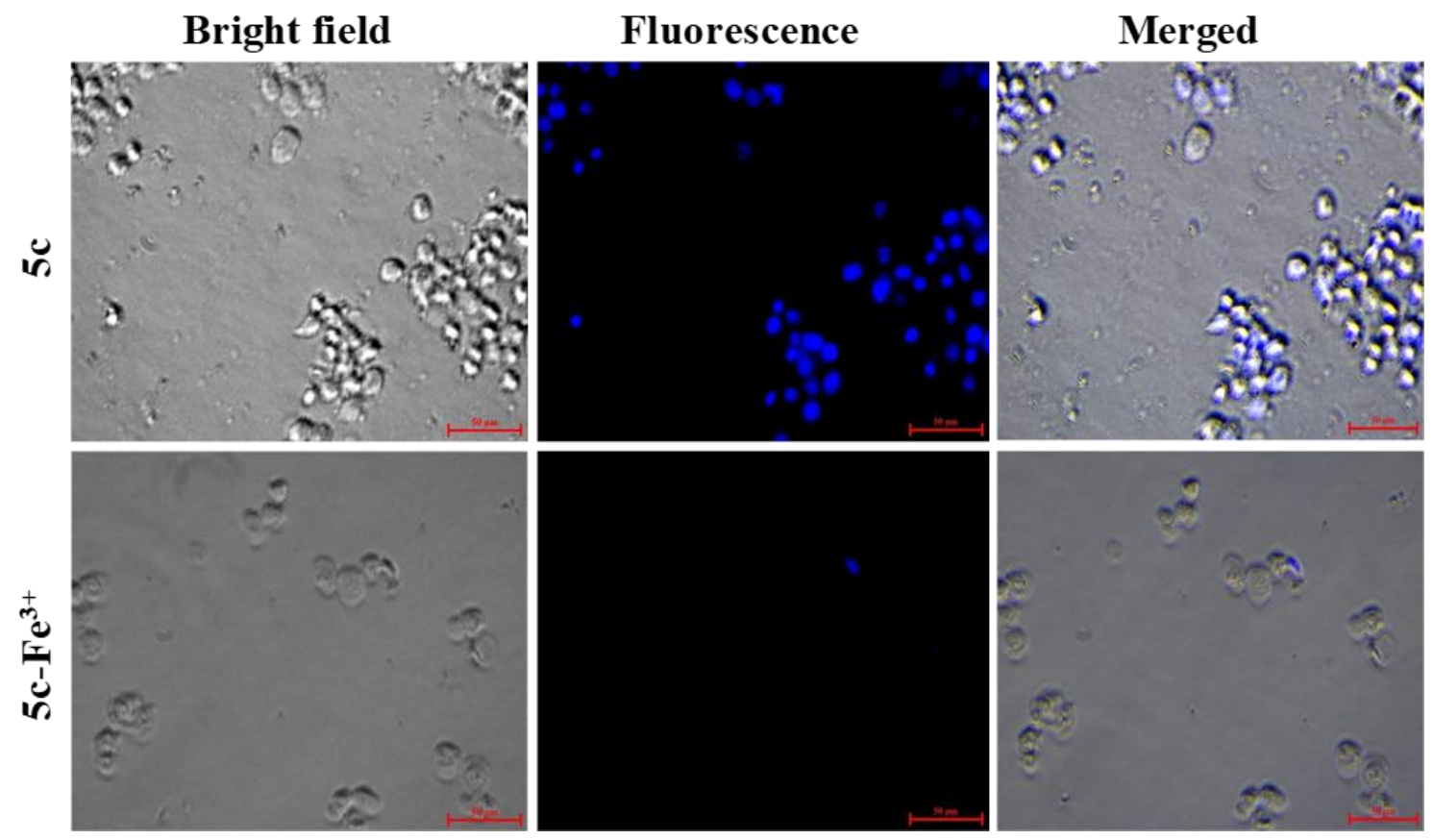

Fig. S9. Fluorescence images and their corresponding bright-field and merged transmission images of HCT116 cells (human colon cancer cell line) incubated with $\mathbf{5 c}(100 \mu \mathrm{g} / \mathrm{mL})$ in the absence or presence of $\mathrm{Fe}^{3+}(100 \mu \mathrm{g} / \mathrm{mL})$ at $37^{\circ} \mathrm{C}$ for $12 \mathrm{~h}$. 


\section{References}

1. Liu, Y.; Mao, Y.; Hu, Y., Gui, J.; Wang, L.; Wang, W.; Zhang, S. The Employment of Sodium Hydride as a Michael Donor in Palladium-catalyzed Reductions of $\alpha, \beta$ Unsaturated Carbonyl Compounds. Adv. Synth. Catal. 2019. 361, 1554.

2. Mandal, T.; Chakraborti, G.; Karmakar, S.; Dash, J. Divergent and Orthogonal Approach to Carbazoles and Pyridoindoles from Oxindoles via Indole Intermediates. Org. Lett., 2018. 20, 4759.

3. Sampson, P. B.; Li, S-W.; Liu, Y.; Pauls, H. W.; Edwards, L.G.; Forrest, B. T.; Feher, M.; Patel N. K. B.; Pan, G-h. Synthesis of Chiral 2-(1H-Indazol-6-yl)-Spiro [Cyclopropane-1,3'- Indolin]-2'-Ones. 2010. WO 2010/115279 Al.

4. Jardim, G. A. M.; Bower, J. F.; da Silva Júnior, E. N. Rh-Catalyzed Reactions of 1,4Benzoquinones with Electrophiles: $\mathrm{C}-\mathrm{H}$ Iodination, Bromination, and Phenylselenation. Org. Lett. 2016, 18, 4454.

5. Jaishankar, M.; Tseten, T., Anbalagan, N.; Mathew, B.B.; Beeregowda, K.N. Toxicity, Mechanism and Health Effects of Some Heavy Metals. Interdiscip. Toxico. 2014, 7, 60.

6. Guo, Y.; Wang, L.; Zhuo, J.; Xu, B.; Li, X.; Zhang, J.; Zhang, Z.; Chi, H.; Dong, Y.; Lu, G. A Pyrene-Based Dual Chemosensor for Colorimetric Detection of $\mathrm{Cu}^{2+}$ and Fluorescent Detection of $\mathrm{Fe}^{3+}$. tetrahedron Lett. 2017, 58, 3951.

7. Gong, X.; Zhang, H.; Jiang, N.; Wang, L.; Wang, G. Oxadiazole-Based 'On-Off' Fluorescence Chemosensor for Rapid Recognition and Detection of $\mathrm{Fe}^{2+}$ and $\mathrm{Fe}^{3+}$ in Aqueous Solution and in Living Cells. Microchem J. 2019, 145, 435.

8. Mohandoss, S.; Sivakamavalli, J.; Vaseeharan, B; Stalin, T. Host-Guest Molecular Recognition Based Fluorescence On-Off-On Chemosensor for Nanomolar Level Detection of $\mathrm{Cu}^{2+}$ and $\mathrm{Cr}_{2} \mathrm{O}_{7}{ }^{2-}$ Ions: Application in XNOR Logic Gate and Human Lung Cancer Living Cell Imaging. Sens. Actuators B Chem. 2016, 234, 300.

9. Mohandoss, S.; Atchudan, R.; Edison, T.N.J.I.; Mishra, K.; Tamargo, R.J.I., Palanisamy; S., Yelithao, K.; You, S; Lee, Y.R. Rapid Response and Highly Selective Sensing of Adenosine Based on Novel Photoluminescent Vanadium Nanoclusters Anchored on $\mathrm{MoS}_{2}$ Nanosheets. Sens. Actuators B Chem. 2020, 306, 127581.

10. Warrier, S.; Kharkar, P.S. Highly selective on-off fluorescence recognition of $\mathrm{Fe}^{3+}$ Based on a Coumarin Derivative and its Application in Live-cell Imaging. Spectrochimica Acta Part A: Molecular and Biomolecular Spectroscopy. 2018, 188, 659. 
11. Mukherjee, S.; Hazra, S.; Chowdhury, S.; Sarkar, S.; Chattopadhyay, K.; Pramanik, A.; A Novel Pyrrole Fused Coumarin Based Highly Sensitive and Selective Fluorescence Chemosensor for Detection of $\mathrm{Cu}^{2+}$ Ions and Applications Towards Live Cell Imaging. J. Photochem. Photobiol. A. 2018, 364, 635. 


\section{Crystal refinement data for compound $\mathbf{4 m}$}

Sample preparation: The crystal was prepared via slow evaporation method using ethyl acetate/hexane/DMSO solvents.

Empirical Formula- $\mathrm{C}_{30} \mathrm{H}_{25} \mathrm{NO}_{5}, \mathrm{C}_{2} \mathrm{H}_{6} \mathrm{SO}, \mathrm{M}=557.64$, Monoclinic, Space group $\mathrm{P} 21 / \mathrm{n}, \mathrm{a}=$ 10.3734(12) $\mathrm{A}, \mathrm{b}=18.095(3) \AA, \mathrm{c}=15.3654(18) \AA, \mathrm{V}=2852.7(6) \AA^{3}, \mathrm{Z}=4, \mathrm{~T}=223(2) \mathrm{K}$, $\rho c a l c d=1.298 \mathrm{Mg} / \mathrm{m}^{3}, 2 \Theta_{\text {max. }}=28.799^{\circ}$, Refinement of 1176 parameters on 7174 independent reflections out of 39331 collected reflections (Rint $=0.0508$ ) led to $\mathrm{R} 1=0.0519[\mathrm{I}>2 \sigma(\mathrm{I})]$, $\mathrm{wR} 2=0.1056$ (all data) and $\mathrm{S}=1.071$ with the largest difference peak and hole of 0.295 and 0 . 1396e. $\AA^{-3}$ respectively. The crystal structure has been deposited at the Cambridge Crystallographic Data Centre (CCDC 2052776). The data can be obtained free of charge via the Internet at www.ccdc.cam.ac.uk/data_request/cif

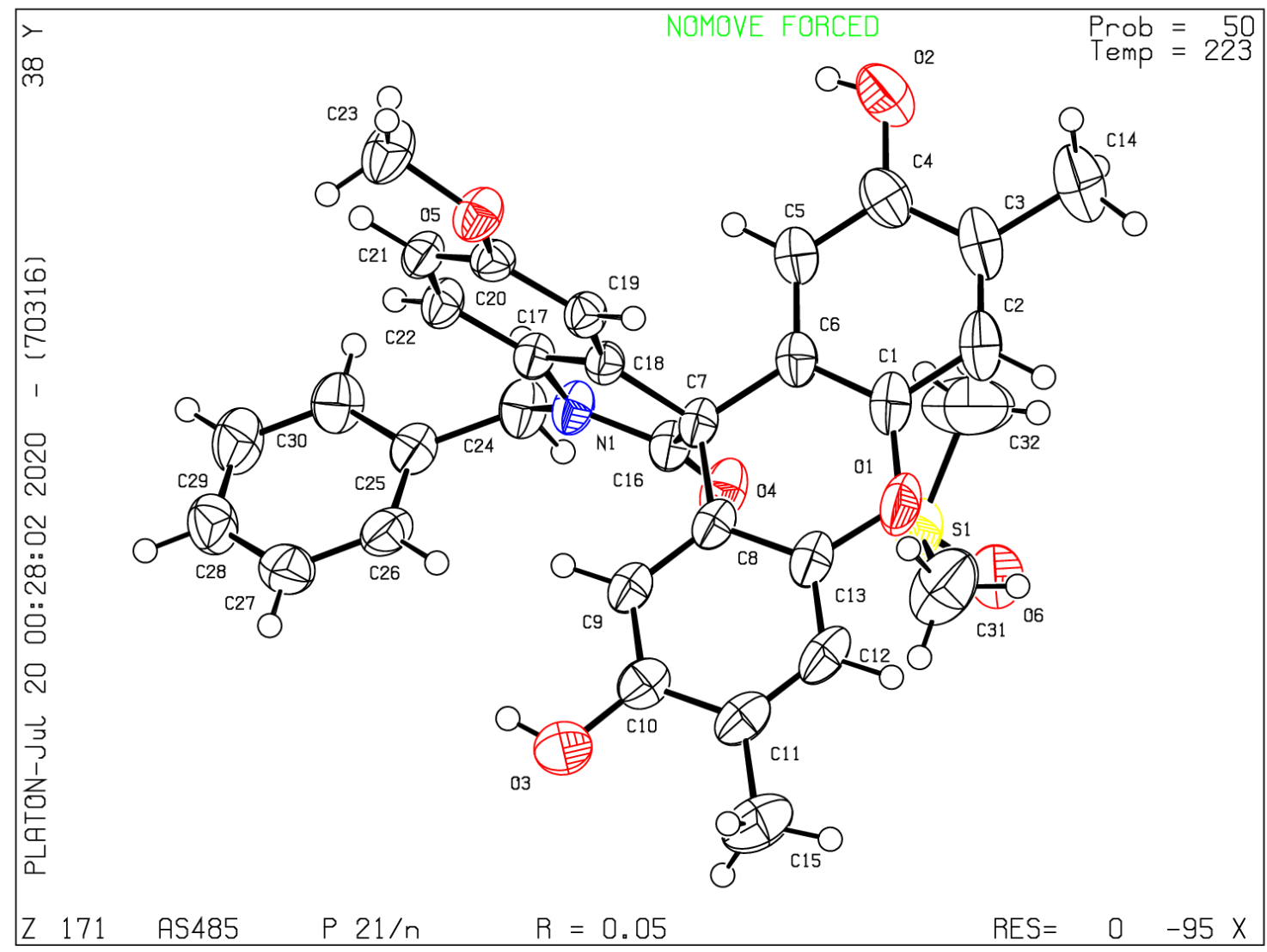

Fig S8. X-ray structure of compound $\mathbf{4 m}$ (ellipsoid contour \% probability-50). 
Table 1. Crystal data and structure refinement for $\mathbf{4 m}$ (AS485).

Identification code

AS485

Empirical formula

C30 H25 N O5, C2 H6 S O

Formula weight

557.64

Temperature

223(2) K

Wavelength

$0.71073 \AA$

Crystal system

Monoclinic

Space group

Unit cell dimensions

Volume

$\mathrm{P} 21 / \mathrm{n}$

$\mathrm{a}=10.3734(12) \AA \quad \alpha=90^{\circ}$.

$\mathrm{b}=18.095(3) \AA \quad \beta=98.479(4)^{\circ}$.

$\mathrm{c}=15.3654(18) \AA \quad \gamma=90^{\circ}$.

Z

Density (calculated)

2852.7(6) $\AA^{3}$

4

$1.298 \mathrm{Mg} / \mathrm{m}^{3}$

Absorption coefficient

$0.159 \mathrm{~mm}^{-1}$

$\mathrm{F}(000)$

1176

Crystal size

$0.292 \times 0.249 \times 0.174 \mathrm{~mm}^{3}$

Theta range for data collection

2.282 to $28.799^{\circ}$.

Index ranges

$-13<=\mathrm{h}<=13,-23<=\mathrm{k}<=24,-19<=1<=20$

Reflections collected

39331

Independent reflections

$7174[\mathrm{R}(\mathrm{int})=0.0508]$

Completeness to theta $=25.242^{\circ}$

$99.7 \%$

Absorption correction

Semi-empirical from equivalents

Max. and min. transmission

0.7457 and 0.6840

Refinement method

Full-matrix least-squares on $\mathrm{F}^{2}$

Data / restraints / parameters

7174 / 0 / 368

Goodness-of-fit on $\mathrm{F}^{2}$

1.024

Final R indices [I $>2 \operatorname{sigma}(\mathrm{I})]$

$\mathrm{R} 1=0.0519, \mathrm{wR} 2=0.1163$

$\mathrm{R}$ indices (all data)

$\mathrm{R} 1=0.0954, \mathrm{wR} 2=0.1396$

Extinction coefficient

$\mathrm{n} / \mathrm{a}$

Largest diff. peak and hole

0.299 and -0.471 e. $\AA^{-3}$ 


\section{Crystal refinement data for $5 \mathrm{e}$}

Sample preparation: The crystal was prepared via slow evaporation method using ethyl acetate/hexane/DMSO solvents.

Empirical Formula- $\mathrm{C}_{36} \mathrm{H}_{25} \mathrm{NO}_{5}, \mathrm{M}=551.57$, Orthorhombic, Space group Pbcn, a = 22.8564(7) $\AA, \mathrm{b}=18.2339(5) \AA, \mathrm{c}=16.2359(4) \AA, \mathrm{V}=6766.5(3) \AA^{3}, \mathrm{Z}=8, \mathrm{~T}=223(2) \mathrm{K}, \rho$ calcd $=1.083$ $\mathrm{Mg} / \mathrm{m}^{3}, 2 \Theta_{\text {max. }}=26.050^{\circ}$, Refinement of 2304 parameters on 6670 independent reflections out of 186133 collected reflections $($ Rint $=0.1992$ ) led to $R 1=0.0433[I>2 \sigma(I)], w R 2=0.1262$ (all data) and $S=0.969$ with the largest difference peak and hole of 0.561 and $-0.201 \mathrm{e} . \AA^{-3}$ respectively. The crystal structure has been deposited at the Cambridge Crystallographic Data Centre (CCDC 2052778). The data can be obtained free of charge via the Internet at www.ccdc.cam.ac.uk/data_request/cif

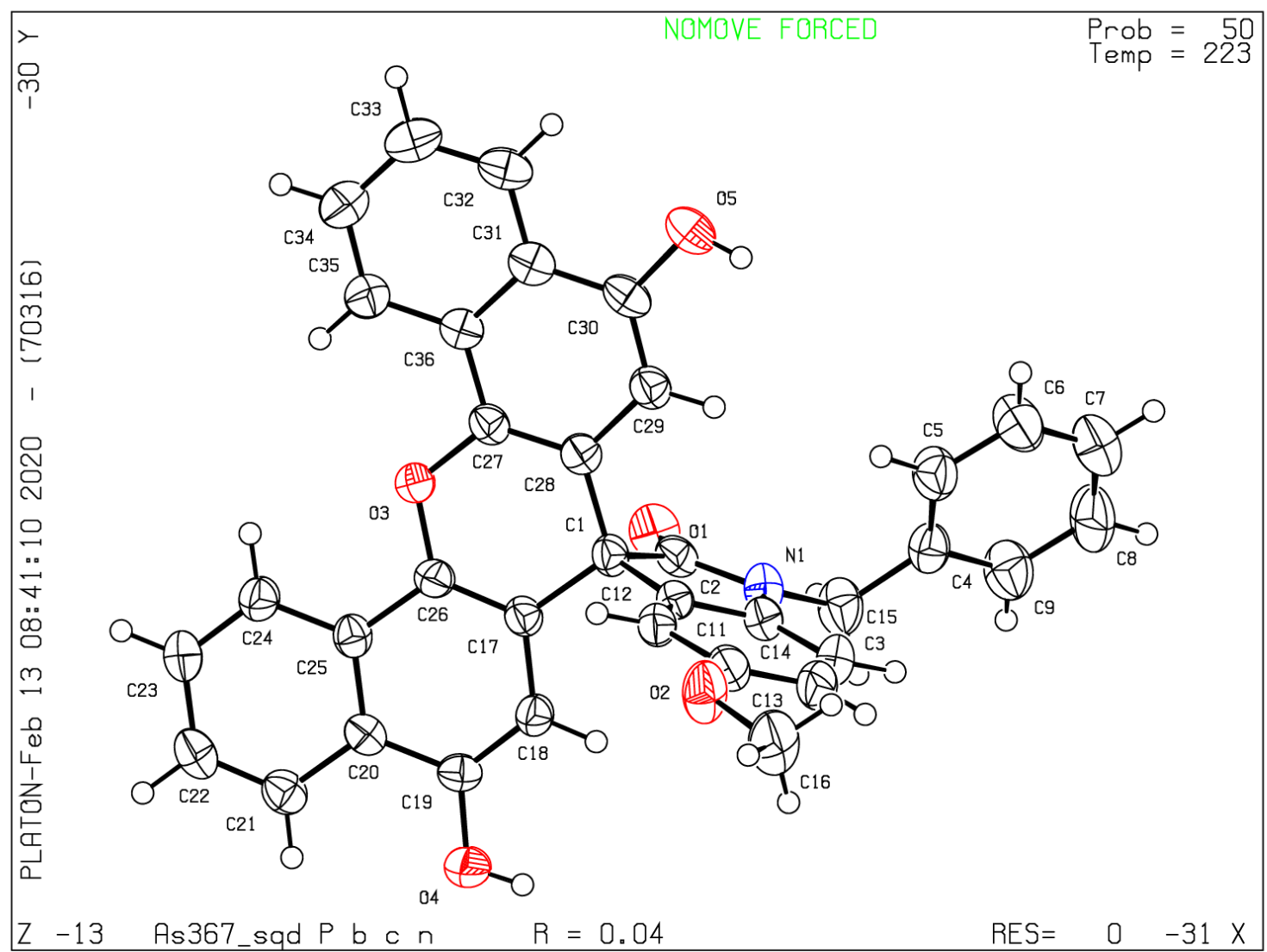

Fig S9. X-ray structure of compound 5e (ellipsoid contour \% probability-50). 
Table 1. Crystal data and structure refinement for 5e (As367_sqd).

Identification code

Empirical formula

Formula weight

Temperature

Wavelength

Crystal system

Space group

Unit cell dimensions

Volume

$\mathrm{Z}$

Density (calculated)

Absorption coefficient

$\mathrm{F}(000)$

Crystal size

Theta range for data collection

Index ranges

Reflections collected

Independent reflections

Completeness to theta $=25.242^{\circ}$

Absorption correction

Max. and min. transmission

Refinement method

Data / restraints / parameters

Goodness-of-fit on $\mathrm{F}^{2}$

Final R indices [I $>2 \operatorname{sigma}(\mathrm{I})]$

$\mathrm{R}$ indices (all data)

Extinction coefficient

Largest diff. peak and hole
As367_sqd

C36 H25 N O5

551.57

223(2) K

$0.71073 \AA$

Orthorhombic

\section{$\mathrm{Pbcn}$}

$\begin{array}{ll}\mathrm{a}=22.8564(7) \AA & \alpha=90^{\circ} . \\ \mathrm{b}=18.2339(5) \AA & \beta=90^{\circ} . \\ \mathrm{c}=16.2359(4) \AA & \gamma=90^{\circ} .\end{array}$

$6766.5(3) \AA^{3}$

8

$1.083 \mathrm{Mg} / \mathrm{m}^{3}$

$0.072 \mathrm{~mm}^{-1}$

2304

$0.283 \times 0.107 \times 0.103 \mathrm{~mm}^{3}$

2.234 to $26.050^{\circ}$.

$-28<=\mathrm{h}<=28,-22<=\mathrm{k}<=22,-20<=1<=20$

186133

$6670[\mathrm{R}(\mathrm{int})=0.1992]$

$99.9 \%$

Semi-empirical from equivalents

0.7433 and 0.7140

Full-matrix least-squares on $\mathrm{F}^{2}$

6670 / 0 / 382

0.969

$\mathrm{R} 1=0.0433, \mathrm{wR} 2=0.1178$

$\mathrm{R} 1=0.0802, \mathrm{wR} 2=0.1262$

$\mathrm{n} / \mathrm{a}$

0.561 and -0.201 e. $\AA^{-3}$ 